\title{
OTIMIZAÇÃO DOS PARÂMETROS GEOMÉTRICOS DE FERMENTADORES CONTÍNUOS APLICADOS NA PRODUÇÃO DE BIOETANOL ATRAVÉS DE SIMULAÇÃO COMPUTACIONAL DO ESCOAMENTO
}

Tese apresentada à Escola de Engenharia de São Carlos da Universidade de São Paulo para obtenção do título de Doutor em Engenharia Mecânica

ESTE EXEMPLAR TRATA-SE DA VERSÃO CORRIGIDA.

A VERSÃO ORIGINAL ENCONTRA-SE DISPONÍVEL JUNTO AO DEPARTAMENTO DE ENGENHARIA MECANICA DA EESC-USP

Área de Concentração: Térmica e Fluídos

Orientador: Prof. Tit. Paulo Seleghim Jr.

São Carlos 
AUTORIZO A REPRODUCCÃO TOTAL OU PARCIAL QESTE TRABALHO, POR QUALQUER MEIO COONVENCIONAL OU ELETRONNICO, PARA FINS DE ESTUDO E PESQUISA, DESDE QUE CITADA A FONTE.

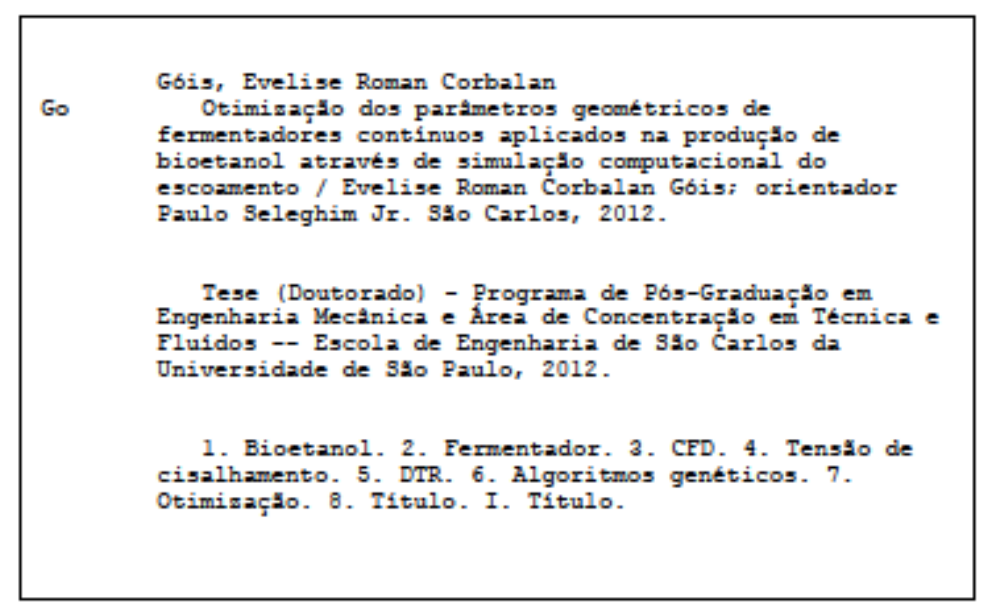


FOLHA DE JULGAMENIO

Candidata: Licenciada FVELISE ROMAN CORBALAN GOIS FREIRE.

Título da lese: "Olimização dos parû̀nctros neunétricos de lermentadores continuos aplicados na produçāo de bicetanol através de simulaçño conlputaciona! do escoamento".

Data dil doflust: 31:08:2012

\section{Comissäo Iulgadora:}

Prol. Titular Paulo Seleghim Junior (Orientador)

(Lscola de Engenharia de Sāo Carlos/LLLSC)

Prol. Associado Oscar Mauricio Hernandez Rodrigucz

(Escola de Engenharia de Sāo (.arlosifFș.)

P'rol. Lr. Marco Anfônio P'enalva Reali

(Escola de Engenharia de Sāo CorlositESSC:

Prof. Associado Leandro Franco de Souza

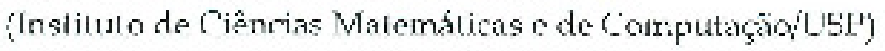

Prof: Dr. José Renato Coury

(Universidade Federal de Săo Carlosi'UfsCar)

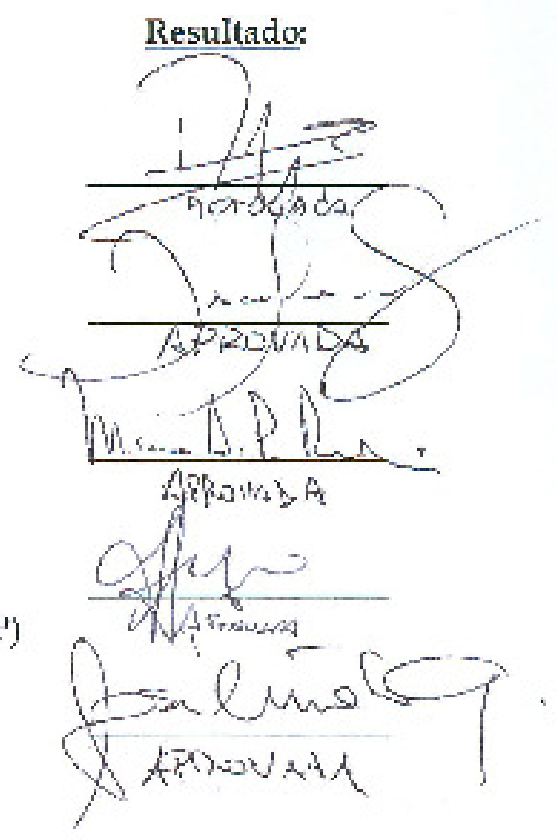

Cootdenadorr do Programa de Pós-Graduaçào en Engenheira Mecânica:

Pruf. Assoriade Marcelo Areina Trindade

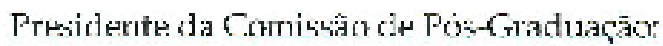

Trof. Tïtular Denis Vinícius Coury 
Dedico este trabalho aos meus pais, Elisabete e Elias, e ao meu irmão Eduardo. 

"A fé e a razão constituem como que duas asas pelas quais o espírito humano se eleva para a contemplação da verdade."

Papa João Paulo II. 



\section{Agradecimentos...}

No final desta etapa, gostaria de agradecer a cada um de vocês com alguns trechos do livro "O Pequeno Príncipe", de Antoine de Saint-Exupéry, com toda sua profundidade e simplicidade.

A Deus, obrigada por me mostrar a cada dia que ciência e fé podem sim caminhar juntas. "Só se vê bem com o coração. O essencial é invisível aos olhos".

"Mas aconteceu que o pequeno príncipe, tendo andado muito tempo pelas areias, pelas rochas e pela neve, descobriu, enfim, uma estrada". Obrigada Prof. Paulo Seleghim Jr, pela orientação, e por me ensinar a encontrar as estradas da minha pesquisa, me mostrando sempre que esta é uma jornada contínua, e me motivando a ter novas visões, pois "a gente só conhece bem as coisas que cativou, disse a raposa." Obrigada pela formação humana e profissional, por confiar em mim e no meu trabalho.

Ao CNPq (Conselho Nacional de Desenvolvimento Científico e Tecnológico) pela concessão da bolsa de doutorado e pelo apoio financeiro para a realização desta pesquisa.

Obrigada, André, meu esposo, por partilhar a sua vida comigo, pelo companheirismo e compreensão em todos os momentos. Obrigada por se aventurar a sonhar comigo! Começamos esta jornada como namorados, e terminamos uma família. E "se tu me cativas, nós teremos necessidade um do outro. Serás para mim único no mundo. E eu serei para ti única no mundo." Eu te amo!

"Foi o tempo que dedicaste à tua rosa que a fez tão importante." Pai, Mãe, Dudu, Vó Maria, Madrinha, Tio Her, Tio Toninho, e Tia Nenê, Tios e primos todos, obrigada por todo o tempo que me dedicaram, do berço até aqui. Em qualquer fase da minha vida, é o amor de vocês que me faz sentir a pessoa mais importante do mundo! Vô Tião, Vó Don'Ana, Teresinha, Leir, Allyson, Família Pimenta e Família Freire, obrigada por me apoiarem com tanto carinho, e por também serem minha família!

Vô Tonico, você sempre foi e sempre será o melhor professor que eu tive! Minhas conquistas são reflexo do seu incentivo e da importância que você sempre soube dar ao conhecimento, em toda sua simplicidade. “E quando estiveres consolado (a gente sempre se 
consola), tu ficarás contente por teres me conhecido. Tu serás sempre meu amigo." Sinto sua falta.

"Cativar significa criar laços, disse a raposa". Rita, amiga e irmã! Sua fé e docilidade são exemplos pra mim. Obrigada por ser minha família em São Carlos, e por ter trazido tanta paz e alegria ao nosso lar.

"Mas se tu me cativas, minha vida será como que cheia de sol. Conhecerei um barulho de passos que será diferente dos outros." Iara, Simone, Jonas, Sávider, Hugo e Adriana, Márcia, Analice, Patrícia, Pri Lenzoni, Letícia, Fernando, Rafaela, Carlão, Alessandro, Tiago, Família Scalassara, Família Estrella, Família Rondão, Família Zottis, Família Alves, Família Belotti, Família Sobral, todo GPP São Carlos (Grupo de Partilha de Profissionais), todas as meninas da República Gratia Plena, enfim, obrigada por caminharem comigo no decorrer destes quatro anos. Agradeço a todos os colegas, funcionários, técnicos, e professores do NETeF, em especial ao Prof. Geraldo pelos ensinamentos e brindes à felicidade durante as pausas para o chá, sempre tão agradáveis . Vocês todos enchem a minha vida de sol. Obrigada, amigos!

E o trabalho continua... ele nunca acaba! E é isso que nos move. "Então, eu me sinto feliz. E todas as estrelas sorriem docemente."

Evelise. 


\section{RESUMO}

GóIS, E. R. C. OTIMIZAÇÃO DOS PARÂMETROS GEOMÉTRICOS DE FERMENTADORES CONTÍNUOS APLICADOS NA PRODUÇÃO DE BIOETANOL ATRAVÉS DE SIMULAÇÃO COMPUTACIONAL DO ESCOAMENTO. 2012. TESE (DOUTORADO) - ESCOLA DE ENGENHARIA DE SÃO CARLOS, UNIVERSIDADE DE SÃO PAULO, SÃO PAULO, 2012.

O aprimoramento dos meios para obtenção do bioetanol a partir de diferentes tipos de biomassa traz novos problemas e desafios para a engenharia. O Brasil, devido a fatores climáticos e uma produção de etanol a partir da cana de açúcar já estabilizada, possui uma posição mundial vantajosa na produção sucroalcooleira. Otimizar os meios já existentes e os em desenvolvimento pode não somente aumentar a eficiência da produção, como também reduzir os impactos ambientais causados pelo modelo de produção atualmente utilizado. $\mathrm{O}$ processo de fermentação é utilizado tanto na produção de etanol de primeira como de segunda geração, portanto melhorias no desempenho dos fermentadores contribui de maneira significante para o melhor aproveitamento da matéria prima. Diversas tentativas de melhorias são apresentadas na literatura, principalmente por meio do estudo de parâmetros do escoamento que podem influenciar o processo fermentativo, como tensão de cisalhamento, perfis de velocidade e tempo de residência, assim como a influência da geometria do fermentador sobre esses parâmetros. Em alguns estudos, algoritmos de otimização são utilizados para determinar os melhores coeficientes das reações químicas, mas não há estudos, até o momento, que proporcionem otimização simultânea dos parâmetros da geometria e do escoamento em um fermentador contínuo, presentes em cerca de $30 \%$ das usinas brasileiras. O objetivo deste trabalho é obter os parâmetros geométricos ideais para um fermentador contínuo, de forma a minimizar a tensão de cisalhamento a variância da distribuição de tempos de residência (DTR) no fermentador. O Ansys CFX® foi utilizado como ferramenta na simulação computacional do escoamento. As geometrias dos fermentadores ideais para cada um dessas análises, obtidas utilizando Algoritmos Genéticos e otimização univariada, respectivamente, foram propostas neste estudo.

Palavras chave: Bioetanol, Fermentador, CFD,Tensão de Cisalhamento, DTR, Algoritmos Genéticos, otimização univariada. 


\begin{abstract}
GÓIS, E. R. C. GEOMETRY PARAMETERS OPTIMIZATION OF A CONTINUOUS FERMENTER APPLIED AT BIOETHANOL PRODUCTION BY FLOW COMPUTATIONAL SIMULATION. 2012. TESE (DOUTORADO) ESCOLA DE ENGENHARIA DE SÃO CARLOS, UNIVERSIDADE DE SÃO PAULO, SÃo PAULO, 2012.

The enhancement of bioethanol production means from different types of biomass presents significant problems and engineering challenges. Due to climate and a wellestablished sugar-cane ethanol production, Brazil is in a privileged position in the global ethanol production scenario. Providing effective means to optimize existing production methods can both improve the efficiency and reduce the environmental impact of the currently used production model. Improvements on this process can have a significant effect in several stages of production, once the production process is used both for first and secondgeneration ethanol. Several attempts to improve the ethanol production process are presented in the literature. Most studies have investigated how to improve parameters such as shear stress, velocity profiles and residence time, and of the influence of the bioreactor geometry on the parameters. The use of genetic algorithms has been reported in some cases, but there have not been reports on studies combining the optimization of flow parameters and algorithms to choose ideal geometric parameters for continuous fermenters, used in $30 \%$ of Brazilian industries in the field. The main aim of this study is to obtain ideal geometric parameters for a continuous fermenter, in order to maximize or minimize flow parameters that can influence on the fermenting process. The aim of this study is obtain the ideal geometry parameters for a continuous fermenter, minimizing two of flow parameters which can influence the fermentation process, namely the shear stress and the variance of residence time distribution (RTD). The flow parameters was obtained by computational fluid dynamics. The ideal fermenter geometries was obtained by two different optimization methods: the genetic algorithms and univariate optimization. The ideal geometries was proposed in this study.
\end{abstract}

Keywords: Ethanol, Fermenter, CFD, Shear Stress, Genetic Algorithms, Univariate optimization. 



\section{LISTA DE FIGURAS}

Figura 1 Primeiro automóvel Ford movido a álcool que se tem notícia no Brasil

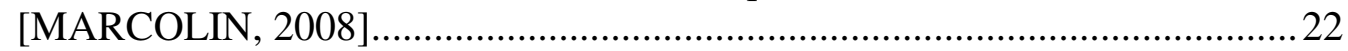

Figura 2 Rotas tecnológicas para a produção de etanol [NOGUEIRA, 2008]......................... 23

Figura 3 Canavial na região de Ribeirão Preto, estado de São Paulo......................................25

Figura 4 Distribuição da produção mundial de etanol em 2006 por NOGUEIRA, 2008.........26

Figura 5 Esquema de produção de etanol de primeira e segunda geração numa usina de cana.

Figura 6 Dornas de fermentação em sistema contínuo em uma usina no interior do estado de São Paulo (foto de Márcia Osaki)............................................................... 32

Figura 7 Protótipo inicial do fermentador em perspectiva isométrica..................................... 34

Figura 8 Estrutura de funcionamento de um algoritmo genético tradicional. .........................44

Figura 9 Aproximação inicial para a geometria do fermentador, em vista frontal...................52

Figura 10 Vista da parte inferior do fermentador, com as respectivas nomenclaturas dos parâmetros geométricos. ........................................................................5

Figura 11 Vista lateral do fermentador, com respectivas nomenclaturas dos parâmetros

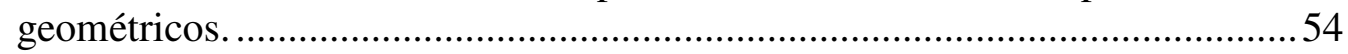

Figura 12 Condições de contorno na entrada e saída do reservatório do fermentador.............57

Figura 13 Algoritmo de acoplamento entre os programas Ansys CFX® e modeFRONTER®.

Figura 14 Injeção de traçador por pulso e curva de concentração na saída do escoamento SASSAKI, 2005

Figura 15 Linhas de corrente em um fermentador com ângulo de entrada perpendicular (esquerda) e com entrada tangencial com ângulo de $60^{\circ}$ (direita)...................72

Figura 16 Malha numérica com 13963 elementos, utilizada em GÓIS; SELEGHIM,

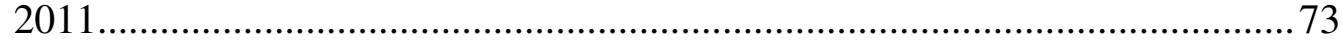

Figura 17 Malha numérica de 130 mil elementos, utilizada para o cálculo da tensão de cisalhamento.

Figura 18 Tensão de cisalhamento (Pa) para cada uma das 51 geometrias testadas. .75

Figura 19 Comportamento das linhas de corrente para a geometria não otimizada...... 79

Figura 20 Comportamento das linhas de corrente para a geometria não otimizada.. 80

Figura 21 Comparação entre os mapas de tensão de cisalhamento no interior do fermentador. Geometria não otimizada (esquerda) e geometria otimizada (direta).

Figura 22 Região de entrada do fluido para a geometria não otimizada, onde ocorre os maiores valores de tensão de cisalhamento. 
Figura 23 Região de entrada do fluido para a geometria otimizada, onde ocorre os maiores valores de tensão de cisalhamento.

Figura 24 Mapa de vorticidade no fermentador, em perspectiva isométrica........................... 83

Figura 25 Malha numérica utilizada para obtenção das curvas DTR. .................................... 86

Figura 26 Variância da distribuição dos tempos de residência para cada uma das geometrias simuladas.

Figura 27 Comparação das linhas de corrente para as geometrias com $\mathrm{h}=120 \mathrm{~cm}$ e ângulo de entrada $90^{\circ}$ (esquerda) e ângulo de entrada $22,5^{\circ}$ (direita)........................ 88

Figura 28 Curvas de concentração típicas de um reator com zonas mortas (Esquerda) e com curto circuito (Direita) .......................................................................... 90

Figura 29 Curvas de concentração para ângulo de $22,5^{\circ}$ e respectivas alturas para a tubulação de saída.

Figura 30 Curva de concentração para ângulo de $45^{\circ}$ em função das alturas simuladas para a tubulação de saída............................................................................ 91

Figura 31 Curva de concentração para ângulo de $67,5^{\circ}$ e respectivas alturas para tubulação de saída.

Figura 32 Curva de concentração para ângulo de $90^{\circ}$ e respectivas alturas para a tubulação de saída. ......................................................................................... 92

Figura 33 Curvas DTR para $\mathrm{h}=120 \mathrm{~cm}$ para cada um dos ângulos testados. 94

Figura 34 Comparação das linhas de corrente para o fermentador com $10 \mathrm{~m}^{3}$ (Esquerta)

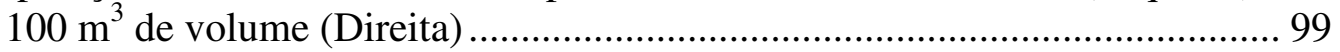




\section{LISTA DE TABELAS}

Tabela 1 Rendimento em litros de bioetanol por tonelada de matéria prima, extraído de NOGUEIRA, 2008.

Tabela 2 Geometria do fermentador, adotada como estimativa inicial 53

Tabela 3 Operadores utilizados pelo MOGA II e respectivas taxas adotadas neste trabalho.

Tabela 4 Parâmetros geométricos combinados para a obtenção das vinte geometrias testadas.

Tabela 5 Especificações das dimensões das 51 geometrias analisadas no estudo da tensão de cisalhamento

Tabela 6 Valores otimizados para os parâmetros da geometria comparados aos valores utilizados como aproximação inicial.

Tabela 7 Comparação dos valores obtidos para a tensão de cisalhamento com resultados experimentais e numéricos encontrados na literatura.

Tabela 8 Teste de malha: dimensões testadas. 85

Tabela 9 Geometria ideal para as duas funções objetivo analisadas neste trabalho. .94 



\section{LISTA DE SÍMBOLOS}

$\rho:$ densidade do fluido $\left[\mathrm{Kg} / \mathrm{m}^{3}\right]$

p: pressão [Pa]

$\varepsilon:$ dissipação da energia cinética turbulenta

$\mathrm{K}$ : energia cinética turbulenta

$\mu:$ viscosidade $\left[\mathrm{m}^{2} / \mathrm{s}\right]$

$\mu_{\mathrm{t}}:$ viscosidade turbulenta $\left[\mathrm{m}^{2} / \mathrm{s}\right]$

$\mu_{\text {eff }}:$ viscosidade efetiva $\left[\mathrm{m}^{2} / \mathrm{s}\right]$

$\tau$ : tensão cisalhante $[\mathrm{Pa}]$

t: tempo [s]

$\mathrm{H}$ : comprimento do corpo principal do fermentador [m]

h: comprimento da tubulação de saída de fluido [m]

$\alpha$ : ângulo entre a tubulação de entrada de fluido e o

corpo principal do fermentador $\left[{ }^{\circ}\right]$

$\mathrm{t}_{\mathrm{i}:}$ passo no tempo $[\mathrm{s}]$

$\mathrm{U}$ : Vetor de velocidades $[\mathrm{m} / \mathrm{s}]$

DTR: Distribuição de tempos de residência [s]

$\mathrm{E}(\mathrm{t})$ : função de distribuição de tempos de residência [s]

$C(t)$ : Concentração do traçador no passo do tempo $t_{i}\left[\mathrm{Kg} / \mathrm{m}^{3}\right]$

$\sigma^{2}:$ Variância $\left[s^{2}\right]$ 



\section{SUMÁRIO}

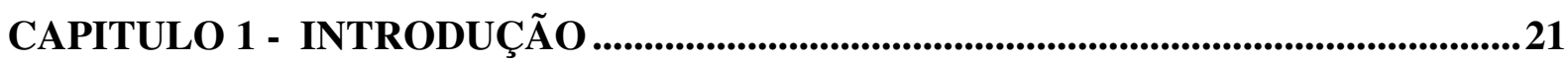

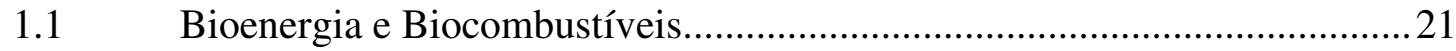

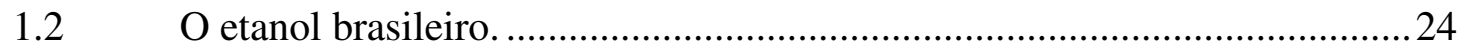

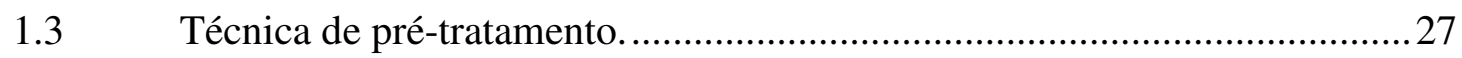

1.4 Biorreatores e o processo de fermentação....................................................29

1.4.1 O processo de fermentação. ........................................................................ 30

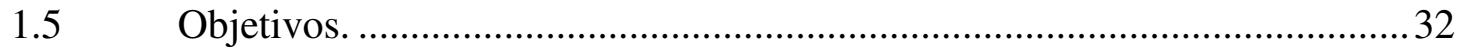

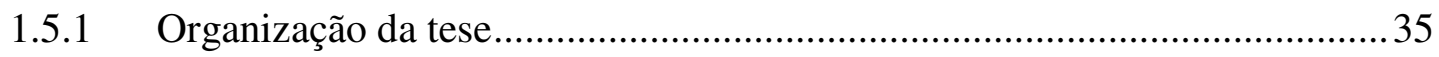

CAPITULO 2 - REVISÃO DA LITERATURA .............................................................37

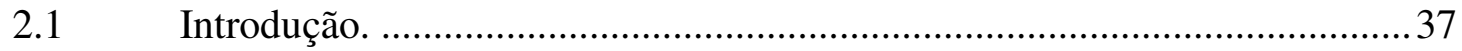

2.2 Mecânica dos Fluidos Computacional e o estudo de biorreatores. ................37

2.2.1 Algoritmos Genéticos e otimização de reatores e biorreatores....................42

2.2.2 Técnica de estímulo-resposta para obtenção da distribuição de tempo de residência (DTR) em tanques agitados de fluxo contínuo. ..........................46

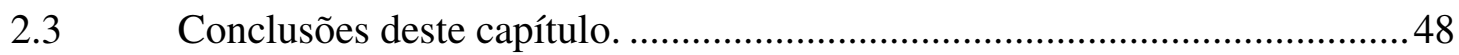

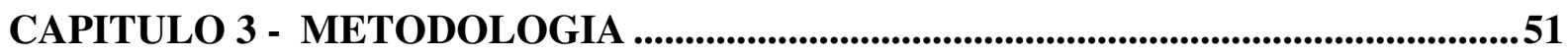

3.1 Aproximação inicial para a geometria do fermentador................................52

3.2 Simulação numérica do escoamento.........................................................55

3.2.1 Discretização das Equações Governantes. ..................................................55

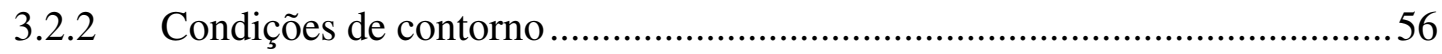

3.2.3 Modelagem da Turbulência....................................................................5

3.2.4 Cálculo da tensão de cisalhamento. .........................................................59

3.2.5 Solução numérica da advecção. ..................................................................60

3.3 Algoritmo Genético com Múltiplos Objetivos..........................................60

3.4 Obtenção da distribuição de tempo de residência utilizando o CFX ............62

3.5 Otimização univariada e geometrias testadas................................................66

3.6 Configurações do cluster utilizado............................................................67

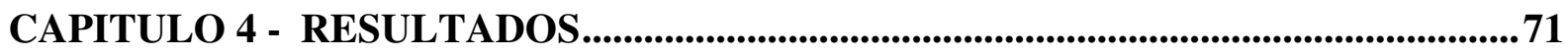

4.1 Análise da tensão de cisalhamento através do acoplamento entre o CFX e o ModeFRONTIER $₫$........................................................................ 71 
4.2 Análise da distribuição de tempos de residência e variância....................... 85

4.2.1 Análise quantitativa da distribuição de tempo de residência: cálculo da

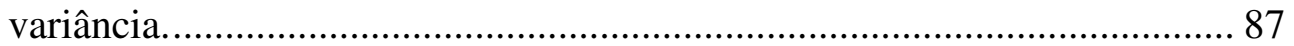

4.2.2 Análise qualitativa das curvas de distribuição de tempos de residência. .... 89

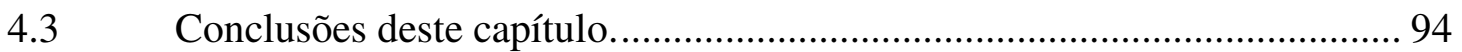

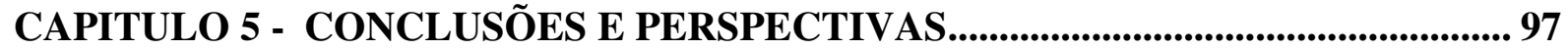

REREFERÊNCIAS BIBLIOGRÁFICAS ....................................................................... 101 


\section{CAPITULO 1 - INTRODUÇÃO}

\section{Bioenergia e Biocombustíveis.}

A bioenergia é utilizada desde os primórdios pela humanidade, considerando que a vida na terra é fundamentada pela energia irradiada pelo Sol. Segundo SARKAR; MODAK, 2005, define-se como bioenergia toda e qualquer forma de energia associada a formas de energia química acumulada mediante processos fotossintéticos. Consequentemente, define-se biomassa como os recursos naturais que dispõe de bioenergia e que podem ser processados para fornecer vetores bioenergéticos mais elaborados e adequados para uso final.

Desde a descoberta do fogo pelo homem, os recursos encontrados no ambiente como madeira e folhas eram utilizados para a produção de energia, destinada principalmente para o cozimento de alimentos, iluminação e aquecimento. Com o processo evolutivo da humanidade, o uso desses materiais foi sendo aprimorado. Durante o século XVIII, as reservas de lenha tornaram-se mais escassas na Europa, trazendo a necessidade de buscar outras alternativas, e desencadeando a Revolução Industrial. Surgiram assim novos equipamentos, como a máquina a vapor, e a lenha começou a ser substituída pelo carvão mineral. A bioenergia, que anteriormente era produzida principalmente tendo madeira como biomassa, foi então em grande parte substituída por recursos não renováveis, inicialmente o carvão mineral, e posteriormente, o petróleo e o gás natural [NOGUEIRA, 2008].

O uso do etanol como combustível não é recente. Ainda na metade do século XIX, o etanol era o combustível adotado por Henri Ford e o óleo de amendoim era a preferência de Rudolf Diesel. Ford afirmava que o etanol seria o combustível do futuro [SONGSTAD et al., 2011] e desenvolveu o Ford Modelo A, no ano de 1896. No entanto, o uso dos biocombustíveis passou a ser descartado logo em seguida, devido a queda dos preços e a abundância de combustíveis derivados de petróleo. A Figura 1 mostra o primeiro automóvel movido a álcool do qual se tem notícias no Brasil, modelo Ford. 


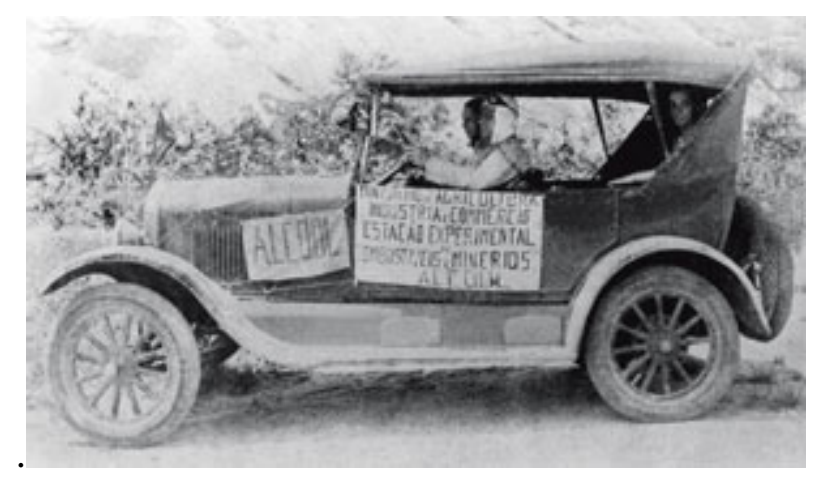

Figura 1 Primeiro automóvel Ford movido a álcool que se tem notícia no Brasil [MARCOLIN, 2008].

Com a exploração da energia solar fossilizada e sua tendência à extinção, ressurge a necessidade de buscar novos meios de produzir a energia fotossintética, que segundo NOGUEIRA, 2008 oferece uma alternativa à necessária evolução da sociedade industrial moderna para um contexto energético mais sustentável e racional.

Dessa forma, existem hoje dois sistemas de exploração de biomassa em uso: o primeiro é baseado em atividades extrativistas, como o caso da madeira, onde não há valorização econômica adequada do produto, com menor eficiência e produtividade. A segunda é baseada na busca de tecnologias eficientes para a produção de energia, com aumento da eficiência e diminuição do impacto ambiental. Neste caso, pode-se incluir a produção de bioetanol a partir de qualquer matéria prima com teor suficiente de açúcar ou amido, como a cana-de-açúcar, milho, mandioca, trigo, beterraba, sorgo, etc. Técnicas de produção de etanol em escala industrial utilizando beterraba como biomassa, por exemplo, são discutidas por [OGBONNA; MASHIMA; TANAKA, 2001].

As rotas tecnológicas para a produção de bioetanol a partir de diferentes matérias primas podem ser observadas na Figura 2. Vale salientar que a diferença entre os processos encontra-se nos meios para a obtenção da solução açucarada fermentável, e a partir desse passo afunilam-se no mesmo processo de fermentação, seguido pela destilação. 


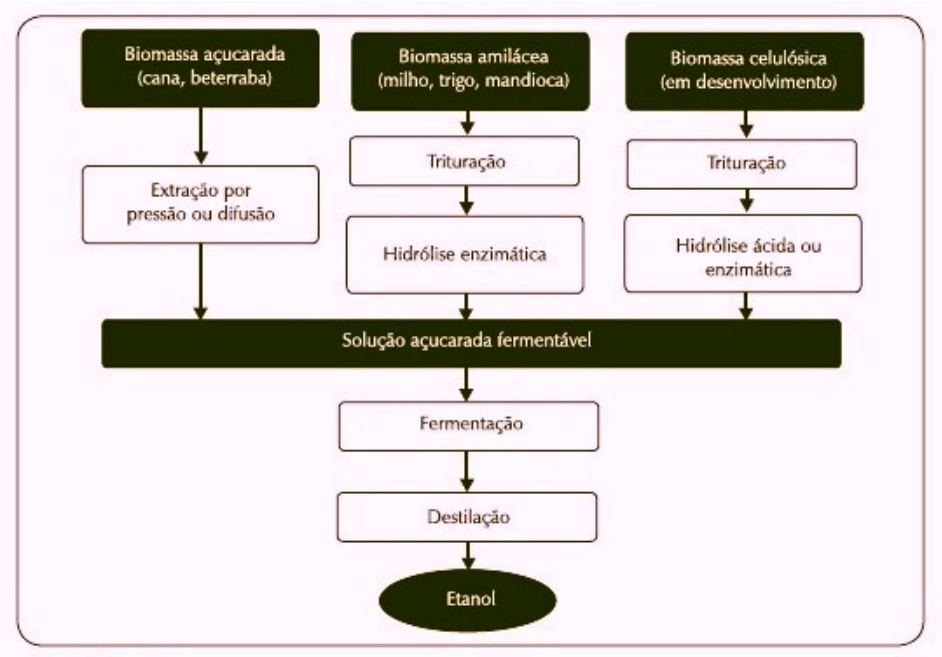

Figura 2 Rotas tecnológicas para a produção de etanol [NOGUEIRA, 2008].

Como visto anteriormente, diversas matérias primas podem ser utilizadas para a produção de etanol. A Tabela 1 mostra dados fornecidos por NOGUEIRA, 2008 sobre o rendimento de bioetanol em litros a partir de uma tonelada de biomassa.

Tabela 1 Rendimento em litros de bioetanol por tonelada de matéria prima, extraído de NOGUEIRA, 2008

\begin{tabular}{|l|c|}
\hline \multicolumn{1}{|c|}{ Matéria prima } & $\begin{array}{c}\text { Rendimento em litros (Por } \\
\text { tonelada) }\end{array}$ \\
\hline Cana de Açúcar & 86 \\
\hline Milho & 460 \\
\hline Beterraba & 75 \\
\hline Mandioca & 170 \\
\hline Trigo & 240 \\
\hline
\end{tabular}

Observa-se na Tabela 1 que o aproveitamento de matérias primas como o milho e a mandioca, por exemplo, é mais vantajoso quando comparado ao rendimento da cana de açúcar como biomassa. No entanto, o rendimento por tonelada ou hectare não é o único fator que influencia na escolha da produção. É necessário levar em conta os fatores climáticos do local, 
a destinação à produção alimentícia, a disponibilidade da energia necessária na produção, assim como a disponibilidade de terra, água, elementos agroquímicos, etc.

Com a necessidade de expandir a produção de etanol sem comprometer áreas agrícolas e com a preocupação dos impactos ambientais causado pela queima dos canaviais durante a colheita da cana, o uso de materiais lignocelulósicos e outros resíduos tem sido motivação de muitos estudos[DIAS et al., 2011]. O etanol, produzido a partir de materiais lignocelulósicos como o bagaço e a palha remanescentes do processo de produção de açúcar e etanol, chamado de etanol de segunda geração, ainda é produzido somente em escalas experimentais. Biomassas alternativas, como o capim elefantes por exemplo, tem servido como material de estudo para a produção de etanol celulósico [XIE et al., 2011]. Consequentemente, o bioetanol produzido diretamente a partir da sacarose ou amido, passou a ser chamado de etanol de primeira geração.

\section{O etanol brasileiro.}

Na década de 70 , o Brasil chegou a importar $80 \%$ do petróleo que consumia. O peso que este gasto trazia ao orçamento levou o governo brasileiro a incentivar meios de retomar a produção de etanol a partir da cana de açúcar, que existia no país desde 1920. Nascia então, em novembro de 1975, o Proálcool, programa do governo que permitiu o investimento maciço do setor privado na produção de etanol. Com o aumento da produção de petróleo e a queda dos preços no mercado internacional, o etanol perdeu competitividade, e em 2001 o mercado estava totalmente desregulamentado, e a competição entre os produtores era livre. Em 2002, uma nova crise na produção petrolífera atinge o país e o interesse por etanol volta a crescer. Para conquistar o mercado que havia perdido o interesse pelos biocombustíveis, as montadores de veículos passaram a trabalhar no desenvolvimento do motor flexível ao combustível, o Flex Fuel Vehicle, popularmente conhecidos no país como carros flex, que são movidos a álcool, gasolina ou ambos [LEITE; LEAL, 2007]. Segundo reportagem publicada pelo Jornal Folha de São Paulo em março de 2011 [ROLLI, 2011], só em fevereiro do mesmo ano foram comercializados 220,67 mil veículos com tecnologia flex, o que representa um aumento de $14,1 \%$ em relação a janeiro de 2011 . No mesmo período, a venda de veículos movidos somente a gasolina cresceu $5,6 \%$.

A alta procura alia-se à capacidade agrária brasileira em produzir cana-de-açúcar. O Brasil conta hoje com uma área de oito milhões de hectares plantada com cana-de-açúcar, 
além de um clima perfeitamente favorável para o crescimento da planta. Segundo dados da CONAB (Campanha Nacional de Abastecimento), a safra 2010/2011 produziu cerca de 625 bilhões de toneladas de cana-de-açúcar, o que resultou em 38,7 milhões de toneladas de açúcar e 27,7 bilhões de litros de etanol. Toda a cana de açúcar produzida é utilizada para a produção de açúcar e bioetanol, e o bagaço usualmente é queimado para alimentação das caldeiras. A Figura 3 mostra um canavial na região de Ribeirão Preto, cena comum para quem percorre o interior do estado de São Paulo.

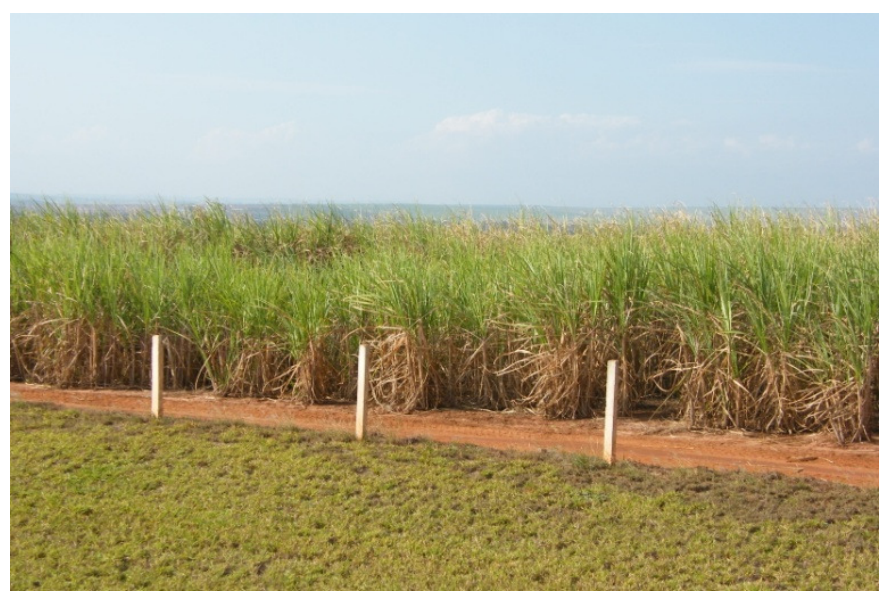

Figura 3 Canavial na região de Ribeirão Preto, estado de São Paulo.

É interessante salientar que o bioetanol é obtido diretamente do caldo através do processo de fermentação (etanol de primeira geração), mas também pode ser obtido durante o processo de produção de açúcar. No processo direto, obtém-se 86 litros de bioetanol. Já no caso em que uma tonelada é utilizada unicamente para a produção de açúcar, obtém-se a partir do melaço cerca de 100 quilos de açúcar além de 20 litros em média de etanol.

Segundo o gráfico mostrado na Figura 4, dado por NOGUEIRA, 2008, o Brasil e os Estados Unidos lideram a produção de bioetanol no mundo. A produção americana, diferentemente do Brasil, utiliza o milho como fonte principal de biomassa.

Assim, com um grande potencial na produção de biomassa, a atuação brasileira no desenvolvimento de tecnologias para a obtenção de biocombustíveis tem aumentado consideravelmente. 


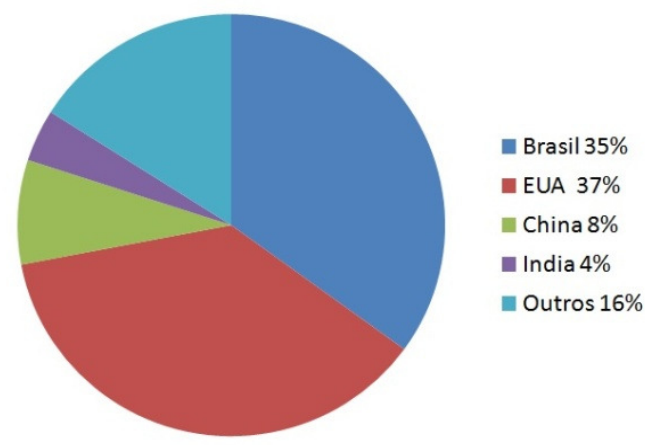

Figura 4 Distribuição da produção mundial de etanol em 2006 por NOGUEIRA, 2008.

Diante de um panorama tão favorável, torna-se necessário estudar meios de melhorar os processos de obtenção do bioetanol já em uso, além de desenvolver novas tecnologias e buscar novas matérias primas.

A posição vantajosa do Brasil na produção de bioetanol a partir de cana-de-açúcar, devido às boas condições climáticas e às áreas agrícolas disponíveis, não pode ser limitada somente na produção de primeira geração. Justamente por possuir uma produção de bioetanol de primeira geração muito bem fundamentada, o Brasil tem condições de viabilizar e liderar a produção de etanol de segunda geração através da integração com o processo já existente para a produção de primeira geração. Essa integração se baseia na divisão de parte da infraestrutura da usina aplicada ao processo de primeira geração, como a concentração de caldo, a fermentação e a destilação [DIAS et al., 2009].

A Figura 5 mostra o esquema das operações unitárias de uma usina de cana-de-açúcar com produção integrada de etanol de primeira e segunda geração.

Considerando uma usina que processa cerca de 500 toneladas de cana-de-açúcar por hora, a biomassa primeiro passa por um processo mecânico de moagem. Deste processo resultam o caldo de cana e o bagaço. A partir do caldo da cana é possível produzir tanto etanol de primeira geração quanto açúcar, como mencionado anteriormente. Para a produção de açúcar, o caldo é cozido, passando em seguida por um processo de cristalização e centrifugação. Já para a produção de etanol de primeira geração, o caldo de cana passa por um processo de fermentação, seguido por destilação. 


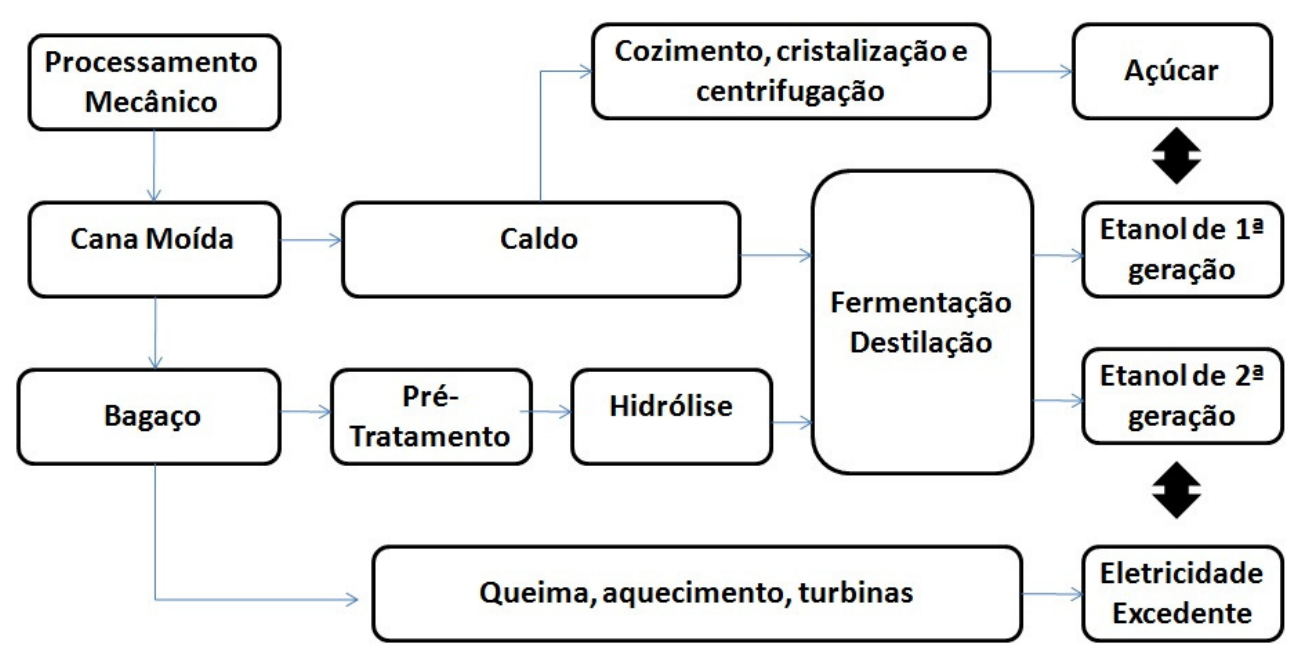

Figura 5 Esquema de produção de etanol de primeira e segunda geração numa usina de cana.

Mesmo que a produção de etanol de segunda geração seja possível, até o momento, somente em pequenas escalas e em laboratório, existe um grande esforço científico e tecnológico para produzir etanol a partir de materiais remanescentes do processo de primeira geração, como o bagaço de cana-de-açúcar e a palha. Cada tonelada de cana gera aproximadamente $140 \mathrm{~kg}$ de bagaço[DIAS et al., 2011]. Como mostra a Figura 5, este bagaço pode ser queimado e sua energia liberada utilizada para alimentar as turbinas, e/ou para a produção de etanol de segunda geração. Para a produção de etanol de segunda geração, o bagaço é submetido à um pré-tratamento, que pode ser mecânico ou químico, seguido pelo processo de hidrólise e finalmente, pelo processo de fermentação. A próxima seção traz uma breve descrição das técnicas de pré- tratamento, hidrólise e fermentação.

\section{Técnica de pré-tratamento.}

Um dos grandes desafios para a produção de etanol de segunda geração é a preparação da biomassa para o processo fermentativo. Materiais lignocelulósicos (como o bagaço e a palha de cana-de-açúcar, por exemplo) devem ser submetidos a um processo de prétratamento para que possam ser utilizados para a produção de etanol. O pré-tratamento consiste em técnicas que possibilitam a remoção da hemicelulose, o que torna a celulose mais suscetível ao ataque enzimático. Os processos para o pré-tratamento da biomassa podem ser classificados como físicos, químicos, combinados e biológicos, mas nenhum deles é, até o momento, competitivo o suficiente quando comparado ao processo estabelecido de primeira geração [DIAS et al., 2011]. 
Dentre os processos físicos pode-se citar o processo de explosão de vapor, onde a biomassa é tratada com vapor saturado seguido de uma rápida descompressão. Dentre os processos químicos, têm-se a hidrólise ácida e a hidrólise alcalina, feitas respectivamente por meio de ácidos e bases. Esses são os processos mais caros dentre os processos de pré tratamento. Ainda, entre os processos químicos, têm-se o organisolv (onde um solvente orgânico é usado para quebrar as ligações internas da lignina) e o processo biológico (onde fungos são utilizados para solubilizar a lignina). Os processos combinados são dois: a explosão de vapor catalisada (onde uma substancia química é adicionada na explosão a vapor aumentando a eficiência da hidrólise enzimática) e o processo chamado Afex (do ammonia fiber explosion), parecido com a técnica de explosão a vapor, mas com o uso de amônia ao invés de vapor saturado. Em alguns casos, $\mathrm{CO}_{2}$ também é utilizado.

No entanto, devido ao grande volume de biomassa que deve ser processada por hora, nem toda técnica pode ser aplicada para a produção de bioetanol a partir de cana de açúcar. Assim, o pré processamento baseado na explosão de vapor torna-se o mais adequado para a produção em grande escala (toneladas por hora). Este processo consiste em duas etapas:

1. Embebição: Baseia-se no processo de misturar água a altas temperaturas e pressão ao bagaço de cana, de forma que a água penetre na parede celular e se aloje entre as sobras e filamentos da celulose, preparando o material para a etapa de queda de pressão.

2. Queda brusca de pressão: $O$ bagaço é inserido em um reator termo pressurizado onde sofre uma queda brusca de pressão. Essa queda faz com que a água que penetrou na parede celular do bagaço evapore explosivamente, rompendo a estrutura do material lignocelulósico, o que faz com que a hemicelulose e celulose se torne altamente hidrolisáveis, evitando a necessidade da adição de componentes químicos.

Este processo tem como resultado uma pasta de fibras de celulose e hemicelulose expandida, suspensa em solução de lignina, cuja separação pode ser feita em uma centrífuga industrial. O material sólido é destinado para hidrolização, e a lignina, por ser de difícil fermentação, pode ser aproveitada para geração de energia. 
O grande desafio desta técnica está na dificuldade de aplicação deste processo a grandes quantidades de biomassa, que pode chegar a centenas de toneladas por hora no caso da cana-de-açúcar. Mesmo tratando-se do processo mais adequado para tratamento de biomassa em grandes quantidades, processar toneladas de bagaço de cana de açúcar limita a construção deste tipo de reator. Atualmente, o processo ainda está em fase de desenvolvimento, somente em escala laboratorial e de bancada.

\section{Biorreatores e o processo de fermentação.}

Diferentemente de reatores baseados em processos mecânicos e físicos, como o controle da temperatura e pressão do sistema, os biorreatores trabalham através de um processo químico. Segundo SCHMIDELL et al., 2005, denominam-se biorreatores, reatores bioquímicos ou ainda reatores biológicos, os reatores químicos nos quais ocorrem uma série de reações químicas biocatalisadas. Esses biocatalisadores podem ser enzimas ou células vivas (microbianas, animais ou vegetais).

Em SCHMIDELL et al., 2005 também pode ser encontrada uma classificação dos biorreatores em três tipos, de acordo com o sistema operacional:

1. Processo em batelada: Uma grande quantidade da cultura é inserida no reator. O processo de fermentação tem tempo de duração determinado, o que em geral dura 4 a 5 dias, mas pode estender-se por até um mês dependendo do tipo de produto esperado. $\mathrm{O}$ volume de material é constante.

2. Processo em batelada alimentada: são caracterizados pela alimentação intermitente ou contínua do mosto ao fermentador. Isso traz algumas vantagens para o processo de produção, pois é possível adicionar precursores para produtos desejados e componentes regulatórios em alguma etapa, além de ser possível controlar a quantidade de nutrientes, o que pode acelerar ou retardar o processo. O volume de material aumenta como passar do tempo.

3. Processo contínuo: O processo é efetivado com entrada e saída do material, o que proporciona um cultivo mais longo e um volume de processamento muito grande comparado ao processo de batelada. Sua principal aplicação é no tratamento de poluentes (planta de lodo ativado, digestores e tanques anaeróbios). Reatores desse tipo são menores, gerando menor custo. $\mathrm{O}$ volume 
de material se mantém constante, pela entrada e saída de material, no entanto, este tipo de cultura está mais suscetível a contaminação.

\subsubsection{O processo de fermentação.}

Segundo CHISTI, 2009, fermentação é um processo que utiliza micro-organismos para converter substratos líquidos ou sólidos em vários produtos. Existem dois tipos de fermentação: em estado sólido e submersa. Na fermentação em estado sólido, os microorganismos crescem sobre um substrato sólido, com pouca ou nenhuma alimentação de água. Assim são produzidos alguns tipos de cogumelos e alguns alimentos tradicionais. $\mathrm{Na}$

fermentação submersa, o substrato é dissolvido no meio. É o tipo de fermentação aplicada na produção de iogurte, cerveja e vinho, por exemplo. Ambos os processos se dividem em aeróbicos e anaeróbicos, ou seja, presença de oxigênio necessária e não necessária, respectivamente. $\mathrm{O}$ processo de fermentação pode ser influenciado também por fatores como temperatura, $\mathrm{pH}$, quantidade de $\mathrm{O}_{2}$ e $\mathrm{CO}_{2}$, ou o tipo de sistema operacional (batelada, contínuo, alimentado, etc.)

Como pode ser visto na Figura 5, o processo de fermentação é parte do processo no corrente modelo brasileiro de produção de etanol de primeira geração. No entanto, ainda que a produção de etanol de segunda geração esteja em fase de pesquisa e seja possível somente em escala de laboratório, a fermentação também faz parte desse processo.

Dessa forma, o processo de fermentação é fundamental para a produção de etanol, tanto de primeira como de segunda geração. Devido à escala de processamento, qualquer melhora no rendimento desses fermentadores resulta em um grande aumento na produção de etanol.

Segundo FREGONESI, 1998, a fermentação para produção de etanol pode ser efetuada por dois diferentes processos: em batelada, onde a fermentação é realizada misturando-se o meio de cultura com o micro-organismo e separando-os por filtração, e que tem duração entre oito e quinze horas; e o processo de fermentação contínuo, em que o microorganismo permanece no interior do reator onde é feita continuamente a passagem de substrato e este é convertido em produto. A vantagem do processo de fermentação em batelada, está na facilidade de operação e no baixo risco de perda de materiais. No entanto, apesar do processo contínuo apresentar maior risco de contaminação que possa comprometer 
a produção, o mesmo não exige adaptação dos micro-organismos ao meio de cultura, fazendo com que a célula apresente crescimento em nível máximo.

Segundo reportagem da Edição 101 Revista Alcoobrás em 2006 (BOSCO, 2006), as usinas no país utilizam em sua maioria o sistema em batelada, mas este processo começou a enfrentar a concorrência com o modelo contínuo naquele mesmo ano, considerado por muitos pesquisadores uma evolução natural do processo em batelada. Ainda segundo a revista, apesar de não haver estatísticas exatas, em 2006 o processo contínuo já era responsável pela produção de cerca de $25 \%$ a $30 \%$ do etanol fabricado no Brasil.

A Figura 6 mostra dornas de fermentação de fluxo contínuo em uma usina de produção de açúcar e etanol, localizada na cidade de Clementina, interior de São Paulo.

É importante salientar também que todo processo de fermentação gera calor, e consequentemente, é importante tratar as formas para controlar o aquecimento, que em alguns casos pode prejudicar o processo. As trocas de calor em processo de fermentação dependem de alguns fatores como o tamanho da superfície, a diferença de temperatura entre o fluido e o vapor de água, as propriedades deste fluido e também da turbulência gerada pelo escoamento.

Como a geometria do fermentador influencia diretamente no tamanho da superfície de contato para troca de calor e no escoamento quando o processo é contínuo, é de suma importância otimizar essa geometria de forma a otimizar as trocas de calor, o escoamento interno ao reator, e consequentemente, o processo de fermentação. 


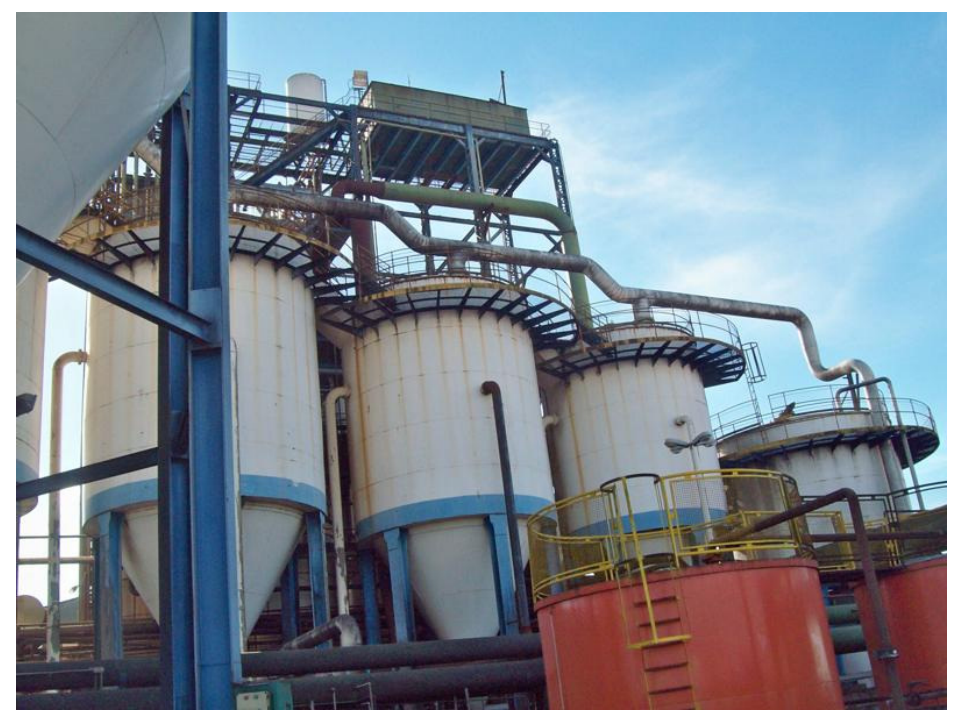

Figura 6 Dornas de fermentação em sistema contínuo em uma usina no interior do estado de São Paulo (foto de Márcia Osaki).

\section{Objetivos.}

Como foi discutido neste capítulo, o processo de fermentação é necessário tanto para a produção de etanol de primeira geração, que ocorre na indústria sucroalcooleira brasileira, como na produção de etanol de segunda geração, ainda em fase de pesquisa e desenvolvimento. O diferencial na aplicação de fermentadores para a produção de etanol são as grandes escalas de processamento necessárias, normalmente centenas de toneladas por hora. Dessa forma, é muito importante melhorar a eficiência dos fermentadores, pois uma pequena melhora tem um grande impacto no resultado final. Essa melhoria no equipamento de fermentação implica no estudo de um conjunto de fatores que influenciam diretamente o processo: a parte estrutural da geometria do fermentador e a possibilidade de sua fabricação industrial, o fenômeno físico do escoamento no fermentador contínuo e o processo químico envolvido, por exemplo. Parâmetros do escoamento influenciam diretamente no fenômeno químico e, consequentemente, na eficiência do fermentador. Dessa forma, otimizar o processo de produção de bioetanol consiste num trabalho multidisciplinar, onde estes fatores devem ser analisados cuidadosamente e em conjunto.

Assim, simular o processo de acordo com as várias condições possíveis é a solução para a melhoria e otimização. Essa simulação pode ser feita tanto experimentalmente, com a construção de um protótipo, quanto computacionalmente, através de programas implementados de forma independente ou comercial. Isto porque estudos experimentais e numéricos não são conflitantes, mas sim complementares. O estudo numérico proporciona a 
análise do processo sem nenhum gasto com a construção do protótipo, tornando-se muito mais viável do que a mais hábil análise experimental [MOUSAVI et al., 2010]. Os resultados obtidos computacionalmente pode ser utilizados como aproximação inicial para a construção ou melhoria de um fermentador, e os resultados do estudo experimental validam os resultados numéricos obtidos durante o processo de análise.

Dentro desse contexto, a proposta desse trabalho é simular computacionalmente o processamento de biomassa, no caso, caldo de cana-de-açúcar, e otimizar parâmetros do escoamento que podem influenciar no processo químico envolvido, como tensão de cisalhamento e tempo de residência . Esta otimização é feita através da mudança dos parâmetros geométricos do fermentador. Mais especificamente, o objetivo deste trabalho é obter os parâmetros geométricos ideais para a estrutura deste fermentador, de forma a maximizar ou minimizar os parâmetros do escoamento que podem influenciar o processo de conversão de biomassa em etanol. A distribuição de tempos de residência foi um dos parâmetros escolhidos por representar o tempo em que cada porção de fluido permanece no interior do fermentador. A análise deste parâmetro é de extrema importância pois, se porções do fluido permanecem tempos muito discrepantes no interior do fermentador, parte dessas reações químicas não serão completadas, e parte das porções do fluido perderão suas propriedades. O segundo parâmetro escolhido foi a tensão de cisalhamento. Este parâmetro está relacionado com a garantia da sobrevivência dos micro-organismos envolvidos na fermentação. Tensões muito altas podem ser prejudiciais, causando a morte desses organismos. 

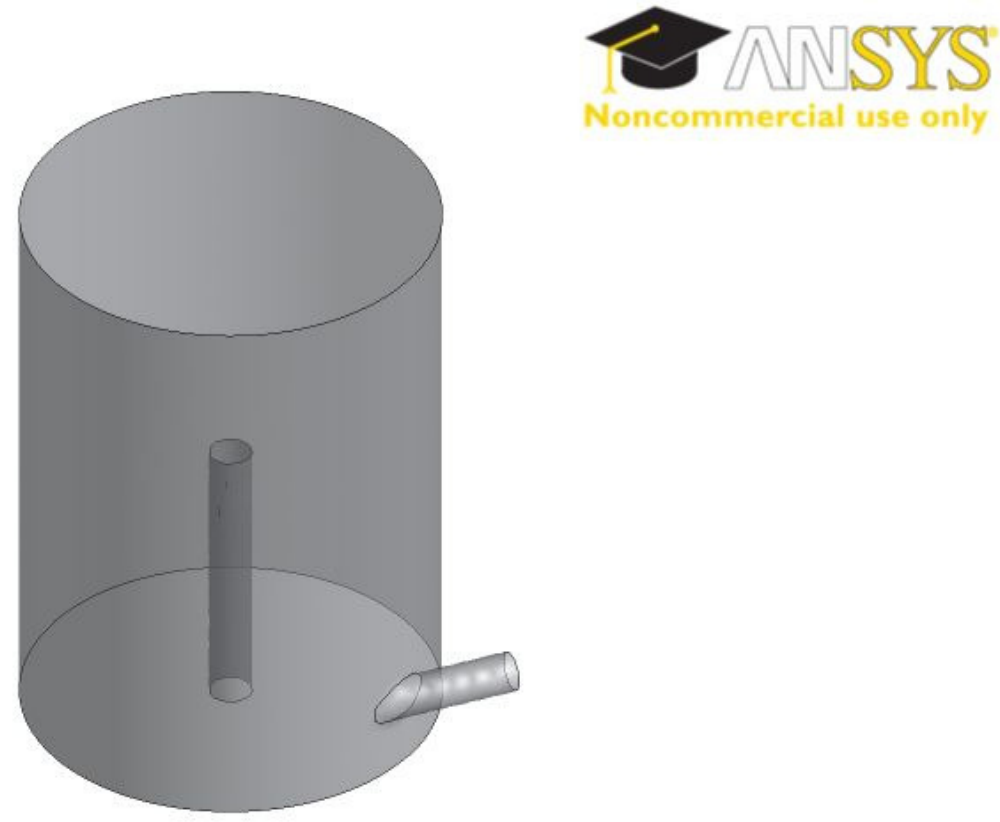

Figura 7 Protótipo inicial do fermentador em perspectiva isométrica.

Para simular o escoamento de forma eficiente optou-se por utilizar o programa comercial ANSYS CFX 13®. Além de proporcionar opções para a simulação, o programa possui uma interface compatível com o programa de otimização modeFRONTIER®, utilizado na etapa em que a tensão de cisalhamento foi utilizada como função objetivo. Neste ambiente é possível automatizar o processo criação da geometria, simulação do escoamento, otimização, e novamente criação da geometria. A geometria utilizada como aproximação inicial para o fermentador é mostrada na Figura 7. Para o processo de otimização, tratando-se de um problema com múltiplos objetivos, foi escolhido o método de Algoritmos Genéticos. Essa classe de algoritmos inspirada na Teoria da Evolução de Darwin, ou seja, nos mecanismos de seleção natural e genética [GOLDBERG, 1989] foi inicialmente desenvolvida por John H. Holland no começo da década de 70, mas só ganhou popularidade após quase 30 anos, como consequência do maior desenvolvimento computacional. O algoritmo geral, explicado detalhadamente no Capítulo 3, é baseado na geração de uma estrutura geométrica, que serve como domínio para a geração da malha computacional. Dessa forma, todas as condições de contorno podem ser modeladas através do Ansys CFX 13®, e as equações que modelam o escoamento são discretizadas e solucionadas. Os resultados são avaliados e selecionados através da aplicação do Algoritmo Genético, e automaticamente, no ambiente 
modeFRONTIER $®$, o processo recomeça com a geração de uma nova geometria, nova malha, e assim consecutivamente até que o número de iterações determinado seja atingido.

Para a análise da distribuição de tempos de residência, o CFX® foi aplicado de forma a simular o escoamento com a injeção de um fluido traçador no início do escoamento. A concentração do traçador é então monitorada na saída do escoamento, e a partir desses dados é possível calcular a distribuição de tempos de residência no interior do fermentador, e calcular sua variância. A metodologia envolvida neste cálculo é descrita com mais detalhes no Capítulo 3. Para este caso, o método de otimização escolhido foi o univariado, em que cada parâmetro é variado a cada iteração, mantendo-se fixos todos os outros. Neste caso, 20 geometrias foram simuladas, com variação na medida do ângulo entre a tubulação de entrada e o tanque principal, e do comprimento da tubulação de saída, fatores que mostraram ter maior influência sobre o escoamento.

Após as análises descritas acima, este trabalho propõe dimensões para a geometria de um fermentador contínuo de forma a melhorar o escoamento interno, aumentando assim sua eficiência. $\mathrm{O}$ estudo inicial contou com a simulação do escoamento em um fermentador de 900 litros, análise esta que abre caminhos para o estudo e aumento das escalas. Neste caso, considerando as grandes escalas, qualquer melhora na eficiência de um fermentador tem grandes impactos na produção de bioetanol. Este trabalho contribui para a melhoria destes equipamentos propondo mudanças simples de serem implementadas, mas que podem trazer benefícios para o processo de produção.

\subsubsection{Organização da tese}

A presente tese está organizada da seguinte maneira:

- Capítulo 1: Introdução. Uma abordagem do contexto geral na produção de biocombustíveis, mais especificamente de bioetanol, baseada em alguns fatos históricos e nas vantagens e limitações da produção na indústria sucroalcooleira brasileira.

- Capítulo 2: Revisão da literatura. É apresentado um panorama geral dos trabalhos científicos onde técnicas computacionais são aplicadas na simulação de reatores e biorreatores, utilizados tanto na produção de biocombustíveis 
como aplicados na indústria alimentícia, farmacêutica, etc. Trabalhos que relacionam técnicas de otimização aplicadas a biorreatores, entre elas os Algoritmos Genéticos, também são considerados neste capítulo.

- Capítulo 3: Metodologia. Neste capítulo são abordados todos os detalhes da modelagem física e numérica do problema, inclusive uma descrição do Algoritmo Genético utilizado e da metodologia de estímulo-resposta para obtenção da distribuição de tempos de residência. A modelagem numérica é apresentada, juntamente com as especificações geométricas do fermentador simulado.

- Capítulo 4: Resultados. Este capítulo é composto por duas partes: na primeira, os resultados da otimização do fermentador através da análise da tensão de cisalhamento e do acoplamento da simulação numérica em CFX com o processo de otimização do programa modeFRONTIER. A segunda parte contempla uma análise da distribuição dos tempos de residência e sua variância através da metodologia de estímulo-resposta por injeção de um traçador no escoamento. Aqui, a técnica de otimização univariada foi aplicada. Os resultados de ambos processos de otimização são discutidos e comparados.

- Capítulo 5: Conclusões, perspectivas e recomendações. A partir da análise dos resultados, o capítulo 5 traz as conclusões deste trabalho, propondo a geometria ótima para o fermentador em escala de bancada, e as perspectivas de trabalhos futuros, que inclui a análise de aumento de escala (scale-up) do fermentador. 


\section{CAPITULO 2 - REVISÃO DA LITERATURA}

\section{Introdução.}

Este capítulo destina-se a revisão de trabalhos sobre a análise computacional de parâmetros geométricos e parâmetros do escoamento em biorreatores e reatores, em suas diversas aplicações. Os trabalhos abordam principalmente conceitos de mecânica dos fluidos computacional como ferramenta para análise e otimização da eficiência de biorreatores, e técnicas de otimização.

A maioria dos trabalhos encontrados na literatura trata da aplicação de técnicas de mecânica dos fluidos computacional para simular escoamentos internos nos mais diversos tipos de biorreatores, dentre eles tanques do tipo agitado, aerado, fermentadores, etc.

\section{Mecânica dos Fluidos Computacional e o estudo de biorreatores.}

HARRIS et al., 1996 aplicaram técnicas de mecânica dos fluidos computacional para estudar três exemplos de escoamento em diferentes equipamentos utilizados em diversos setores da engenharia. $\mathrm{O}$ primeiro deles foi um tanque agitado. Neste caso, foram ressaltadas as técnicas de modelagem de turbulência, muito importante na simulação do escoamento dentro desse tipo de reator, técnicas que ainda não eram muito satisfatórias na época. Foi utilizado o programa Fluent ${ }^{\circledR}$, com a superfície do líquido modelada em condições de não deslizamento, e a turbulência foi descrita utilizando o modelo de turbulência k- $\varepsilon$. As paredes foram tratadas como superfície livre, o que gerou uma boa concordância com os resultados experimentais.

No segundo exemplo estudado, foram feitas simulações de um escoamento não Newtoniano e com variação de temperatura em uma extrusora. As técnicas de CFD foram aplicadas com o intuito de obter os perfis de temperatura e o tempo de residência, ambos os fatores que podem influenciar na qualidade do produto final desejado. Além disso, este tipo de reator apresenta uma geometria mais complexa, e o estudo do tempo de residência ajuda a evitar recirculações que podem causar a degradação dos polímeros. Para isso, foi usado o software comercial POLIFLOW®, a geometria foi simplificada por questões de custo computacional e a malha foi refinada em algumas regiões de maior tensão de cisalhamento. $\mathrm{O}$ 
deslizamento e a transferência de calor foram definidos como nulos na parede e ao redor das pás rotantes. No entanto, na época, esta simulação exigia mais do que $1300 \mathrm{Mb}$ de RAM, o que tornava inviável o refinamento da malha. Por conta disso, foram apresentados somente resultados para simulações isotérmicas. Através desses resultados, foi possível obter regiões em que altas temperaturas coincidiam com regiões com alto tempo de residência, sendo possível assim identificar regiões do escoamento que favoreciam a degradação do polímero. Por fim, o terceiro exemplo estudado foi a simulação de um escoamento turbulento de gás com reações químicas acontecendo consecutivamente e simultaneamente, e a influência da turbulência do escoamento no andamento das reações químicas. Neste caso, a principal dificuldade é escolher com a maior exatidão possível os parâmetros utilizados nas reações químicas, que são acoplados as equações, modelando assim a fração de massa das espécies. As simulações para o terceiro caso estudado foram efetuadas em duas dimensões devido ao alto custo computacional exigido. Pode-se perceber que a grande preocupação há dez anos era o tempo computacional gasto para efetuar as simulações. Hoje este ainda é um problema, no entanto, com menos dificuldades em relação à década passada. Como já era previsto por HARRIS et al., 1996, a simulação do desempenho de reatores é mais viável através da utilização de software comercial, mesmo que estes softwares ainda não tivessem um grande leque de modelos implementados na época, como pode-se obter hoje com o aprimoramento do $\mathrm{CFX}{ }^{\circledR}$ e do Fluent ${ }^{\circledR}$, por exemplo.

DAVIDSON et al., 2003 utilizaram o programa Fluent ${ }^{\circledR}$ para estimar a distribuição de tempo de circulação das partículas em biorreatores, definido como o intervalo de tempo entre duas passagens consecutivas de uma mesma partícula por uma região pré definida. Foram usados três tipos de tanques agitados como casos teste, com escoamento e turbulência modelados pelas equações de Navier-Stokes e o modelo k- $\varepsilon$, respectivamente. As malhas utilizadas para discretização do domínio computacional foram muito parecidas, pois o formato dos tanques não variou muito. $\mathrm{O}$ número de partículas injetadas foi crescente no primeiro, segundo e terceiro tanque, variando entre 15175 e 35700 e o tempo para rastrear todas as partículas era uma função do número e do passo no tempo. Os resultados foram satisfatórios qualitativamente, quando comparados à análises experimentais baseadas em processamento de sinais. Conclui-se que os métodos utilizados por eles durante as análises experimentais resultaram em distribuições de probabilidade com menor exatidão. As análises de baseadas em simulações computacionais do escoamento proporcionaram resultados mais eficientes no que diz respeito a captura da distribuição de tempo de residência. 
MICALE et al., 2004 utilizaram o programa CFX® com a possibilidade de simular o aparecimento de uma camada de líquido transparente em um escoamento liquido sólido num reator agitado por um impelidor. Para isso, foi utilizado o modelo Euleriano-Euleriano, que reproduziu corretamente o fenômeno, já muito conhecido experimentalmente até então, mas ainda pouco explorado computacionalmente. Concluiu-se que as características dessa camada variavam de acordo com a velocidade da hélice, e essa camada líquida transparente é resultado da diminuição da velocidade do líquido em relação a velocidade das partículas.

Levando em conta que a estrutura do reator possui relações intrínsecas com as condições de operação e hidrodinâmicas, estudos foram feitos a fim de otimizar a performance do reator como consequência da otimização dos parâmetros estruturais. PATWARDHAN et al., 2005 efetuaram o estudo experimental e numérico da performance de um reator agitado por dois impelidores, com escoamento gás-líquido e velocidade de rotação do impelidor constante igual a $70 \mathrm{rpm}$. O estudo numérico permitiu uma análise detalhada do perfil de velocidades e do tempo de residência do fluido no reator, ambos fatores que possuem relação direta com as reações químicas esperadas. Neste trabalho, foram efetuadas três modificações como caso teste, todas baseadas em modificações nas dimensões do impelidor, alterando assim sua potência e eficiência. Para cada caso teste foi efetuada uma nova simulação. Os resultados foram validados, e o modelo numérico forneceu uma boa aproximação para a distribuição do tempo de residência do reator em escala industrial, que nesta aplicação tem um volume de aproximadamente $100 \mathrm{~m}^{3}$. Uma boa aproximação para a fração volumétrica in siu (hold-up) média de gás também foi encontrada, apesar dos autores especificarem somente dados da porcentagem de melhora na performance do biorreator. É interessante salientar que foram escolhidas três geometrias de impelidor para serem testadas, e as simulações foram limitadas ao teste destas três geometrias.

Uma aplicação interessante de biorreatores, mas diferente do que é tratado neste trabalho, pode ser vista no estudo desenvolvido por HUTMACHER; SINGH, 2008. Neste trabalho, técnicas computacionais foram utilizadas para simular o cultivo de células, utilizadas na reparação, substituição e regeneração de órgãos e tecidos, em biorreatores. Para isso, os biorreatores devem reproduzir, da melhor maneira possível, o ambiente fisiológico de crescimento em desenvolvimento desse tipo de células e as técnicas de CFD são utilizadas para simular o escoamento de nutrientes entre suportes que servem como base para o crescimento e desenvolvimento das células. Da mesma maneira em que ocorre em outras 
aplicações, a simulação permitiu aprimorar a estrutura do biorreator de forma a favorecer o processo, antes da fabricação. Este trabalho traz uma revisão bibliográfica dos avanços e limitações do uso de técnicas computacionais para simular este tipo de aplicação. Pôde-se concluir que, apesar de ferramenta computacional ter um valor imenso neste tipo de estudo, ainda faz-se necessário aprimorar os modelos, principalmente no caso em que se deseja simular a interação visco elástica entre fluido e partícula, e claro, no aumento do custo computacional deste tipo de simulação.

Muitas vezes estudos experimentais podem ser limitantes quando se quer analisar quantitativamente um fenômeno, além de custarem muito tempo e investimento financeiro. Dessa forma, até por volta de 2008, estudos quantitativos e numéricos eram limitados no que se refere a biorretores centrífugos com impelidor. XIA et al., 2008 apresentaram um estudo numérico utilizando o programa Fluent ${ }^{\circledR}$ para entender melhor o perfil de velocidade, recirculação, a tensão de cisalhamento, e a distribuição do tempo de residência, neste caso, chamada de distribuição de tempo de circulação, dentro de um biorreator com impelidor. Os resultados dessas simulações foram concordantes com resultados experimentais desenvolvidos pelo mesmo grupo. Foram testados oito tipo de impelidores, num reator de 5 litros. O estudo numérico proporcionou a identificação de três zonas de recirculação, prejudiciais para a mistura desejada no biorreator. É interessante notar que XIA et al., 2008 observaram a necessidade de atentar-se para as variações que podem ocorrer no perfil de velocidade, tensão de cisalhamento e outros parâmetros do escoamento importantes para o bom do desempenho do biorreator quando a escala é aumentada. Em grande escala o comportamento do escoamento é diferente quando comparado a um reator em pequena escala. Esta diferença deve-se à variação que pode ocorrer nos perfis de velocidade, na circulação de líquido, nas modificações nas tensões de cisalhamento, e das distribuições de tempo de residência [XIA et al., 2008].

PRIESKE; DREWS; KRAUME, 2008 estudaram, experimental e numericamente, o escoamento gás-líquido em um reator de membranas aplicado em sistemas de tratamento e reutilização de água. O programa ANSYS CFX 10® foi utilizado para testar diferentes geometrias, referente às dimensões e espaçamento entre as membranas. As simulações foram efetuadas numa malha com 35000 elementos e uma aproximação Euleriana-Euleriana. A modelagem da turbulência foi dividida em duas partes: a parte contínua foi modelada por SST (Shear Stress Transport) e a fase dispersa utilizando Zero-Equation. Experimentalmente foi 
possível concluir que a fração volumétrica do gás é menor quando as membranas são adicionadas ao escoamento, assim como comparar o escoamento com três diferentes dimensões de membrana.

Simulações computacionais também foram utilizadas por WANG; DONG, 2008 para determinar a tensão de cisalhamento e transferência de massa em biorreatores. O objetivo das simulações foi obter informações sobre a concentração de glucose e lactose para diferentes formatos e a tensão de cisalhamento nas diferentes geometrias dos biorreatores. A simulação 3D foi efetuada utilizando o programa FLUENT®, e malhas tetraédricas híbridas. Foi possível concluir que a posição de entrada e saída de fluido e a vazão mássica na entrada tem uma relação quadrática com a tensão de cisalhamento, ou seja, para garantir um ambiente adequado para o desenvolvimento celular.

Um dos estudos mais recentes neste campo é o trabalho desenvolvido por SHAO et al., 2010. Foi efetuado um estudo experimental e numérico da influência da potência da hélice num reator do tipo tanque agitado de três litros, aplicado à produção de etanol celulósico. Dados como a densidade e a viscosidades do líquido, a densidade e as dimensões das partículas, e a fração volumétrica da parte sólida foram determinadas experimentalmente. A partir desses dados, o escoamento foi simulado utilizando o programa Fluent ${ }^{\circ}$. O grau de mistura ótimo foi obtido testando várias velocidades de rotação da hélice. Uma contribuição deste trabalho é que, para este caso de aplicação, a reação química só é efetiva quando todas as partículas permanecem suspensas como consequência do movimento da hélice. Além disso, uma das conclusões mais interessantes deste trabalho está na relação entre a velocidade da hélice e a velocidade ascensional das partículas em suspensão. O fato da velocidade ascensional das partículas ser maior do que a velocidade da hélice não implica na melhora do desempenho químico do reator.

Segundo UM; HANLEY, 2008 o entendimento da reologia de biomassa suspensa é muito importante para o projeto do equipamento e para estimar a desempenho do processo. $\mathrm{O}$ principal objetivo do trabalho foi investigar experimentalmente o comportamento reológico de suspensões sólidas para ajustar um modelo apropriado aos dados experimentais e determinar a distribuição de viscosidade turbulenta durante o processo de fermentação do etanol. Estes resultados experimentais serviram de embasamento para as simulações computacionais. As simulações foram efetuadas através do Fluent 6.2.20®, a turbulência foi modelada utilizando k- $\varepsilon$. Foi utilizada uma malha não estruturada com 570.000 tetraedros e 
182000 nós e o erro relativo normalizado foi adotado como sendo $10^{-4}$, sendo atingido após 5000 iterações. A análise reológica de substratos sólidos no biorreator durante a hidrólise enzimática e a fermentação do etanol mostraram um acentuado decréscimo da viscosidade em função do tempo, assim como uma dependência direta entre viscosidade aparente do caldo submetido ao processo de fermentação e a temperatura e concentração de biomassa. Além disso, o biorreator utilizado na produção de etanol deve sempre operar com concentração de biomassa abaixo do especificado para garantir eficiência na mistura. No caso do fermentador estudado por UM; HANLEY, 2008 operam com até $20 \%$ de biomassa. No entanto, o aumento da concentração compromete negativamente o escoamento, a mistura e a distribuição de sólidos.

MOUSAVI et al., 2010 utilizaram CFD para simular e otimizar parâmetros que influenciam a produção de biomassa em um biorreator horizontal tubular. O diâmetro do reator é reduzido, de apenas 0,03 m., e com escoamento em loop. Foi avaliada a influência de quatro parâmetros: velocidade de entrada de ar, velocidade de entrada de líquido, diâmetro da bolha e viscosidade. Este tipo de biorreator é adequado somente para baixa escala. Com o uso de uma malha extremamente refinada, o modelo computacional foi muito útil para analisar a influência dos parâmetros nas reações químicas, e foram concordantes com os resultados experimentais desenvolvidos. No entanto, este tipo de aplicação não é compatível com a escala de produção requerida pela simulação do processo industrial de produção de etanol em um fermentador.

\subsubsection{Algoritmos Genéticos e otimização de reatores e biorreatores.}

Como visto anteriormente, o trabalho desenvolvido por PATWARDHAN et al., 2005 mostra que é importante relacionar a estrutura de um reator com as condições de operação e hidrodinâmica, objetivando melhorias no desempenho do biorreator. No entanto, os autores efetuaram uma otimização manual da estrutura do reator estudado, ou seja, foram escolhidas três modificações a serem feitas no impelidor, e, então, a simulação do escoamento foi efetuada, juntamente com a simulação das reações químicas para cada uma das geometrias do impelidor. A escolha de um número de modificações limitado, ou seja, de um número de parâmetros a serem otimizados, impediu que novas estruturas fossem propostas e testadas. Automatizar e efetuar essa escolha de maneira efetiva, possibilita o aumento do número de 
opções estruturais analisadas, e que poderiam proporcionar um melhor desempenho do equipamento. Essa automatização pode ser feita utilizando um algoritmo de otimização.

Uma visão interessante sobre o que é otimização é dada por BEIGHTLER; PHILLIPS; WILDE, 1979, citada por GOLDBERG, 1989, que diz: "O anseio do homem pela perfeição encontra expressão na teoria de otimização. Esta teoria estuda como descrever e obter o que é o Melhor, uma vez que sabe como medir e alterar o que é bom e o que é ruim... A teoria de otimização engloba o estudo quantitativo do ótimo e como encontrá-lo."

Métodos de otimização podem ser classificados de diversas maneiras, como mostrado em RAO, 2009. As classificações podem ser organizadas nas seguintes formas: na existência de restrições; na natureza das variáveis de projeto; na estrutura física do problema; na natureza das equações envolvidas; na natureza determinística das variáveis e no número de funções objetivo.

Dependendo do número de funções objetivo a serem minimizadas ou maximizadas, um problema de otimização pode ser classificado como problemas com simples objetivo ou com múltiplos objetivos. Em um problema com simples objetivo, somente uma função ou parâmetro do problema deve ser otimizado. Todavia, em um problema com múltiplos objetivos, vários parâmetros serão otimizados simultaneamente.

$\mathrm{Na}$ maioria das aplicações industriais de reatores e biorreatores, uma grande quantidade de parâmetros, sejam estes geométricos, químicos ou do escoamento, podem influenciar no seu desempenho, ou seja, trata-se de um problema com múltiplos objetivos. Uma análise adequada desses parâmetros torna-se necessária para otimizar o biorreator e suas condições de operação e os Algoritmos Genéticos são uma ferramenta adequada a este tipo de problema.

Segundo GOLDBERG, 1989, Algoritmos Genéticos são algoritmos de busca baseados no mecanismo de seleção natural e genética natural. Ou ainda, podem ser definidos como uma classe de métodos tradicionais não estocásticos aptos para solucionar complexos problemas de otimização do mundo real [KORDABADI; JAHANMIRI, 2005]. Esta classe de algoritmos foi inicialmente proposta por John H. Holland no início da década de 70, inspirada na teoria da evolução proposta pelo cientista inglês Charles Darwin. A inspiração de Darwin veio da viagem que o cientista fez a bordo do Beagle, um navio britânico com a missão de explorar 
regiões costeira ao redor do mundo, numa viagem entre os anos de 1831 e 1836. Durante a passagem pelas Ilhas Galápagos, Darwin notou que havia diferentes tipos de pássaros em cada uma das ilhas do arquipélago, como consequência da diferença ambiental entre as ilhas. Ou seja, os pássaros melhor adaptados sobreviviam, e os menos adaptados eram eliminados. A metodologia dos Algoritmos Genéticos para otimizar uma ou mais funções é justamente esta: de acordo com um determinado problema (ambiente), é possível buscar vetores de solução (indivíduos) para uma função objetivo (adaptatividade) de forma a se aproximar o máximo possível da melhor solução.

Dessa forma, a aplicação das técnicas de CFD e Algoritmos Genéticos em problemas da engenharia tem crescido constantemente e nas mais diversas áreas como, por exemplo, na otimização de reatores nucleares ALIM et al., 2008e muito frequentemente na otimização de perfis de asas em aviões [PARK; LEE, 2010]. A idéia geral de um Algoritmo Genético, como mostra a Figura 8, é começar com uma população inicial de pontos (no caso deste trabalho, valores de parâmetros geométricos do reator), escolhida randomicamente. Cada um desses pontos é calculado de acordo com a função objetivo a ser otimizada. Uma nova população é então formada de acordo com o parâmetro de seleção de indivíduos escolhido, até que a convergência desejada seja atingida.

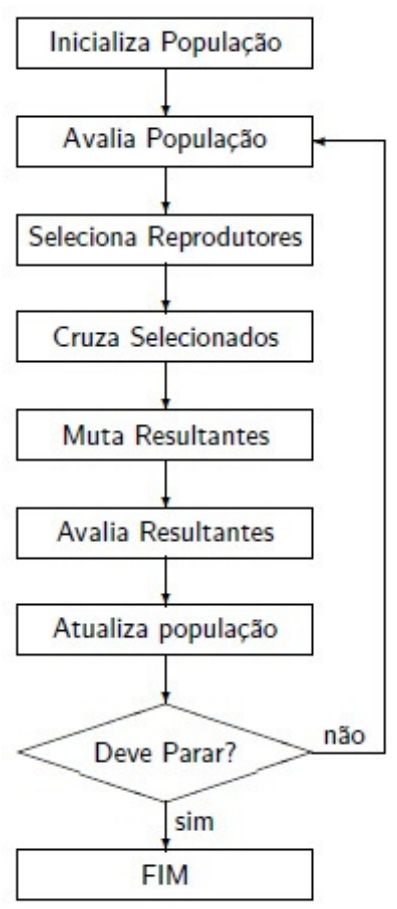

Figura 8 Estrutura de funcionamento de um algoritmo genético tradicional. 
KORDABADI; JAHANMIRI, 2005 aplicaram Algoritmos Genéticos para otimizar um reator para síntese de metanol. O trabalho foi desenvolvido com o objetivo de obter duas aproximações: encontrar o perfil de temperatura ótimo para a reação, e em seguida, desenvolver um reator de forma a maximizar a produção de metanol. As otimizações foram estudadas aplicando-se o modelo heterogêneo para o escoamento, onde o gradiente entre as fases (fluida e sólida) é considerado. O reator proposto obteve uma melhora de 2,9\% após o processo de otimização.

Algoritmos Genéticos são também uma ferramenta muito favorável na otimização de fermentadores em diferentes aplicações e configurações. Diversas análises são encontradas na literatura, como, por exemplo, o trabalho de OLIVEIRA, 2007, que utilizou Algoritmos Genéticos para otimizar os parâmetros cinéticos do efeito da inibição do etanol em um fermentador contínuo do tipo torre com células imobilizadas. OLIVEIRA, 2007 utilizou, além dos Algoritmos Genéticos, uma análise baseada na avaliação da superfície de resposta, que possibilita a visualização do comportamento das variáveis de otimização. Com isso, as melhores condições de operação para as variáveis manipuladas foram obtidas. Um trabalho parecido foi desenvolvido por RIVERA et al., 2008, que utilizaram um Algoritmo Genético com codificação real para otimizar os parâmetros cinéticos do modelo das reações químicas em um fermentador em formato de torre com micro-organismos imobilizados, modelo este considerado alternativo para a produção de bioetanol. O fermentador contou com uma vazão de $40 \mathrm{~mL} / \mathrm{h}$, bem menor que a utilizada neste trabalho, e o Algoritmo Genético, combinado com outro algoritmo de otimização, o método Quase-Newton, para uma segunda avaliação dos parâmetros cinéticos mais importantes, resultou na melhoria na estimativa dos parâmetros cinéticos do modelo químico.

$\mathrm{Na}$ maioria dos casos, como pode ser visto pelos trabalhos aqui citados, os Algoritmos Genéticos são utilizados para otimizar parâmetros cinéticos das reações químicas envolvidas no processo de fermentação. Em outras palavras, a aplicação baseia-se em otimizar uma equação matemática baseada em parâmetros químicos, que modela a reação química. No entanto, os Algoritmos Genéticos podem ser uma ferramenta extremamente útil para analisar os parâmetros envolvidos no escoamento do fermentador contínuo, como perfis de velocidade, tensão de cisalhamento, tempo de residência, etc, parâmetros estes que também têm uma forte influência no processo de fermentação, podendo contribuir ou prejudicá-lo. Até o presente momento, não consta na literatura trabalhos em que Algoritmos Genéticos são 
combinados a técnicas de dinâmica dos fluidos computacional e aplicados como ferramenta para otimização de fermentadores contínuos em grande escala. Dessa forma, uma das motivações deste trabalho é aplicar Algoritmos Genéticos com o objetivo de otimizar os parâmetros do escoamento através da seleção de parâmetros geométricos de um fermentador contínuo, como uma alternativa na busca de um melhor desempenho neste tipo de equipamento comumente utilizado na indústria sucroalcooleira brasileira.

2.2.2 Técnica de estímulo-resposta para obtenção da distribuição de tempo de residência (DTR) em tanques agitados de fluxo contínuo.

A distribuição de tempo de residência é um parâmetro do escoamento que influencia diretamente as reações químicas envolvidas no processo de fermentação. Se o caldo permanece tempo demais no fermentador, perde suas propriedades. Se o caldo não permanece tempo suficiente, as reações químicas não são completadas. Dessa forma, a análise da distribuição de tempos de residência é uma maneira eficiente de caracterizar o desempenho de um biorreator, sendo possível investigar a maneira como o fluido escoa pelo reservatório. Além disso, é possível conhecer o tempo que cada porção de fluido permanece dentro do biorreator.

Uma técnica experimental muito eficiente para obtenção da curva de distribuição de residência é a técnica de estímulo-resposta com injeção de um fluido traçador no escoamento. Em um reator de bancada, GAVRILESCU; TUDOSE, 1999 utilizaram a técnica para efetuar um estudo experimental da distribuição de tempo de residência somente na fase líquida de um reator tubos concêntricos do tipo air-lift. Neste caso, através da análise da distribuição dos tempos de residência e da variância, foi possível concluir que o reator estudado possui um escoamento mais uniforme do que os reatores tubulares e em colunas de bolhas. As conclusões tem grande importância prática, pois culturas aeróbicas são dependentes e podem ser prejudicadas por deficiências no escoamento.

Uma grande quantidade de trabalhos utilizando a técnica de estímulo-resposta trata da aplicação em reatores de tanque agitado para escoamentos multifásicos. A distribuição de tempos de residência e sua variância foram calculadas por CHOI et al., 2004 para determinar a agitação ideal de impelidores em reator agitado e contínuo. O comportamento do traçador foi calculado experimentalmente e computacionalmente. A análise computacional foi efetuada 
utilizando o software computacional FLUENT e o modelo K- $\varepsilon$ para o fenômeno turbulento. Foram simulados somente $20 \mathrm{~s}$ de escoamento, e os resultados fornecidos pelo programa tiveram uma boa concordância com os resultados experimentais. Interessante notar que os autores simularam o escoamento para o caso de repouso dos impelidores, no entanto, os resultados não apresentaram suficiente precisão. No presente estudo, a modelagem numérica para o fermentador (que não possui agitadores), foi efetuada com sucesso, o que será discutido com detalhes no Capítulo 4. No entanto CHOI et al., 2004 puderam concluir que o aumento da frequência de rotação do impelidor resultou em uma maior precisão do tempo de residência médio e sua variância. Um melhor desempenho foi obtido com a utilização do programa comercial FLUENT no estudo de LE MOULLEC et al., 2008). O escoamento em um reator de tratamento de esgoto foi simulado tridimensionalmente

Um estudo mais recente de simulação experimental e computacional de escoamento em reator de tanque agitado foi efetuado por DING et al., 2010. O reator de 17 litros (escala de bancada) é utilizado para geração de bio-hidrogênio e sua performance foi simulada tridimensionalmente. A análise da distribuição de tempo de residência e sua dispersão contribuiu para obter uma melhor distribuição do campo de velocidades do escoamento, mesmo com velocidades mais baixas na movimentação do impelidor, resultando em economia de energia e diminuição dos custos de operação. Para calcular a distribuição de tempos de residência os autores utilizaram, além da técnica de estímulo-resposta, o método de rastreamento de partículas, que exige um maior esforço computacional.

Além da aplicação em reatores e biorreatores, a técnica de estímulo-resposta também foi útil na análise de outros tipos de equipamento, como mostrado no estudo de SARRIS et al., 2006. Os autores aplicaram a técnica numericamente para obter a distribuição de tempo de residência em um leito de ânodo em células (dispositivo eletroquímico que transforma continuamente a energia química em energia elétrica) a partir de etanol, equipamento este que desperta interesse por minimizar os impactos ambientais. Os resultados foram verificados e o modelo pôde ser utilizado na melhora da eficiência deste tipo de equipamento, cujo objetivo foi aumentar o tempo de residência. Concluiu-se que os valores de tempo de residência são diretamente proporcionais ao número de Reynolds do escoamento no interior do equipamento. ZHANG; PAN; REMPEL, 2007 trabalharam na investigação da distribuição de tempo de residência em contactores. Este tipo de reator é utilizado na separação de materiais, podendo ser aplicado tanto para sistemas monofásicos quanto para bifásicos. Simulações experimentais 
desse tipo de reator são limitadas pelo custo do equipamento e por restrições de prazo. Assim, as simulações numéricas foram efetuadas utilizando o programa comercial CFX, e o modelo $\mathrm{K}-\varepsilon$ foi utilizando para as regiões turbulentas. A malha numérica foi refinada na parede do reator.

A descrição da modelagem computacional da técnica de estímulo-resposta está detalhada no Capítulo 3.

Como pode ser visto, não há na literatura dados de simulações experimentais ou computacionais do escoamento em fermentadores contínuos de grande escala, aplicados na produção de bioetanol a partir da cana de açúcar. Isso acontece por que a produção, principalmente a brasileira, está mais focada em evitar a contaminação do processo, que muitas vezes ainda é feito de maneira pouco cuidadosa, do que na melhora da eficiência através da análise da geometria do equipamento. Como já mencionado anteriormente, devido as grandes escalas de processamento, qualquer melhoria no processo tem um grande impacto econômico e ambiental, o que torna os estudos necessários.

\section{Conclusões deste capítulo.}

Considerando os estudos encontrados na literatura, simular computacionalmente o escoamento em reatores e biorreatores com o objetivo de melhorar o desempenho industrial é um campo desafiador e amplo. Considerando a necessidade da busca por técnicas de melhoria na produção de biocombustíveis, melhorias estas que possuem impactos não só econômicos, como também ambientais, aliada à falta de tecnologias capazes de processar grandes quantidades exigidas na industria sucroalcooleira, têm-se a motivação necessária para o estudo computacional de equipamentos utilizados para o processamento de biomassa, no caso deste trabalho, fermentadores. Apesar das vastas pesquisas encontradas na literatura sobre o escoamento em biorreatores e a influência dos parâmetros da geometria neste escoamento, permanece a necessidade de combinar técnicas de dinâmica dos fluidos computacional com técnicas de otimização, assim como feito em otimização de perfis da asas de aviões e design de automóveis por exemplo.

Alguns trabalhos contribuíram para este avanço, mas ainda de maneira limitada, como por exemplo, PATWARDHAN et al., 2005 que estudaram a otimização em apenas três tipos de geometria de impelidor. OLIVEIRA, 2007 utilizou Algoritmos Genéticos para aperfeiçoar 
parâmetros das equações que modelam a cinética química da produção de etanol, mas não os combinou com fatores do escoamento.Como já mencionado anteriormente, estudos experimentais e computacionais da tensão de cisalhamento em tanques agitados foram efetuados por UM; HANLEY, 2008 e XIA et al., 2008, por exemplo, mas em nenhum deles foi aplicada um método de busca estocástico para otimização. A modelagem computacional da técnica de estímulo-resposta foi efetuada em diversos estudos, como em GAVRILESCU; TUDOSE, 1999

GAVRILESCU; TUDOSE, 1999, LE MOULLEC et al., 2008, CHOI et al., 2004 e DING et al., 2010, mas até o momento, não foi reportada nenhuma aplicação da técnica no estudo de fermentadores utilizados no modelo atual das usinas brasileiras.

Assim, este trabalho de doutorado está fundamentado na necessidade de estudar computacionalmente a sensibilidade do escoamento em fermentadores contínuos em relação aos parâmetros da geometria, combinando esta análise a técnicas de otimização. Foram estudados a tensão de cisalhamento e a distribuição de tempos de residência no fermentador, através da aplicação de algoritmos genéticos e otimização univariada, respectivamente. A partir deste estudo, propõem-se duas geometrias otimizadas para o fermentador, cuja aplicação resulta numa melhoria de eficiência deste tipo de equipamento, amplamente utilizado na indústria sucroalcooleira brasileira. Considerando as altas escalas de processamento, qualquer melhoria é muito significativa em termos não somente de lucros, como também em relação à redução dos impactos ambientais. 



\section{CAPITULO 3 - METODOLOGIA}

Como já discutido anteriormente, os parâmetros do escoamento em um fermentador utilizado para produção de etanol a partir do bagaço de cana-de-açúcar têm influência direta sobre as reações químicas envolvidas no processo. Esses parâmetros podem ser o perfil de velocidade, vorticidade, tempo de residência, tensão de cisalhamento, dispersão turbulenta, etc. Desta maneira, uma análise adequada da influência da geometria do fermentador no escoamento pode aumentar consideravelmente a eficiência do mesmo. Isso porque, considerando as dimensões dos fermentadores utilizados e as altas taxas de processamento, um pequeno aumento na eficiência do fermentador causa um grande aumento na eficiência do processo químico. Uma reportagem publicada na edição124 da revista ALCOOLBrás em 2008 (BOSCO, 2010) mostra que uma usina que processa dois milhões de toneladas de cana de açúcar por safra, ou seja, 12 mil toneladas por dia, produz cerca de 180 milhões de litros de álcool neste período. Neste caso, $1 \%$ de aumento no rendimento do fermentador representa um aumento de produção de 1,8 milhões de litros de etanol, cerca de 20 a 30\% de lucro no resultado final.

Diante das limitações de custo e tempo para efetuar estudos experimentais neste campo e considerando o grande avanço tecnológico de processadores e computadores, a Dinâmica dos Fluidos Computacional ou CFD( do inglês Computational Fluid Dynamics) tem se tornado uma excelente ferramenta para o estudo dos mais diversos escoamentos e suas aplicações industriais [DONG; WANG, 2008].

Este capítulo descreve como as ferramentas computacionais de mecânica dos fluidos computacional (mais especificamente, o programa CFX®) e de otimização (neste trabalho, o programa modeFRONTIER $®$ e o método de otimização univariada) foram utilizadas no estudo do escoamento de caldo de cana-de-acúcar em um fermentador utilizado na produção de bioetanol. Para isso, a aproximação inicial da geometria do fermentador foi tomada em formato cilíndrico, composta por uma única entrada e uma única saída de fluido. O detalhamento da geometria está contemplado na próxima seção. 


\section{Aproximação inicial para a geometria do fermentador.}

Como descrito em WILLIAMS; SAINI; WICK, 2002, fermentadores com formato cilíndrico permitem um crescimento homogêneo dos seres vivos utilizados como catalisadores da reação, pois garantem uma menor tensão de cisalhamento. Dessa forma, a estimativa inicial da geometria do fermentador simulado neste trabalho conta com um reservatório central em formato cilíndrico, uma tubulação para entrada de fluido também cilíndrica localizada na parte lateral inferior da tubulação central. Para a saída de fluido há uma tubulação também cilíndrica, interna ao reservatório principal. A Figura 9 mostra a vista frontal da geometria adotada para o fermentador neste trabalho.
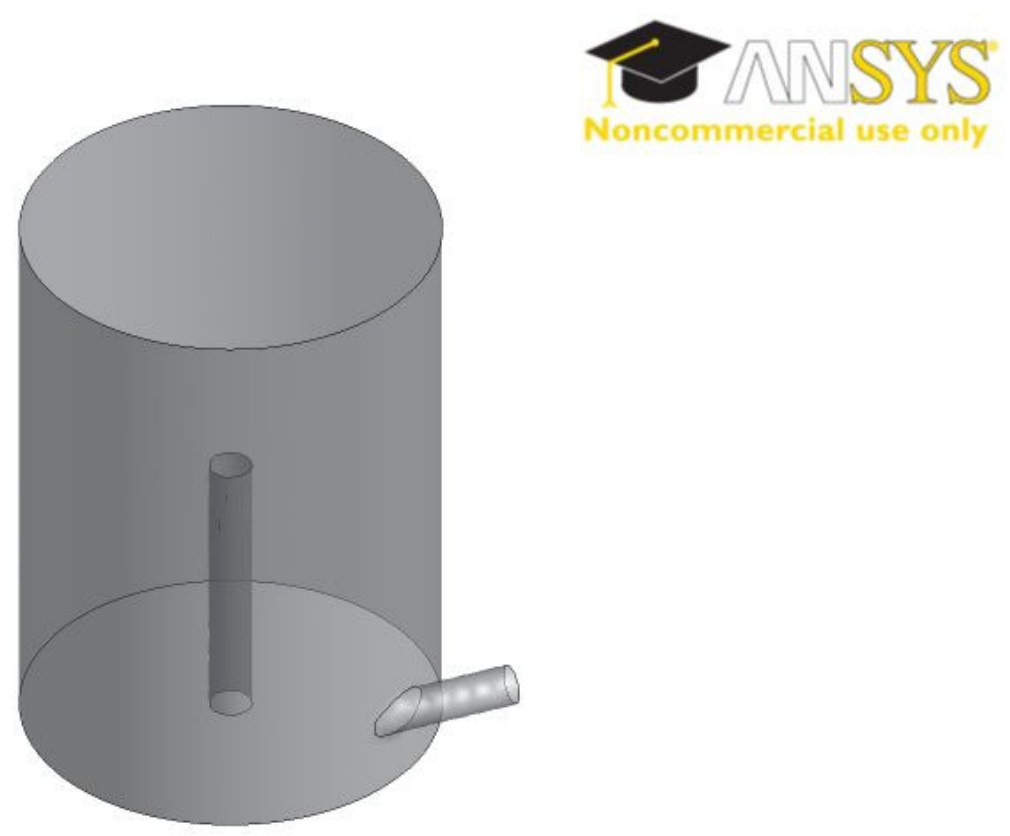

Figura 9 Aproximação inicial para a geometria do fermentador, em vista frontal.

Esta configuração de geometria difere da comumente utilizada nos fermentadores em operação nas usinas, que possuem entrada na parte inferior do tanque, mas a tubulação de saída encontra-se na parte superior do equipamento. Posicionando a saída de fluido na parte central do tanque proporciona uma modificação no comportamento do escoamento

As dimensões adotadas na aproximação inicial da geometria estão especificadas na Tabela 2. As dimensões especificadas na tabela foram adotadas apenas como estimativas iniciais, em consequência dos dados requeridos para a aplicação do algoritmo genético 
utilizado neste estudo. Em cada uma das simulações efetuadas foi possível escolher os parâmetros da geometria a serem modificados de forma a otimizar os parâmetros do escoamento. Essas estimativas foram propostas levando em conta a factibilidade de construção de um protótipo experimental, e a viabilidade de implementação das modificações na indústria sucro-acooleira.

Tabela 2 Geometria do fermentador, adotada como estimativa inicial

\begin{tabular}{|c|c|}
\hline Região & Dimensões \\
\hline $\begin{array}{c}\text { Diâmetro do tubo de entrada } \\
\text { (d) }\end{array}$ & $0,1 \mathrm{~m}$ \\
\hline $\begin{array}{c}\text { Diâmetro do tubo de saída } \\
(\mathrm{d})\end{array}$ & $0,1 \mathrm{~m}$ \\
\hline Diâmetro do reservatório \\
(D)
\end{tabular}

A Figura 10 mostra a localização do ângulo entre o tubulação para entrada de fluido e o reservatório, a partir da vista inferior do fermentador. $\mathrm{O}$ diâmetro do reservatório principal e das tubulações de entrada e saída estão denotados por D e d respectivamente. 


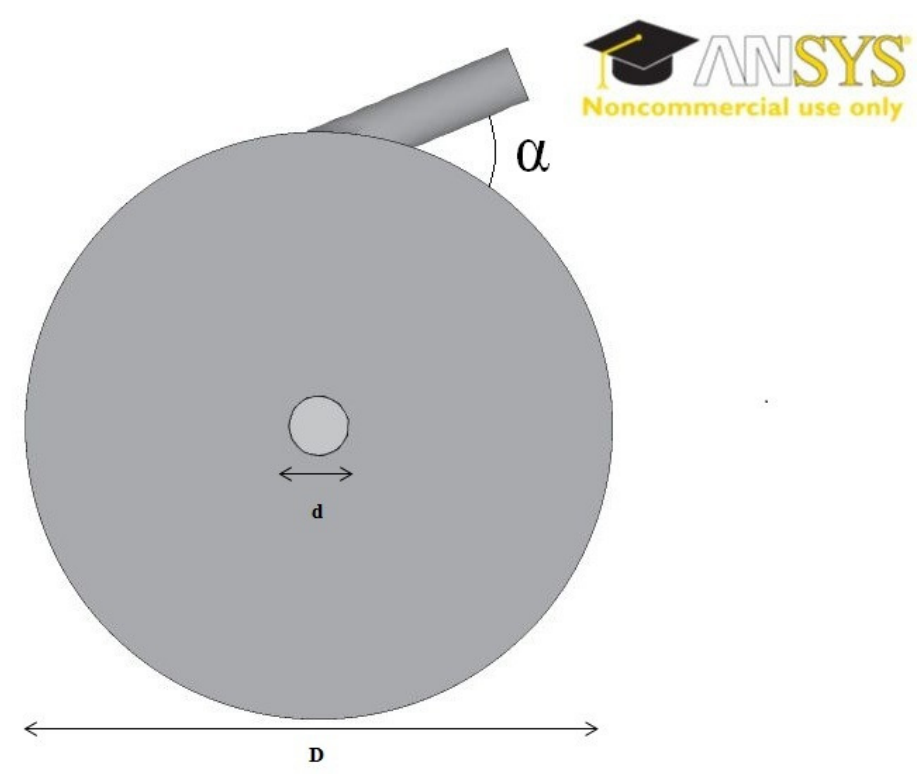

Figura 10 Vista da parte inferior do fermentador, com as respectivas nomenclaturas dos parâmetros geométricos.

A nomenclatura utilizada para as demais dimensões do fermentador são mostradas na Figura 11 ,a partir da vista lateral do equipamento. A altura do tanque principal do fermentador é denotada como $\mathrm{H}$, e a altura da tubulação central para saída de fluido tem denotação h. Novamente, D é o diâmetro do reservatório principal.

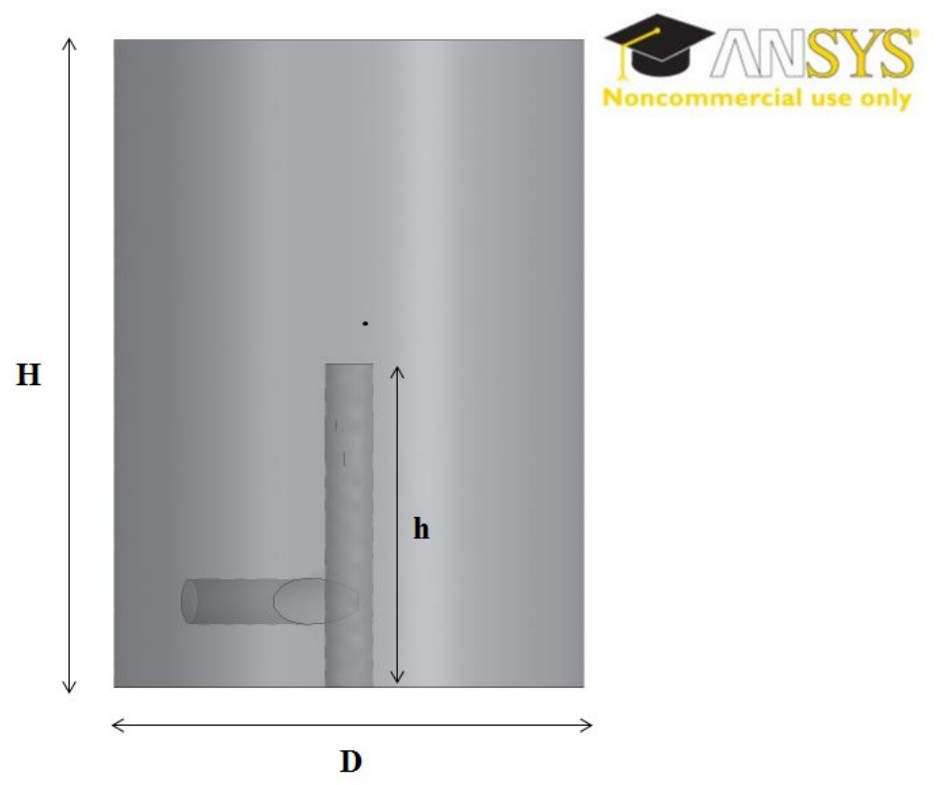

Figura 11 Vista lateral do fermentador, com respectivas nomenclaturas dos parâmetros geométricos. 


\section{Simulação numérica do escoamento.}

\subsubsection{Discretização das Equações Governantes.}

Os escoamentos em geral podem ser descritos matematicamente por um conjunto de equações datadas do século XIX, as Equações de Navier-Stokes. Essas equações são resultantes dos trabalhos pioneiros de Claude Navier (1822), Simeon Poisson (1829) e do inglês George Stokes (1845) [FORTUNA, 2000]. A Equação 1 é conhecida como equação da continuidade, e representa o princípio da conservação de massa. A Equação 2 representa a forma generalizada para as equações de momento, ou seja, a taxa de variação temporal de momento do fluido é igual à resultante das forças que atuam sobre o fluido. Estas equações são resultado da aplicação da segunda lei de Newton, relativa a conservação da quantidade de movimento.

$$
\begin{gathered}
\frac{\partial \rho}{\partial t}+\nabla \cdot(\rho U)=0 \\
\frac{\partial(\rho U)}{\partial t}+\nabla \cdot(\rho U X U)=-\nabla p+\nabla \cdot \tau+S N
\end{gathered}
$$

O tensor das tensões é dado pela Equação (3):

$$
\tau=\mu\left[\nabla U+(\nabla U)^{T}-\frac{2}{3} \delta(\nabla \cdot U)\right]
$$

O termo SN modela outras forças que possam existir no escoamento, como a ação de um impelidor, um obstáculo ao escoamento ou a gravidade.

Tratando-se de um conjunto de equações diferenciais parciais não lineares e de segunda ordem, as equações de Navier-Stokes não têm solução analítica em regiões arbitrárias e condições de contorno generalizadas [FORTUNA, 2000]. No entanto, as equações de Navier-Stokes podem ser discretizadas e solucionadas numericamente.

Uma das técnicas mais conhecidas de discretização, e a utilizada neste trabalho através do programa Ansys $\mathrm{CFX}{ }^{\circledR}$, é o Método dos Volumes Finitos. Após a discretização do domínio, as propriedades do fluido são definidas em cada um dos nós da malha computacional. Uma região de interesse é então criada ao redor dos nós, chamada volume de 
controle. As equações são então discretizadas e solucionadas numericamente para cada um desses volumes. Dessa forma, pode ser obtida uma aproximação do valor de cada uma das variáveis buscadas em pontos específicos do domínio. Os termos difusivos são aproximados pela aplicação da técnica de elementos finitos e funções de forma são utilizadas no cálculo das derivadas parciais. As derivadas das funções de forma são expressas em função das derivadas locais através de uma matriz Jacobiana, e o gradiente é calculado através de uma interpolação linear, o que garante a robustez do método. A integração do gradiente de pressão é feita de maneira análoga,através da aplicação de função de forma e interpolação.

\subsubsection{Condições de contorno}

Segundo FORTUNA, 2000, em problemas que envolvem equações diferenciais parciais, podem-se especificar três tipos básicos de condições para a variável a ser calculada na fronteira (ou contorno) que delimita o escoamento:

- Condição do tipo Dirichlet: o valor da variável é especificado na fronteira;

- Condição do tipo Neumann: o gradiente normal ou tangencial é especificado na fronteira;

- Condição do tipo Robin: é especificada uma combinação linear das condições de Dirichlet e Neumann na fronteira.

Neste trabalho foram adotadas três condições de contorno para simular o escoamento: condição de entrada de fluido no domínio de solução, condição de saída de fluido do domínio de solução e condição sobre uma superfície rígida, impermeável ou parede. Para todos os casos simulados foi adotado um escoamento incompressível, isotérmico e permanente, e o fluido escolhido foi a água.

As condições de contorno na entrada e saída de fluido foram definidas somente nas regiões de entrada e saída de fluido, como pode ser visto na Figura 12. A parede inclui toda a região com exceção das seções de entrada e saída.

Para a entrada de fluido, tanto no caso tangencial quanto no caso perpendicular, foi atribuída uma velocidade normal de $0,1 \mathrm{~m} / \mathrm{s}$ (condição de Dirichlet). Na saída, a pressão média estática foi definida como $0 \mathrm{~Pa}$. Em toda a região definida como parede, foi adotada a condição de Dirichlet de não deslizamento (no-slip). 


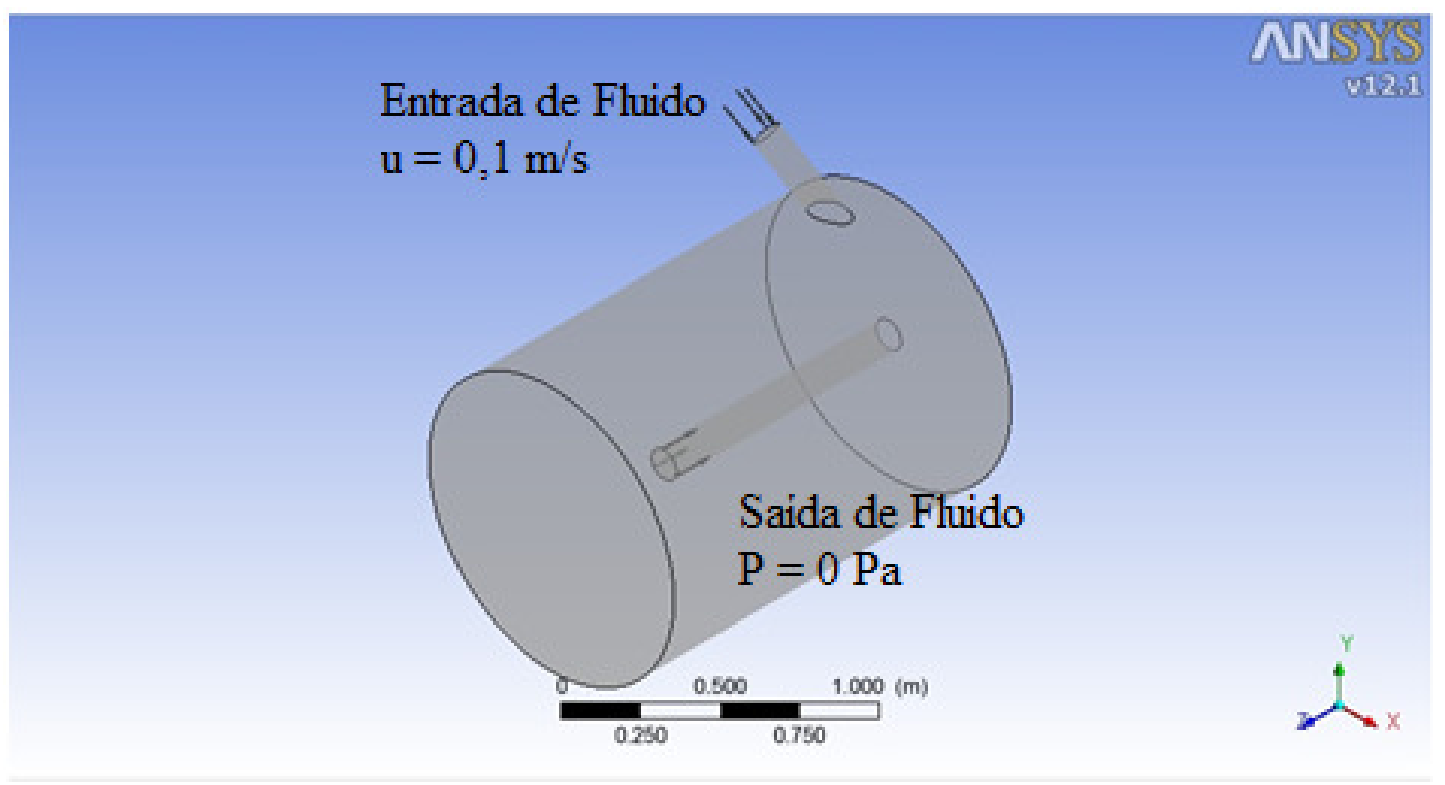

Figura 12 Condições de contorno na entrada e saída do reservatório do fermentador.

\subsubsection{Modelagem da Turbulência}

Para determinar a necessidade ou não da modelagem da turbulência, o número de Reynolds foi calculado como a razão entre as forças viscosas e as forças inerciais do escoamento, dado pela Equação (4):

$$
\operatorname{Re}=\frac{\rho u D}{\mu}
$$

em que $\rho$ é a densidade do fluido, u é a velocidade normal escalar do escoamento, D é o diâmetro do tubo de entrada e $\mu$ é a viscosidade dinâmica do fluido.

A hipótese é que o fluido entra em regime turbulento no fermentador, mas perde energia durante o escoamento. Mesmo com a perda de energia, o regime de escoamento não se modifica, e torna-se necessária a modelagem da turbulência no interior do fermentador.

O ANSYS CFX 13.0® oferece as seguintes possibilidades de modelagem do fenômeno da turbulência:

- Modelo k- $\varepsilon$,

- Modelo k- $\varepsilon$ RNG,

- Modelos de tensão turbulenta de Reynolds, 
- Modelo Zero Equação,

- Modelo k- $\varepsilon$ de turbulência.

O modelo de turbulência de tensão de Reynolds busca a solução das equações de transporte para as tensões de Reynolds individualmente. Este modelo é adequado para escoamentos com curvatura intensa e tendência de descolamento, mas tende a ser menos robusto do que o modelo $\mathrm{k}-\varepsilon$, por exemplo. Já o modelo de turbulência de equação nula resolve uma equação algébrica para calcular a viscosidade turbulenta. Este modelo é comumente utilizado para obter soluções rápidas e robustas, mas não é muito utilizado para simular escoamentos muito complexos.

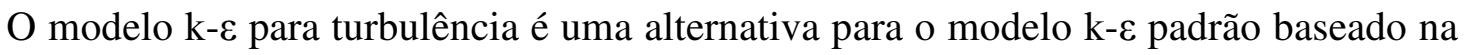
renormalização das equações da Navier-Stokes. O esquema de transporte para geração e dissipação de turbulência são os mesmos para o modelo k- $\varepsilon$ tradicional, mas a modelagem das constantes é feita de forma diferente.

O modelo k- $\varepsilon$ padrão é baseado no conceito de que a turbulência consiste em pequenos vórtices em contínua formação e dissipação. Este modelo resolve duas equações de transporte adicionais: uma para a geração de turbulência (k) e outra para a dissipação da turbulência $(\varepsilon)$. Este modelo foi escolhido por apresentar um desempenho melhor na captura da recirculação do fluido.

No Ansys $\mathrm{CFX}{ }^{\circledR}$, o modelo k- $\varepsilon$ padrão introduz duas novas variáveis nas equações que modelam o escoamento. No caso, as equações de conservação de massa ficam da forma:

$$
\frac{\partial \rho}{\partial t}+\frac{\partial}{\partial x_{j}}\left(\rho U_{j}\right)=0
$$

Analogamente, as equações para a quantidade de movimento tornam-se:

$$
\frac{\partial \rho U_{i}}{\partial t}+\frac{\partial}{\partial x_{j}}\left(\rho U_{i} U_{j}\right)=-\frac{\partial p}{\partial x_{i}}+\frac{\partial}{\partial x_{j}}\left[\mu_{e f f}\left(\frac{\partial U_{i}}{\partial x_{j}}+\frac{\partial U_{j}}{\partial x_{i}}\right)\right]+S_{M}
$$

em que, $S_{M}$ representa as forças que agem sobre o corpo, $\mu_{\text {eff }}$ a viscosidade efetiva resultado da turbulência. A viscosidade efetiva é definida como a soma da viscosidade do fluido com a viscosidade turbulenta, ou seja: 


$$
\mu_{e f f}=\mu+\mu_{t}
$$

O modelo k- $\varepsilon$ assume ainda que a viscosidade turbulenta está relacionada com a energia cinética turbulenta e a dissipação através da relação da Equação (8):

$$
\mu_{t}=C \rho \frac{K^{2}}{\varepsilon}
$$

em que C é uma constante.

Assim como em DAVIDSON et al., 2003, UM; HANLEY, 2008 e XIA et al., 2008, o modelo k- $\varepsilon$ foi utilizado neste trabalho para modelagem da turbulência no escoamento no fermentador.

\subsubsection{Cálculo da tensão de cisalhamento.}

No ANSYS CFX 13.0®, assim como usualmente, o tensor das deformações é definido como pode ser visto na Equação (9).

$$
S_{i j}=\frac{1}{2}\left(\frac{\partial U_{i}}{\partial x_{j}}+\frac{\partial U_{j}}{\partial x_{i}}\right)
$$

Este tensor, para o caso tridimensional, é formado por nove elementos e possui três escalares invariantes. Dentre eles, a taxa de deformação cisalhante, no CFX, Shear Strain Rate, é definida como mostrado na Equação (10).

$$
\text { sstrnr }=\left[2 \frac{\partial U_{i}}{\partial x_{j}} \cdot S_{i j}\right]^{1 / 2}
$$

Considerando os três componentes da velocidade $U_{i j}, U_{x}, U_{y}$ e $U_{z}$, temos que a taxa de deformação em um ponto do fluido é dada por:

$$
\text { sstrnr }=\left[2 .\left\{\left(\frac{\partial U_{x}}{\partial x}\right)^{2}+\left(\frac{\partial U_{y}}{\partial y}\right)^{2}+\left(\frac{\partial U_{z}}{\partial z}\right)^{2}\right\}+\left(\frac{\partial U_{x}}{\partial y}+\frac{\partial U_{y}}{\partial x}\right)^{2}+\left(\frac{\partial U_{x}}{\partial z}+\frac{\partial U_{z}}{\partial x}\right)^{2}+\left(\frac{\partial U_{y}}{\partial z}+\frac{\partial U_{z}}{\partial y}\right)^{2}\right]^{1 / 2}
$$


Assim, considerando a tensão de cisalhamento (ou shear stress como definido no CFX) como um parâmetro do escoamento a ser otimizado, a Equação 12 foi utilizada para calcular o valor da tensão de cisalhamento em cada ponto da malha computacional:

$$
\text { ShearStress }=\text { sstrnr } .\left(\mu+\mu_{t}\right)
$$

em que $\mu$ é a viscosidade do fluido e $\mu_{\mathrm{t}}$ é a viscosidade turbulenta do fluido. $\mathrm{O}$ cálculo da viscosidade turbulenta depende do modelo de turbulência aplicado ao problema. Como neste trabalho o modelo utilizado para modelagem da turbulência foi o k-E padrão, o coeficiente de viscosidade turbulenta é dado por:

$$
\mu_{t}=C \cdot \frac{K^{2}}{\varepsilon}
$$

Em relação à tensão cisalhante na parede, neste trabalho, analogamente ao trabalho de HARRIS et al., 1996 e WILLIAMS; SAINI; WICK, 2002, a condição de não deslizamento (no-slip) foi adotada, ou seja, a velocidade do fluido em toda a parede do reservatório é nula.

\subsubsection{Solução numérica da advecção.}

Para resolver a parte advectiva das equações de Navier-Stokes o método escolhido foi o High Resolution, cujo o fator de mistura varia através do domínio. Em regiões com baixa variação de gradiente, o coeficiente de mistura ficará próximo de um, garantindo a exatidão do método. Em regiões em que o gradiente varia bruscamente, o coeficiente de mistura ficará próximo de zero, garantindo a robustez do método.

\section{Algoritmo Genético com Múltiplos Objetivos}

Após a definição da modelagem do escoamento, foi necessário propor novas geometrias de maneira automática, e não testar um número reduzido de configurações para a geometria do fermentador. Essa automatização resultada em ganho de tempo computacional, de maneira que as geometrias vão sendo analisadas de forma a se aproximar de um resultado ideal, incluindo as restrições de construção de um protótipo. Uma alternativa para automatização deste processo de otimização é o acoplamento entre um algoritmo de otimização e as simulações do escoamento. Para efetuar este escoamento, foi utilizado o programa modeFRONTIER $®$, e o algoritmo de otimização escolhido foi o Algoritmo 
Genético com Múltiplos Objetivos II, ou MOGA II (do inglês Multi-Objective Genetic Algorithm). O MOGA II é uma versão melhorada do MOGA, primeira versão do algoritmo genético com múltiplos objetivos. Comparado com a versão anterior,a melhora deste método o está na combinação de cinco operadores de reprodução em um mesmo método: seleção, cruzamento clássico, cruzamento direcional, mutação e elitismo. A cada passo do processo de reprodução, um dos cinco operadores é escolhido e utilizado na iteração. O uso do cruzamento direcional no MOGA II é uma exclusividade do algoritmo implementado no modeFRONTIER®. O cruzamento direcional favorece a convergência do algoritmo e funciona considerando que uma direção de melhora pode ser escolhida comparando os valores da adaptatividade (fitness) de dois indivíduos usados como referência. A direção é então calculada comparando o fitness deste indivíduo com o fitness de outros dois indivíduos na mesma geração. Um novo indivíduo é então criado pelo movimento randômico em uma direção ponderada.

Além do cruzamento direcional, um diferencial do MOGA II implementado no modeFRONTIER ® é o uso do elitismo. O elitismo nessa nova versão, segundo POLES, 2003, é aplicado segundo o seguinte algoritmo:

1. MOGA II começa com uma população inicial $\mathrm{P}$ de tamanho $\mathrm{N}$, e o conjunto elite $\mathrm{E}$ vazio $(\mathrm{E}=\varphi)$.

2. Uma nova população $\mathrm{P}^{\prime}$ é criada de forma que $\mathrm{P}^{\prime}=\mathrm{P} \mathrm{U}$ E.

3. Se a cardinalidade de $\mathrm{P}^{\prime}$ é maior que $\mathrm{P}, \mathrm{P}^{\prime}$ é reduzido removendo-se randomicamente os pontos excedentes.

4. $\mathrm{P}^{\prime}$ evolui para $\mathrm{P}^{\prime \prime}$ através da aplicação de todos os operadores de MOGA II

5. O fitness da população $\mathrm{P}^{\prime \prime}$ é calculado.

6. Todos os designs não dominados são copiados de $\mathrm{P}$ " para E.

7. E é atualizado e os designs dominados e duplicados são removidos.

8. O conjunto E é redimensionado por remoção randômica de pontos excedentes.

9. Retorna para o passo 2 considerando $\mathrm{P}$ " como um novo $\mathrm{P}$.

O algoritmo de acoplamento pode ser visto no fluxograma da Figura 8. Foram escolhidos valores iniciais factíveis experimentalmente para parâmetros da geometria utilizada como aproximação inicial. A partir dessa geometria, criada no Design Modeling, 
ferramenta do Ansys 13.0, pôde-se gerar uma malha, utilizando também uma ferramenta do Ansys 13.0, o Ansys Meshing.

Utilizando o CFX® como solver, o escoamento foi modelado e solucionado. No modeFRONTIER $®$, através da execução do MOGA II, os parâmetros geométricos foram avaliados de forma a encontrar a geometria adequada, satisfazendo a função objetivo. A cada iteração, uma nova geometria é proposta, levando em conta as taxas de mutação, cruzamento, elitismo, e demais operações do algoritmo genético determinadas no programa modeFRONTIER. As taxas adotadas para os operadores utilizados no MOGA II são apresentados na Tabela 3.

Tabela 3 Operadores utilizados pelo MOGA II e respectivas taxas adotadas neste trabalho.

\begin{tabular}{|c|c|}
\hline Operador do MOGA II & Taxa \\
\hline Cruzamento & 0,5 \\
\hline Seleção & 0,05 \\
\hline Mutação & 0,1 \\
\hline
\end{tabular}

Outra vantagem da utilização do acoplamento é que a malha numérica para cada geometria também é atualizada automaticamente a cada iteração do algoritmo de otimização, neste caso, a cada geração do algoritmo genético modificado.

\section{Obtenção da distribuição de tempo de residência utilizando o CFX}

A necessidade de buscar por biorreatores mais eficientes é constante nos mais diversos ramos da indústria, e não somente na sucroalcooleira Busca-se por equipamentos mais eficientes,ou ideais, que contribuam para o aumento da produtividade e dos lucros finais, assim como a redução dos impactos ambientais. 
O escoamento em um biorreator é considerado ideal quando diferentes porções do fluido permanecem por tempos semelhantes no interior do equipamento .Este tempo que a porção de fluido permanece no interior do equipamento é denominado tempo de residência.

Uma das formas de aferir o tempo que as partículas de fluido permanecem dentro do biorreator é utilizar a técnica de estímulo resposta, inserindo um fluido traçador no escoamento. Como mencionado por SASSAKI, 2005, traçador é qualquer produto que, incorporado na massa de uma substância, permite investigar o comportamento desta em um determinado processo físico ou químico, durante seu escoamento. $\mathrm{O}$ traçador é um escalar passivo, ou seja, é transportado pelo escoamento sem que o mesmo sofra nenhuma influência.

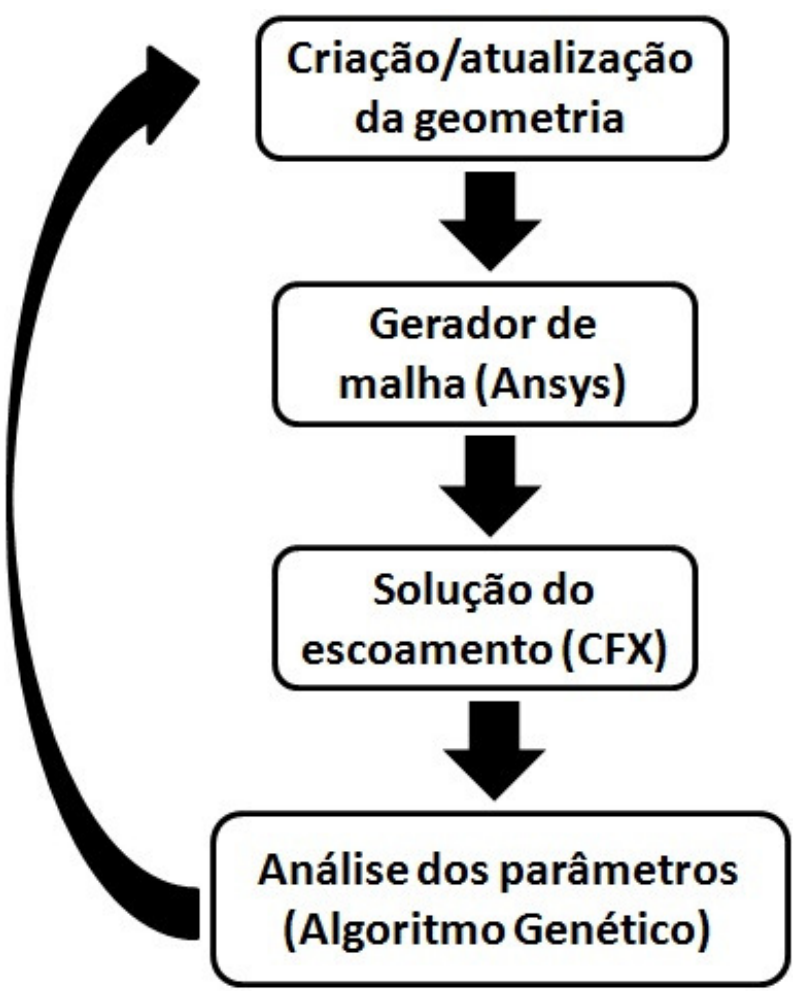

Figura 13 Algoritmo de acoplamento entre os programas Ansys CFX® e modeFRONTER®.

Para a modelagem numérica no Ansys CFX®, o traçador é definido através de uma variável adicional escalar, e solucionado através da equação utilizada no trabalho de XIA et al., 2008, dada pela Equação 14:

$$
\frac{\partial \phi}{\partial t}+\nabla \cdot(U \phi)=\nabla \cdot\left(\left(\rho D_{\phi}+\frac{\mu_{t}}{S_{c h} C_{t}}\right) \nabla \cdot\left(\frac{\phi}{\rho}\right)\right)+S_{\phi}
$$


onde $\varphi$ é a concentração do traçador em $\left[\mathrm{Kg} / \mathrm{m}^{3}\right], \mathrm{D}_{\varphi}$ é a difusividade cinemática do traçador e $S_{\text {ch }}$ é o número de Schmidt turbulento, com valor aproximadamente igual a 1.

A injeção do traçador no escoamento pode ser efetuada de diversas formas, dentre elas a injeção por pulso. Neste estudo, a modelagem foi feita na condição de contorno na entrada através de uma função step. Esta função foi modelada no CFX analogamente ao trabalho de LE MOULLEC et al., 2008:, e é dada pela Equação 15.

$$
\text { Pulso }=1\left[K_{g m^{\wedge}} 3\right]^{*} \operatorname{step}\left(\frac{(1[s]-t)}{1[s]}\right)
$$

Após a injeção do traçador no início do escoamento através do pulso, a concentração do mesmo foi monitorada como condição de contorno na saída do escoamento. Para isso, foi modelado no CFX através de um Monitoring Point, obtendo-se a curva de concentração, como pode ser visto na Figura 14.

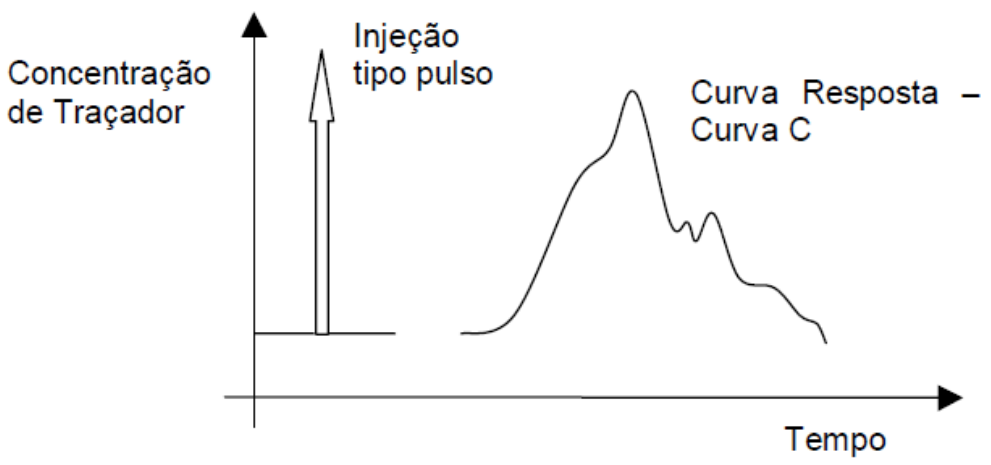

Figura 14 Injeção de traçador por pulso e curva de concentração na saída do escoamento SASSAKI, 2005

A análise qualitativa da tendência da curva de concentração permite avaliar características específicas do escoamento. Curvas que apresentam instabilidades nos primeiros segundos da simulação são características de curto-circuito, ou seja, as porções do fluido permanecem menos do que o esperado no interior do reator. Já reatores com algum volume morto, ou seja, recirculação no interior do reator, apresentam curvas com alta concentração nos últimos intervalos de tempo de simulação.

Com o objetivo de diminuir o tempo computacional, as simulações do traçador, assim como no estudo de LE MOULLEC et al., 2008, foram efetuadas em duas etapas. 
Primeiramente, o escoamento foi simulado como permanente, e, após a convergência, foi utilizada como condição inicial para o escoamento transiente. Nesta etapa, o traçador foi inserido através da modelagem do pulso na condição de contorno de entrada, e, na sequência, a equação de transporte transiente foi solucionada.

Para uma análise quantitativa das características do escoamento, é necessário obter a distribuição dos tempos de residência. Para isso, obtém-se a curva $\mathrm{E}(\mathrm{t})$, definida em SASSAKI, 2005 como a função que representa a distribuição de idades do fluido na saída do equipamento, e pode ser calculada através da Equação (16):

$$
E(t)=\frac{C\left(t_{i}\right)}{\int_{0}^{\infty} C\left(t_{i}\right) \Delta t}
$$

onde $\mathrm{C}\left(\mathrm{t}_{\mathrm{i}}\right)$ representa o valor da concentração de traçador monitorado na saída do escoamento para cada passo no tempo simulado.

A partir da Equação 16 é possível obter a média da distribuição de tempos de residência. A média da distribuição de tempos de residência é um parâmetro associado a DTR, e é definido com mostra a Equação 17:

$$
t_{s}=\frac{\int_{0}^{\infty} t_{i} C\left(t_{i}\right) \Delta t}{\int_{0}^{\infty} C\left(t_{i}\right) \Delta t}
$$

Uma formulação já em função dos pontos discretos da curva de concentração foi fornecida por GAVRILESCU; TUDOSE, 1999, mostrada na Equação 16 :

$$
t_{s} \cong \frac{\sum t_{i} C\left(t_{i}\right) \Delta t_{i}}{\sum C\left(t_{i}\right) \Delta t_{i}}
$$

No entanto, além do tempo de residência médio é importante entender como o tempo de residência de cada uma das partículas de fluido varia durante o escoamento. Essa variação pode comprometer as reações químicas envolvidas no processo. Torna-se necessário conhecer a variância do tempo de residência, ou seja, o quão longe os resultados de tempo de residência encontrados estão longe do esperado. Conhecendo o valor do tempo de residência, 
a variância da distribuição de tempos de residência pode ser obtida de acordo com a Equação 19:

$$
\sigma^{2} \cong \frac{\sum\left(t_{i}-t_{s}\right)^{2} C\left(t_{i}\right) \Delta t_{i}}{\sum C\left(t_{i}\right) \Delta t_{i}}
$$

Neste estudo, o tempo de residência e a sua variância foram calculados de acordo com as Equações 18 e 19. Para simplificação dos cálculos das integrais envolvidas, o valor do passo no tempo foi definido como unitário. Para cada uma das vinte geometrias propostas, foram simulados 600 segundos de escoamento.

\section{Otimização univariada e geometrias testadas.}

Além da técnica de acoplamento entre o algoritmo de otimização e a simulação do escoamento de maneira automática, uma otimização não automática também foi efetuada.Para encontrar a geometria com desempenho ideal em relação a distribuição de tempos de residência do fermentador, foi aplicada a técnica de otimização univariada.

O método de otimização univariada é classificado como um método sequencial, também chamado de método do fator único. O algoritmo consiste em fixar os fatores que estão sendo estudados em um certo nível, com exceção de um deles. Este fator é variado, até que o objetivo da otimização seja atingido. Na segunda iteração, este fator é então fixado, e um novo fator é escolhido para a variação. Segundo EIRAS; ANDRADE, 1995, a metodologia é simples, e por isso uma das mais aplicadas nas análises químicas.

Foram testadas vinte combinações de ângulo e altura, sendo o ângulo o valor entre a tubulação de entrada de fluido e o tanque do fermentador, e a altura o valor correspondente do comprimento da tubulação de saída de fluido, localizada na parte interna do tanque do fermentador. Os valores foram escolhidos calculando o ponto médio entre as dimensões factíveis do fermentador. A Tabela 4 mostra os valores dos ângulos e das altura combinados para a obtenção das vinte geometrias simuladas. Para valores de ângulo de entrada foram escolhidos $22,5^{\circ}, 45^{\circ}, 67,5^{\circ}$ e $90^{\circ}$. Os comprimentos escolhidos para a altura da tubulação de saída foram $30 \mathrm{~cm}, 52,5 \mathrm{~cm}, 75 \mathrm{~cm}, 97,5 \mathrm{~cm}$ e $120 \mathrm{~cm}$. 
Tabela 4 Parâmetros geométricos combinados para a obtenção das vinte geometrias testadas.

\begin{tabular}{|c|c|c|c|c|c|}
\hline $\begin{array}{c}\text { Ângulos } \alpha \\
\left({ }^{\circ}\right)\end{array}$ & 22,5 & 45 & 67,5 & 90 & - \\
\hline $\begin{array}{c}\text { Alturas h de } \\
\text { saída (cm) }\end{array}$ & 30 & 52,5 & 75 & 97,5 & 120 \\
\hline
\end{tabular}

\section{Configurações do cluster utilizado.}

A máquina utilizada para as simulações computacionais foi uma SGI Altix XE 1300

Cluster com 80 Cores e 192 GB RAM. A máquina é composta por 6 compute nodes contidos

em 3 servidores Altix XE 340 sendo cada nó configurado com:

- 12 Cores compostos por 3 sockets Intel Xeon Quad-Core 5520 de

2.26-GHz, com 8MB cachê,

- $\quad 5.86 \mathrm{GT} / \mathrm{s}$; 
- 24-GB de memória DDR3 1333 MHz;

- 1 (um) disco de 500-GB SATA2;

- 2 (dois) ports Gigabit Ethernet;

Além dos nós, a máquina conta com um processador head node Altiz XE 270, configurado da seguinte maneira:

- 8 Cores compostos por 2 sockets Intel Xeon Quad-Core

- 5520 de 2.26-GHz, com 8MB cachê, 5.86 GT/s;

- 48-GB de memória DDR3 1333 MHz; 
- 8 (oito) discos de 1000-GB SATA2;

- RAID 5;

- DVD-RW

- Fonte Redundante;

- 2 (dois) ports Gigabit Ethernet; 



\section{CAPITULO 4 - RESULTADOS}

Este capítulo traz os resultados da análise da influência da geometria no desempenho de um fermentador aplicado na produção de bioetanol, juntamente com a busca pela geometria ótima para esta aplicação. As simulações foram divididas em duas partes. $\mathrm{Na}$ primeira análise, o otimização é efetuada através do acoplamento de um Algoritmo Genético às simulações do escoamento em CFX. O acoplamento é feito através do programa ModeFRONTIER ${ }^{\circledR}$, tendo como função objetivo minimizar o valor máximo da tensão de cisalhamento no domínio do fermentador.

A segunda análise tem como função objetivo minimizar a variância da distribuição de tempos de residência (DTR). As curvas DTR foram obtidas computacionalmente através do monitoramento da concentração de um traçador injetado na entrada do escoamento através de um pulso. Em seguida, o método de otimização univariada foi aplicado com o objetivo de determinar a geometria que favorece a função objetivo em questão. A primeira iteração deste método consiste em fixar os parâmetros analisados com exceto de um, que é variado. No segundo ciclo, este último é então fixado, e um segundo valor é escolhido para ser variado, até que o melhor valor para a função objetivo seja encontrado.

Dessa forma, este capítulo apresenta os resultados obtidos para a análise da tensão de cisalhamento e da distribuição de tempos de residência. Para cada um dos casos, a geometria mais adequada para que as funções objetivos sejam satisfeitas são determinada.

\section{Análise da tensão de cisalhamento através do acoplamento entre o CFX e o ModeFRONTIER®.}

Como foi discutido nos capítulos anteriores, os parâmetros geométricos do fermentador podem influenciar diretamente o escoamento interno e consequentemente, afetar as reações químicas envolvidas no processo de fermentação. Com o intuito de entender melhor essa influência e determinar os parâmetros da geometria que favorecem o escoamento, foram simulados dois casos com acoplamento completo, como está descrito a seguir. A viscosidade do caldo de cana foi escolhida segundo o estudo da reologia e propriedades fluidodinâmicas do caldo de cana-de-açúcar desenvolvido por ASTOLFI-FILHO et al., 2011, 
assim como a temperatura constante de $34^{\circ} \mathrm{C}$. O escoamento foi definido como incompressível, isotérmico e permanente.

Inicialmente, com o intuito de compreender a sensibilidade dos parâmetros hidrodinâmicos com a modificação dos parâmetros geométricos, foram utilizados dois valores diferentes para o ângulo $\alpha$ entre a tubulação de entrada e o reservatório do fermentador: $60^{\circ} \mathrm{e}$ $90^{\circ}$.

A Figura 15 mostra a comparação das linhas de corrente em um fermentador com entrada perpendicular e tangencial, respectivamente. Com a mudança do ângulo de entrada do escoamento é possível controlar o comportamento das linhas de corrente. A sensibilidade das linhas de corrente com a modificação do ângulo de entrada fica explícita nesta figura. A entrada tangencial impulsiona o fluido dentro do fermentador, minimizando recirculações, que são indesejáveis no processo de conversão da sacarose em etanol.
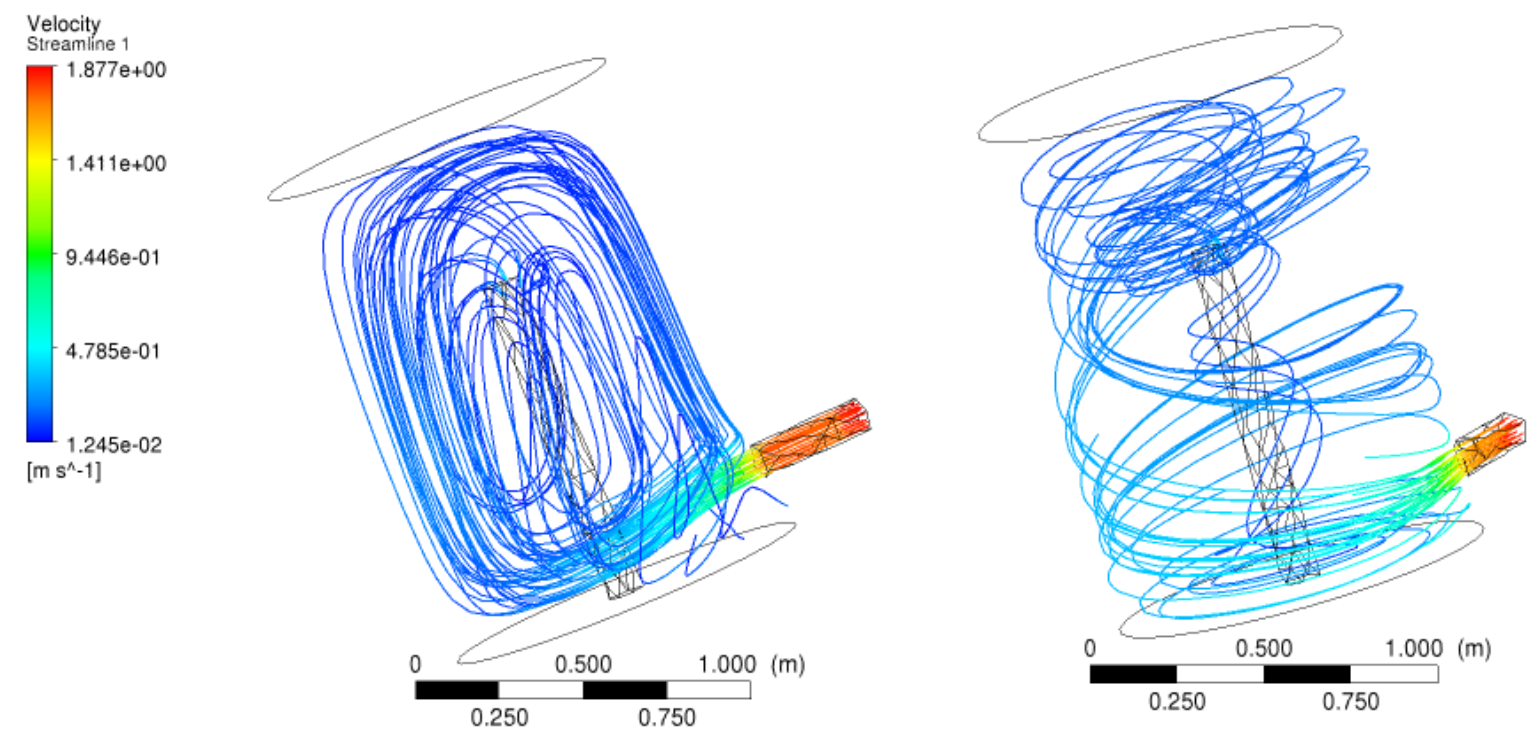

Figura 15 Linhas de corrente em um fermentador com ângulo de entrada perpendicular (esquerda) e com entrada tangencial com ângulo de $60^{\circ}$ (direita).

Os primeiros resultados do acoplamento entre o CFX® e o modeFRONTIER $®$ foram simulados em um computador simples, com 6 GB de memória RAM instalada, sistema operacional de 64 bits, Intel Core i5 2,4MHz. O objetivo do primeiro teste foi minimizar a média aritmética das velocidades, através de modificações nos valores para a altura da 
tubulação de saída h. A malha tetraédrica utilizada contou com 2787 nós e 13963 elementos, como mostra a Figura 16.

Nessas simulações foram testados 46 valores diferentes para altura do tubo de saída do escoamento, mantendo-se os demais parâmetros geométricos. Foi possível concluir que o valor para a altura do tubo de saída de fluido que garante o mínimo das médias da velocidade foi $0,46 \mathrm{~m}$. O custo computacional da simulação com o acoplamento com o ModeFRONTIER ${ }^{\circledR}$ foi de aproximadamente 27 horas. . Maiores detalhes podem ser encontrados em GÓIS; SELEGHIM, 2011
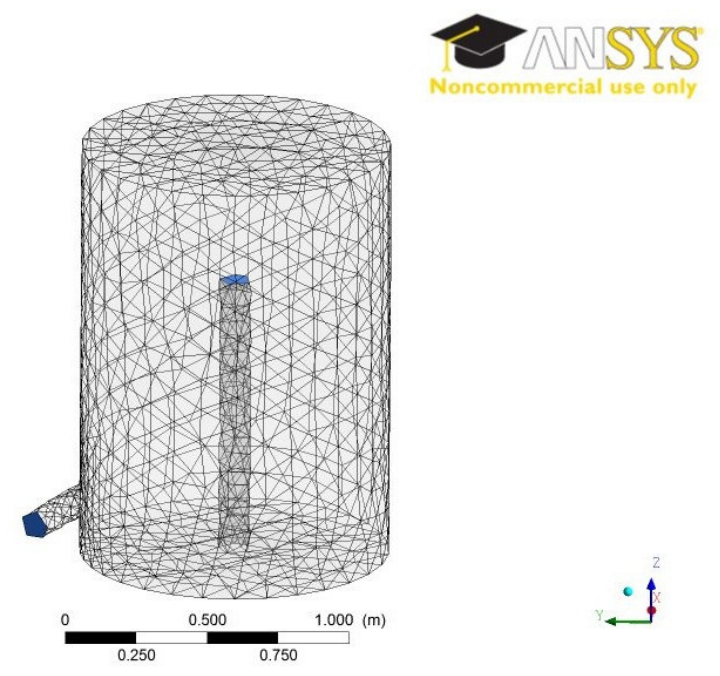

Figura 16 Malha numérica com 13963 elementos, utilizada em GÓIS; SELEGHIM, 2011

Como mencionado em LANGE; TAILLANDIER; RIBA, 2001, é inevitável que a levedura sofra as tensões devido ao efeito fluidodinâmico. Assim, é importante estudar este efeito, que pode prejudicar a viabilidade dos organismos vivos utilizados no processo de fermentação. Considerando essa necessidade, o objetivo da próxima etapa de simulação foi minimizar as tensões de cisalhamento WILLIAMS; SAINI; WICK, 2002, calculada como descrito no capítulo anterior. Os parâmetros da geometria otimizados foram a altura do reservatório cilíndrico do fermentador $(\mathrm{H})$, o valor do ângulo entre a tubulação de entrada de fluido e o reservatório ( $\alpha$ ), e a altura da tubulação de saída de fluido (h). A escolha dos parâmetros foi baseada na influência dos mesmos nas linhas de corrente do biorreator, ou seja, na sensibilidade dos parâmetros hidrodinâmicos em relação aos parâmetros geométricos. 
Analogamente aos estudos de UM; HANLEY, 2008 e DONG; WANG, 2008, o erro adotado foi $\mathrm{RMS}=10^{-4}$. A malha computacional foi composta por 130 mil elementos e 23 mil nós, como mostra a Figura 17. O tempo computacional para simular 51 geometrias foi aproximadamente 12 horas, utilizando o toda a capacidade de processamento da Altix SGi, com as especificações descritas no Capítulo 3.

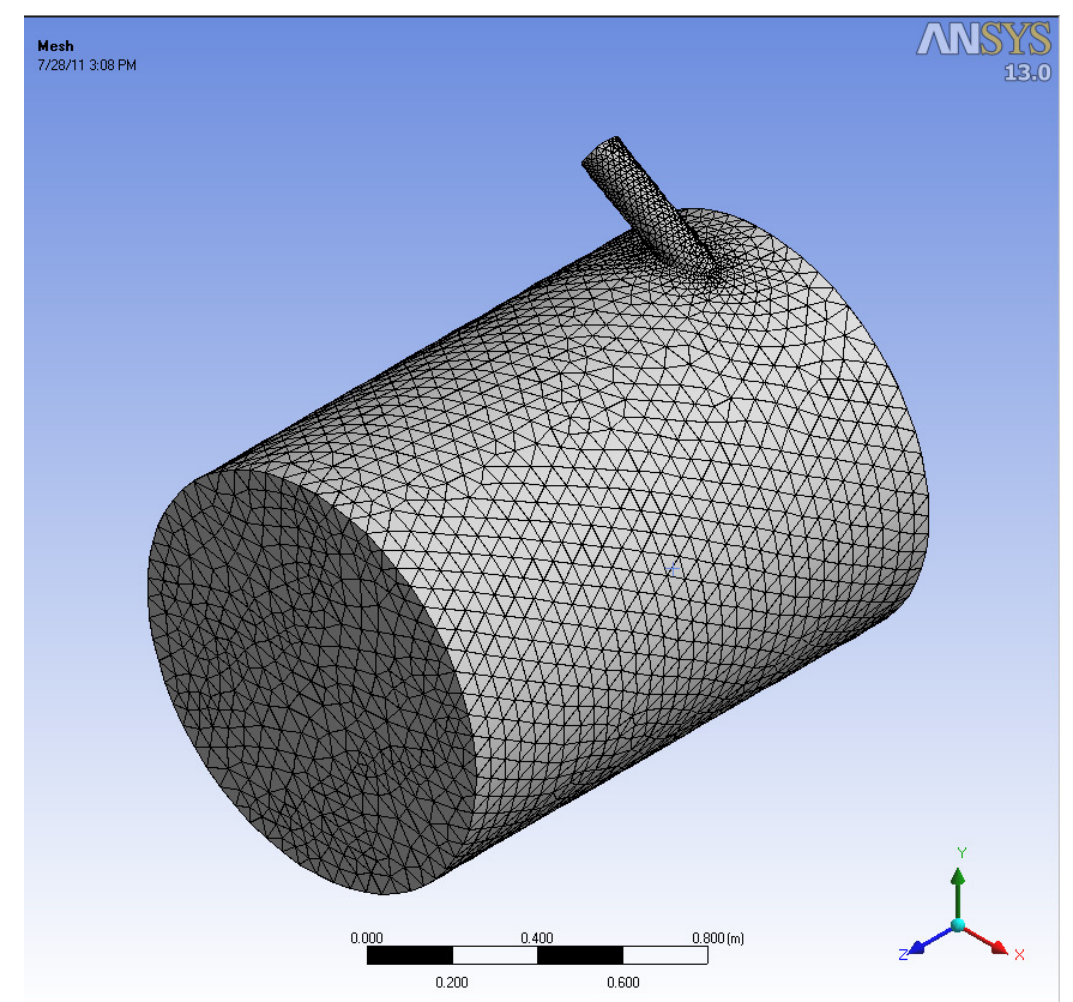

Figura 17 Malha numérica de 130 mil elementos, utilizada para o cálculo da tensão de cisalhamento.

O gráfico na Figura 18 mostra os valores da tensão de cisalhamento já minimizada em relação a cada uma das 51 geometrias testadas, identificadas em ordem numérica. Para cada iteração do algoritmo genético, o CFX efetua o cálculo do valor máximo da tensão de cisalhamento dada pela Equação 12 em cada ponto da malha computacional. A função objetivo aqui adotada foi minimizar o máximo dessa tensão de cisalhamento. Assim, o menor

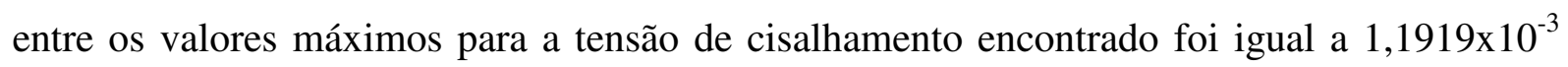
$\mathrm{Pa}$, correspondente à geometria de número 44. As dimensões de cada uma das 51 geometrias testadas estão especificadas na Tabela 5. 


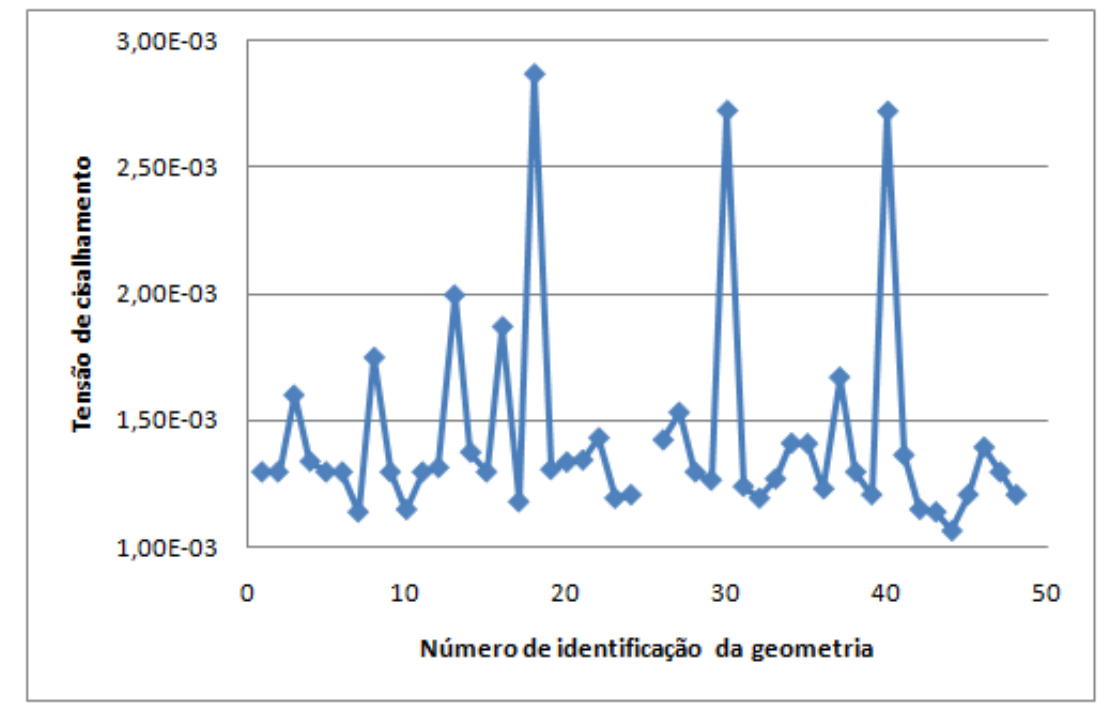

Figura 18 Tensão de cisalhamento $(\mathrm{Pa})$ para cada uma das 51 geometrias testadas.

Tabela 5 Especificações das dimensões das 51 geometrias analisadas no estudo da tensão de cisalhamento

\begin{tabular}{|c|c|c|c|}
\hline $\begin{array}{c}\text { Identificação da } \\
\text { geometria }\end{array}$ & $\begin{array}{c}\text { Altura do } \\
\text { reservatório } H[\mathrm{~cm}]\end{array}$ & Ângulo $\alpha\left[{ }^{\circ}\right]$ & $\begin{array}{c}\text { Altura da tubulação } \\
\text { de saída } h[\mathrm{~cm}]\end{array}$ \\
\hline 0 & 150 & 60 & 100 \\
\hline 1 & 200 & 2 & 40 \\
\hline 2 & 85 & 31 & 70 \\
\hline 3 & 117 & 16,5 & 55 \\
\hline 4 & 52,5 & 45,5 & 85 \\
\hline 5 & 68,7 & 23,7 & 77,5 \\
\hline 6 & 133,7 & 52,7 & 47,5 \\
\hline 7 & 101,2 & 9,25 & 92,5 \\
\hline
\end{tabular}




\begin{tabular}{|c|c|c|c|}
\hline 8 & 36,2 & 38,2 & 62,5 \\
\hline 9 & 44,3 & 20,1 & 96,2 \\
\hline 10 & 109,3 & 49,12 & 66,2 \\
\hline 11 & 150 & 60 & 100 \\
\hline 12 & 62,5 & 2,29 & 40 \\
\hline 13 & 68,5 & 11 & 58,2 \\
\hline 14 & 117,5 & 16,5 & 62,4 \\
\hline 15 & 20 & 45,5 & 40 \\
\hline 16 & 66,7 & 23,7 & 65,8 \\
\hline 17 & 101,3 & 9,25 & 47,5 \\
\hline 18 & 92,5 & 60 & 90,2 \\
\hline 19 & 81,4 & 23,6 & 42,7 \\
\hline 20 & 109,3 & 59,8 & 66,2 \\
\hline 21 & 133,7 & 2,2 & 47,3 \\
\hline 22 & 109,6 & 28,8 & 56,8 \\
\hline 23 & 144,7 & 40,8 & 49,9 \\
\hline 24 & 62,5 & 2,7 & 40 \\
\hline
\end{tabular}




\begin{tabular}{|c|c|c|c|}
\hline 25 & 150 & 55,4 & 40 \\
\hline 26 & 133,7 & 52,7 & 65,8 \\
\hline 27 & 74,7 & 2 & 42,3 \\
\hline 28 & 81,4 & 23,6 & 42,7 \\
\hline 29 & 89,1 & 34 & 72,1 \\
\hline 30 & 36,6 & 59,8 & 42,7 \\
\hline 31 & 62,5 & 59,8 & 46,5 \\
\hline 32 & 46,3 & 14,5 & 42,5 \\
\hline 33 & 107,7 & 41,2 & 59,6 \\
\hline 34 & 86,1 & 40 & 49,9 \\
\hline 35 & 150 & 30,8 & 66,6 \\
\hline 36 & 134 & 52,7 & 65,8 \\
\hline 37 & 104,2 & 59,5 & 44,1 \\
\hline 38 & 86,9 & 40 & 49,2 \\
\hline 39 & 89,1 & 14,7 & 72,1 \\
\hline 40 & 36,6 & 59,8 & 42,7 \\
\hline 41 & 133,7 & 52,7 & 65,8 \\
\hline
\end{tabular}




\begin{tabular}{|c|c|c|c|}
\hline 42 & 46,3 & 52,7 & 42,5 \\
\hline 43 & 65,6 & 52,7 & 47,5 \\
\hline 44 & 150 & 41 & 50 \\
\hline 45 & 150 & 30,5 & 47,5 \\
\hline 46 & 133,7 & 52,7 & 44,1 \\
\hline 47 & 102,1 & 59,5 & 65,8 \\
\hline 48 & 55,1 & 52,7 & 40 \\
\hline 49 & 36,6 & 45,5 & 42,7 \\
\hline 50 & 133,7 & 59,8 & 65,8 \\
\hline 51 & & & \\
\hline
\end{tabular}

A geometria que proporciona a tensão de cisalhamento mínima possui ângulo de entrada $\alpha=41^{\circ}$, altura do reservatório $H=1,45 \mathrm{~m}$ e altura da tubulação de saída de fluido $\mathrm{h}=$ 0,5 m. Assim, conclui-se que a geometria ideal para o caso da análise de tensão de cisalhamento é factível. É interessante notar que o valor para a altura de saída h na análise de tensão de cisalhamento $(0,50 \mathrm{~m})$ é aproximado ao valor encontrado para o mesmo parâmetro na análise de média de velocidades $(0,46 \mathrm{~m})$. Conclui-se que valores de $\mathrm{h}$ ideais são aproximadamente a metade do valor determinado para a altura do reservatório $\mathrm{H}$.

Uma comparação das dimensões entre a geometria inicial, antes do processo de otimização, e a geometria otimizada do fermentador é efetuada na Tabela 6. As dimensões após a otimização mostram que a alteração mais significativa seria na altura da tubulação de saída do fluido h, onde ocorreu uma redução de 50\%. A segunda alteração mais significativa ocorreu no ângulo $\alpha$ entre a tubulação de entrada e o reservatório principal do fermentador, 
com redução de aproximadamente $32 \%$. A altura $\mathrm{H}$ do reservatório permaneceu praticamente inalterada.

Tabela 6 Valores otimizados para os parâmetros da geometria comparados aos valores utilizados como aproximação inicial.

\begin{tabular}{|l|c|c|}
\hline $\begin{array}{c}\text { Parâmetros do Algoritmo } \\
\text { Genético }\end{array}$ & Dimensões iniciais & $\begin{array}{c}\text { Dimensões após } \\
\text { otimização }\end{array}$ \\
\hline Ângulo de entrada $(\alpha)$ & $60^{\circ}$ & $41^{\circ}$ \\
\hline Altura do reservatório (H) & $1,50 \mathrm{~m}$ & $1,45 \mathrm{~m}$ \\
\hline $\begin{array}{l}\text { Altura da tubulação de saída } \\
\text { de fluido (h) }\end{array}$ & $1,0 \mathrm{~m}$ & $0,50 \mathrm{~m}$ \\
\hline
\end{tabular}

A Figura 19 mostra o comportamento das linhas de corrente para a geometria do fermentador antes do processo de otimização. A avaliação qualitativa da figura mostra um comportamento controlado, mas com alto tempo de residência e ocorrência de circulação.
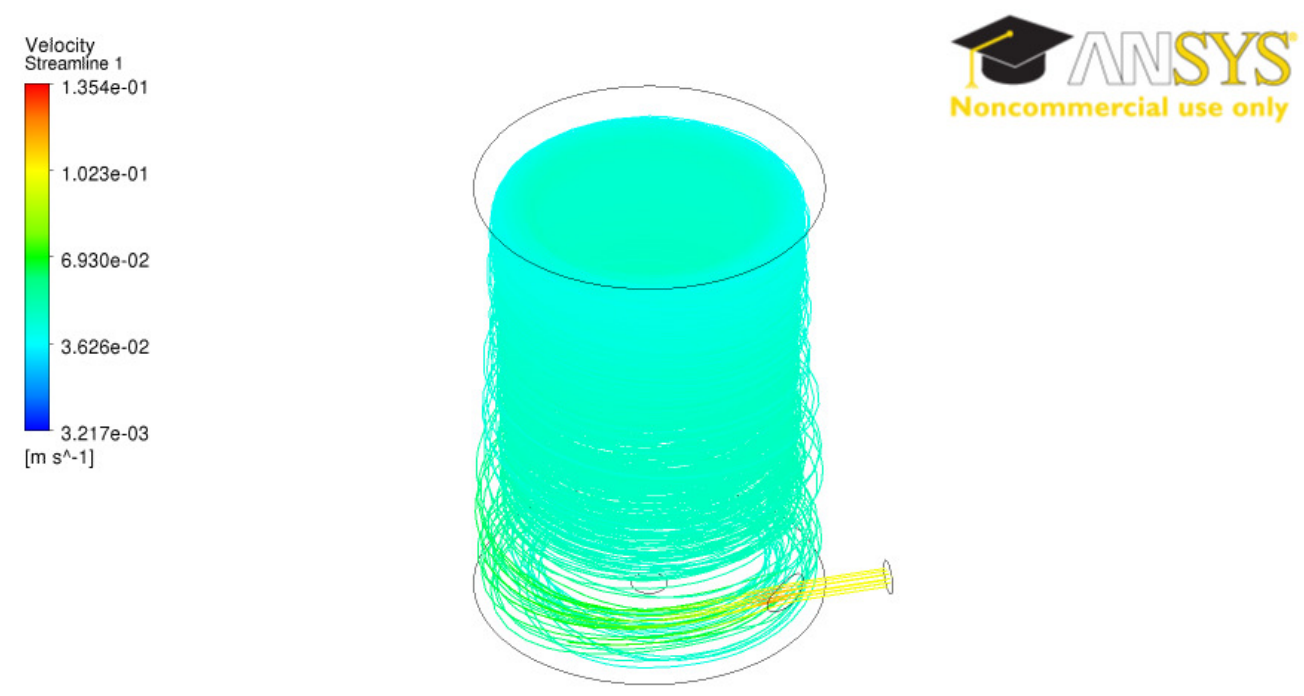

Figura 19 Comportamento das linhas de corrente para a geometria não otimizada. 

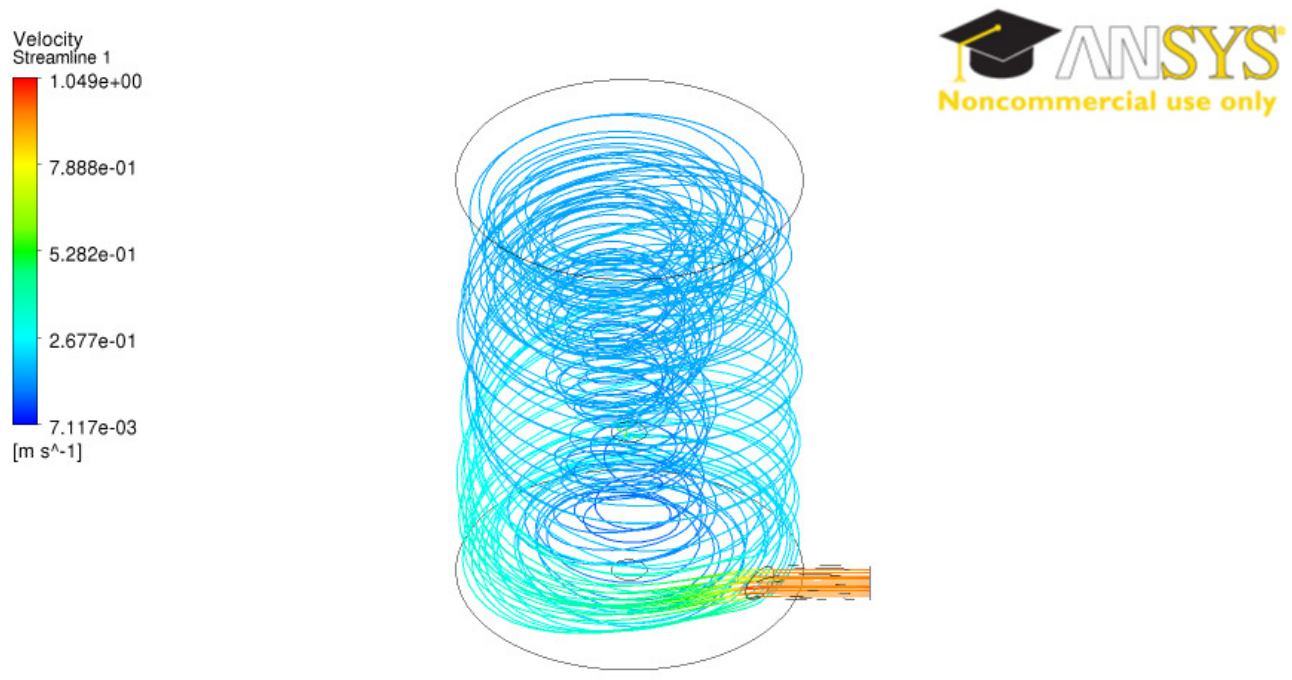

Figura 20 Comportamento das linhas de corrente para a geometria não otimizada..

Após a otimização da geometria, as recirculações são amenizadas, como pode ser observado na Figura 20. A redução no valor da altura da tubulação de saída $h$ favorece o escoamento. Qualitativamente, nota-se a redução do tempo de residência, consequência da diminuição das recirculações.

A Figura 21 traz uma comparação entre os mapas das taxas de deformação, diretamente proporcional à tensão de cisalhamento.

Como pode ser observado nos mapas de tensão de cisalhamento mostrados na Figura 21, é na região de entrada do fermentador em que a tensão de cisalhamento atinge seus valores mais elevados.

É interessante observar que a geometria ideal, ou seja, aquela que proporciona a menor tensão de cisalhamento no fermentador, apresenta duas regiões onde a tensão de cisalhamento apresenta valores mais elevados e maior variação: a entrada do escoamento, e a região da tubulação de saída. Isso mostra que, apesar da geometria otimizada proporcionar os menores valores para a tensão de cisalhamento, a mesma possui mais regiões com variação nas taxas de deformação. Em outras palavras, a viabilidade dos organismos vivos pode estar prejudicada tanto na entrada quanto na saída do escoamento. 
Shear Strain Rate

3.117e-01

2.806e-01

$2.494 \mathrm{e}-01$

2.182e-01

$1.871 \mathrm{e}-01$

$1.559 \mathrm{e}-01$

$1.247 \mathrm{e}-01$

$9.354 \mathrm{e}-02$

6.236e-02

3.119e-02

$2.028 \mathrm{e}-05$

[s^-11
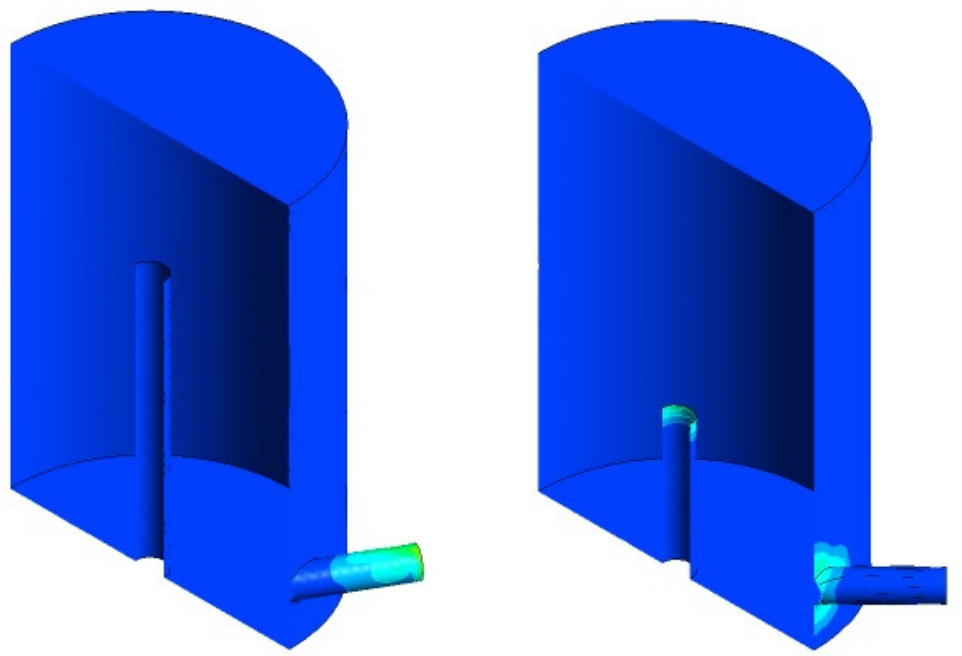

Figura 21 Comparação entre os mapas de tensão de cisalhamento no interior do fermentador. Geometria não otimizada (esquerda) e geometria otimizada (direta).

As Figuras 22 e 23 mostram as regiões de entrada da geometria não otimizada e otimizada, respectivamente, com maior detalhamento. Na Figura 22, nota-se a ocorrência de valores mais elevados para tensão de cisalhamento, que não é o objetivo da otimização efetuada.

Para a geometria otimizada, é possível observar na Figura 23 a região de altas tensões de cisalhamento se localiza mais próxima do reservatório do fermentador do que da área de entrada de fluido. As figuras confirmam a análise quantitativa, em que a geometria otimizada proporciona menores valores para tensão de cisalhamento. 

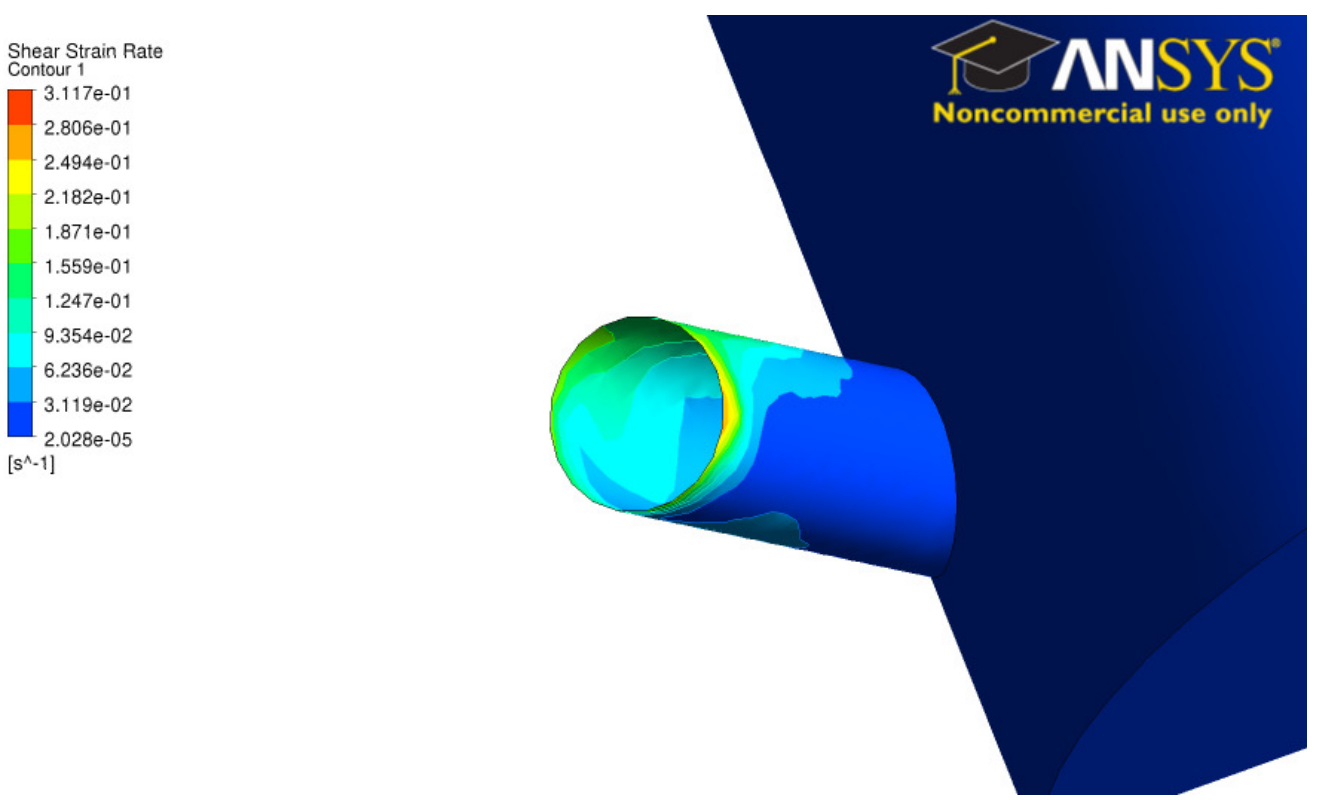

Figura 22 Região de entrada do fluido para a geometria não otimizada, onde ocorre os maiores valores de tensão de cisalhamento.
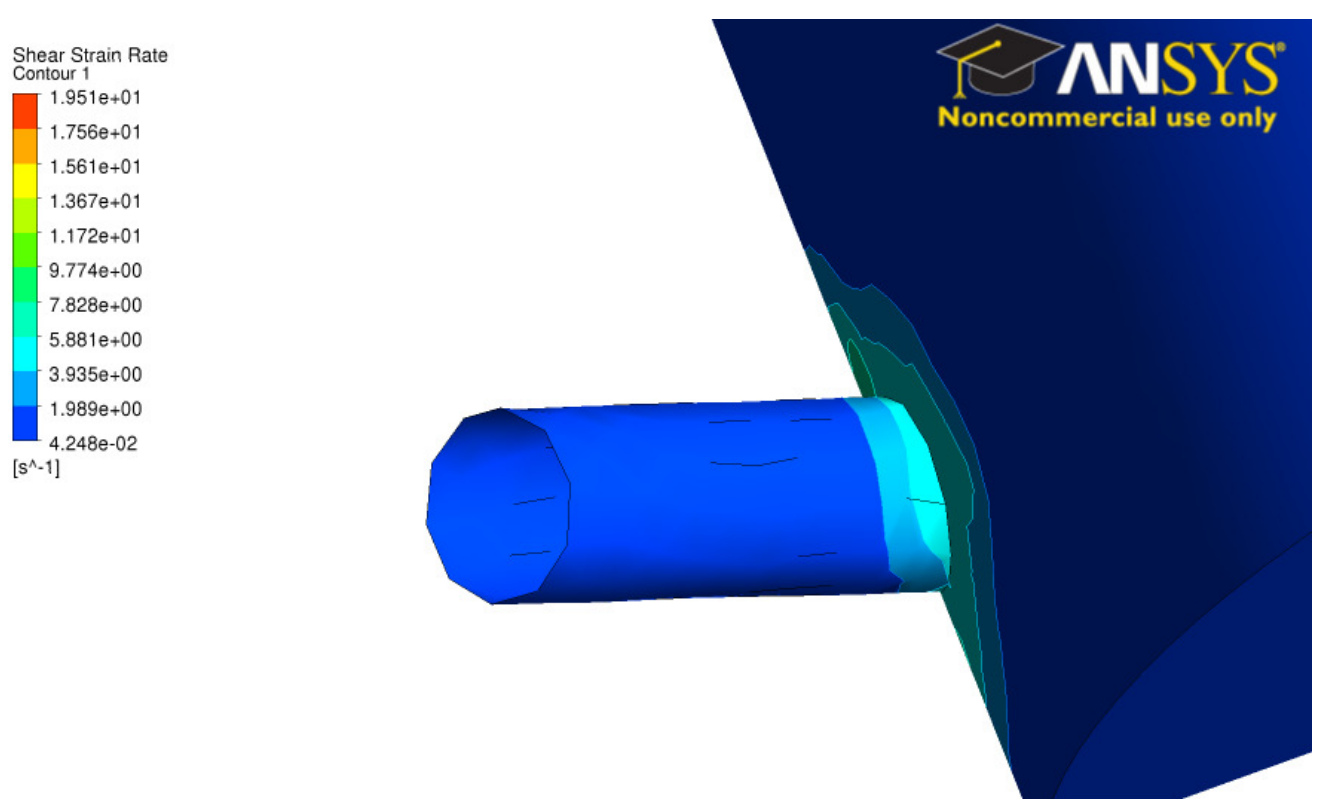

Figura 23 Região de entrada do fluido para a geometria otimizada, onde ocorre os maiores valores de tensão de cisalhamento.

A Figura 24 mostra o mapa de vorticidade no fermentador, que assim como a tensão de cisalhamento, também possui maior concentração de altos valores na região de entrada do equipamento. 

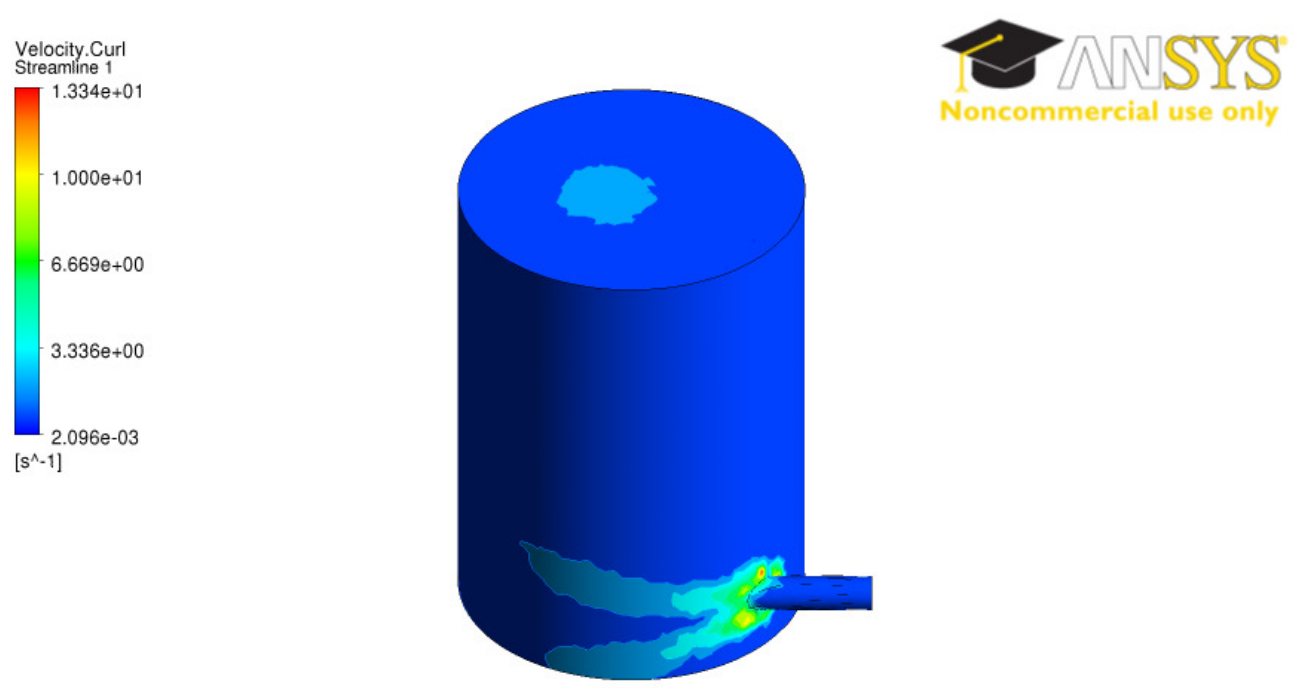

Figura 24 Mapa de vorticidade no fermentador, em perspectiva isométrica.

Como já mencionado anteriormente, não há, até o presente momento, trabalhos na literatura que contemplem os cálculos de tensão de cisalhamento em fermentadores utilizados na produção de etanol em grandes escalas. Dessa forma, os resultados deste estudo foram comparados com quatro outras análises de tensão de cisalhamento encontradas na literatura que, apesar de apresentar diferentes dimensões, proporciona uma comparação em termos de viabilidade dos organismos vivos.

A Tabela 7 mostra valores para a tensão de cisalhamento calculada em quatro trabalhos encontrados na literatura, comparados ao valor encontrado neste trabalho WILLIAMS; SAINI; WICK, 2002 simularam experimental e computacionalmente o escoamento em um biorreator de cilindros concêntricos aplicados para o desenvolvimento de células animais. DONG; WANG, 2008 simularam o escoamento em um biorreator de dimensões muito pequenas, e testaram 19 geometrias diferentes de um biorreator sem nenhuma agitação, a fim de obter o menor valor possível para a tensão de cisalhamento, mostrado na Tabela 7. Já em UM; HANLEY, 2008 foi efetuado um estudo da influência dos valores de concentração de substrato nas tensões de cisalhamento em um fermentador com agitação de dois impelidores. XIA et al., 2008 efetuaram um estudo numérico da tensão de cisalhamento em um biorreator de 5 litros com agitação por impelidor, que pode ser aplicado a qualquer processo que envolva biocatalisadores. $\mathrm{O}$ valor mostrado na tabela corresponde à média das tensões de cisalhamento para o impelidor com frequência de 200 rpm. 
Apesar das diferenças entre as aplicações dos trabalhos considerados, o objetivo desta comparação foi verificar se a geometria obtida após o processo de otimização seria factível em escala de bancada, não só pela possibilidade de construção, como também pela necessidade de proporcionar a menor tensão de cisalhamento possível, de forma a evitar a morte de biocatalisadores importantes para o processo fermentativo, como já discutido anteriormente.

Tabela 7 Comparação dos valores obtidos para a tensão de cisalhamento com resultados experimentais e numéricos encontrados na literatura.

\begin{tabular}{|l|c|}
\hline \multicolumn{1}{|c|}{ Estudo } & $\begin{array}{c}\text { Tensão de cisalhamento } \\
\text { (Pa) }\end{array}$ \\
\hline $\begin{array}{l}\text { WILLIAMS; SAINI; } \\
\text { WICK, 2002 }\end{array}$ & $158 \times 10^{-3}$ \\
\hline DONG; WANG, 2008 & $0,002 \times 10^{-3}$ \\
\hline UM; HANLEY, 2008 & $1 \times 10^{-3}$ \\
\hline XIA et al., 2008 & $17 \times 10^{-3}$ \\
\hline Presente estudo & $1,19 \times 10^{-3}$ \\
\hline
\end{tabular}

O máximo valor para a tensão de cisalhamento obtido neste trabalho foi menor do que a média da tensão de cisalhamento encontrada nos estudos de WILLIAMS; SAINI; WICK, 2002 e XIA et al., 2008. Apesar da comparação ter sido efetuada para diferentes equipamentos, a geometria aqui estudada parece proporcionar uma tensão de cisalhamento com valor máximo menor do que a média encontrada na literatura. Assim, neste caso, pode-se concluir que esta geometria proporciona a viabilidade dos organismos vivos, ou seja, favorecem a sua sobrevivência. 


\section{Análise da distribuição de tempos de residência e variância.}

Para o estudo da distribuição de tempo de residência, como mencionado anteriormente, o escoamento foi simulado em 20 geometrias diferentes para o fermentador, resultantes de uma combinação de variações do ângulo de entrada $\alpha$ e do comprimento da tubulação de saída de fluido h, parâmetros estes escolhidos por terem maior influência no escoamento.

A curva de distribuição de tempo de residência foi obtida utilizando a modelagem computacional do método de estímulo-resposta, onde um traçador é inserido como condição de contorno no início do escoamento, e sua concentração é monitorada na saída do mesmo.

Também foi efetuado uma análise da malha numérica, com o intuito de obter o melhor custo-benefício computacional da simulação do escoamento no fermentador. $\mathrm{O}$ escoamento foi simulado utilizando três diferentes configurações de malhas, como mostra a Tabela 8:

Tabela 8 Teste de malha: dimensões testadas.

\begin{tabular}{|c|c|c|}
\hline & Número de elementos: & Erro em relação a Malha 3 \\
\hline Malha 1 & 12000 & $84 \%$ \\
\hline Malha 2 & 62000 & $9 \%$ \\
\hline Malha 3 & 350000 & - \\
\hline
\end{tabular}

O escoamento foi simulado para cada uma das malhas propostas, e uma comparação do campo de velocidades obtido para cada uma delas foi efetuada. Comparando-se o campo de velocidades obtido com a malha mais grossa com o campo obtido com a malha mais refinada, obteve-se uma melhora de $84 \%$. Assim, a malha escolhida por melhor custobenefício para as simulações para obtenção da distribuição dos tempos de residência foi a malha mais fina, mostrada na Figura 25, composta por aproximadamente 350 mil elementos e 60 mil nós. 
A simulação foi definida como transiente, e foram simulados 600 segundos de escoamento, com passo no tempo de 1 segundo. O traçador foi injetado na entrada do escoamento através de um pulso, e sua concentração foi monitorada na saída. A partir da análise dos resultados da concentração do traçador na saída do escoamento para cada passo no tempo, pôde-se calcular a distribuição do tempo de residência e, consequentemente, foi possível calcular a variância desta distribuição.

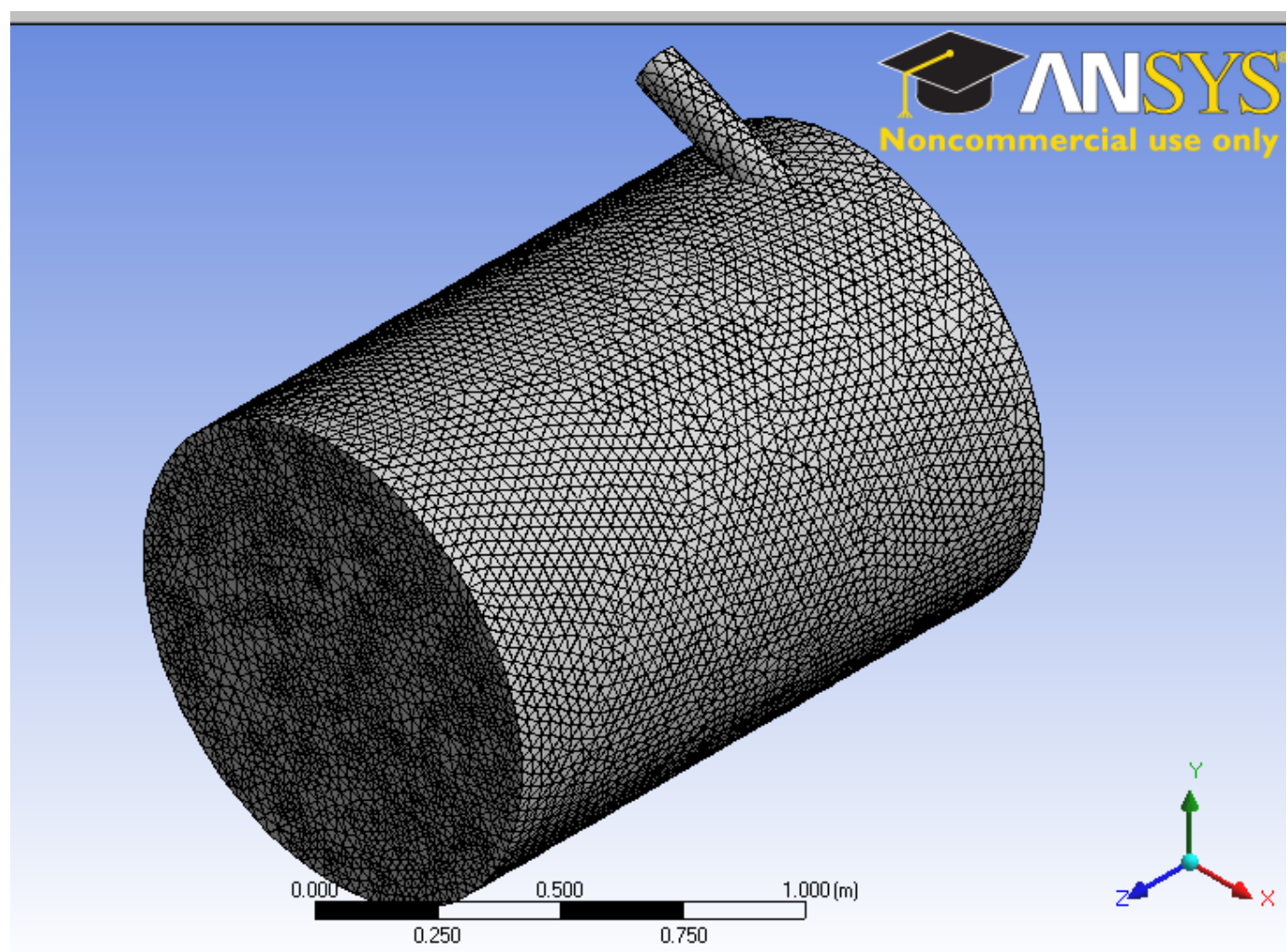

Figura 25 Malha numérica utilizada para obtenção das curvas DTR.

O objetivo da otimização foi identificar a geometria do fermentador que proporciona a minimização da variância da distribuição dos tempos de residência. Isso porque, como mencionado anteriormente, o caldo de cana necessita permanecer o tempo adequado no interior do fermentador para que as reações químicas sejam completadas (LANGE; TAILLANDIER; RIBA, 2001). Se porções diferentes do fluido possuem tempos de residência discrepantes, a reação química será prejudicada, pois parte dessas porções perderão suas propriedades químicas por ficarem tempo em demasia, e parte das porções não completarão as reações químicas. Este problema tende a aumentar com o aumento no tamanho do fermentador. Dessa forma, o fermentador ideal é aquele cuja geometria garante que a variância da distribuição dos tempos de residência seja a menor possível. 
4.2.1 Análise quantitativa da distribuição de tempo de residência: cálculo da variância.

Com a utilização do monitoring point, foi possível exportar um arquivo a partir do CFX contendo os dados da concentração do traçador na saída do fermentador, e a partir desses dados, efetuar o cálculo do tempo de residência e de sua variância, através das Equações 18 e 19.

A Figura 26 mostra os valores obtidos para a variância da distribuição de tempos de residência para cada uma das 20 geometrias simuladas (lembrando que a função objetivo desta otimização foi minimizar o valor da variância da distribuição de tempos de residência).

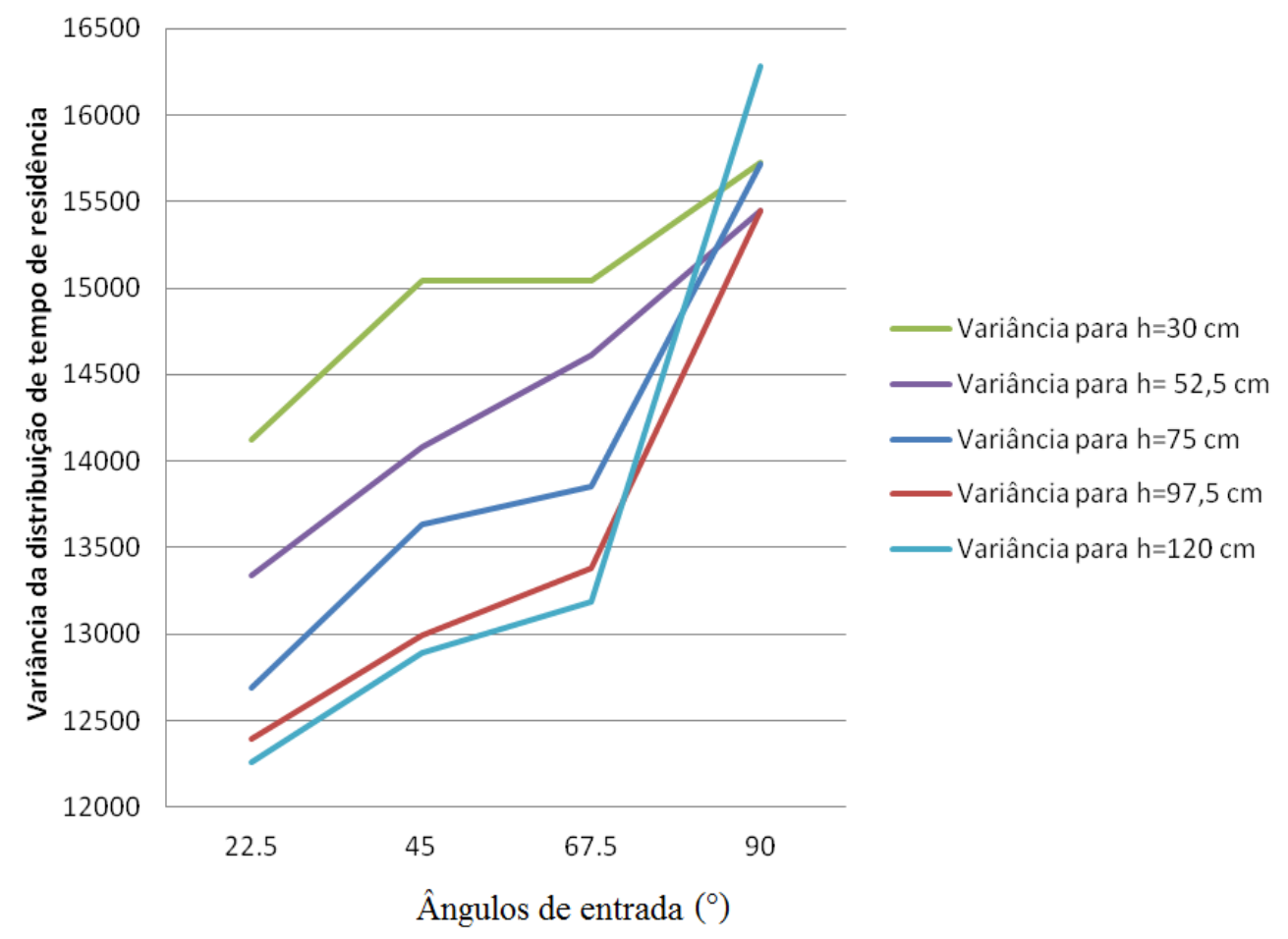

Figura 26 Variância da distribuição dos tempos de residência para cada uma das geometrias simuladas.

Interessante notar que, para todos os valores de comprimento da tubulação de saída h, a variância da distribuição de tempos de residência apresentou uma mesma tendência de máximo e de mínimo. Como o esperado após a análise qualitativa, o ângulo de entrada de fluido $\alpha=90^{\circ}$ favorece valores mais altos para a variância da distribuição de tempos de residência. 
Para as cinco variações de $h$ para a geometria, o ângulo $\alpha=22,5^{\circ}$ proporcionou o menor valor da variância, ou seja, este ângulo é adequado para que todas as porções do fluido permaneçam, em média, o mesmo tempo no interior do fermentador durante o escoamento. Isso impede que parte do caldo da cana perca suas propriedades químicas durante o processo por ficar tempo demais, e parte do caldo não complete o processo, por permanecer no fermentador menos tempo que o necessário.

Assim, conclui-se que a geometria ideal para o fermentador, ou seja, a geometria que proporciona a menor variância para a distribuição de tempos de residência, é aquela cujos ângulo de entrada $\alpha$ e o comprimento da tubulação de saída h medem respectivamente $22,5^{\circ} \mathrm{e}$ $120 \mathrm{~cm}$. O pior valor para a variância, ou seja, o valor mais alto, ocorre também para esta mesma configuração de geometria. A Figura 27 mostra uma comparação qualitativa das linhas de corrente entre a pior e a melhor geometria para o fermentador.
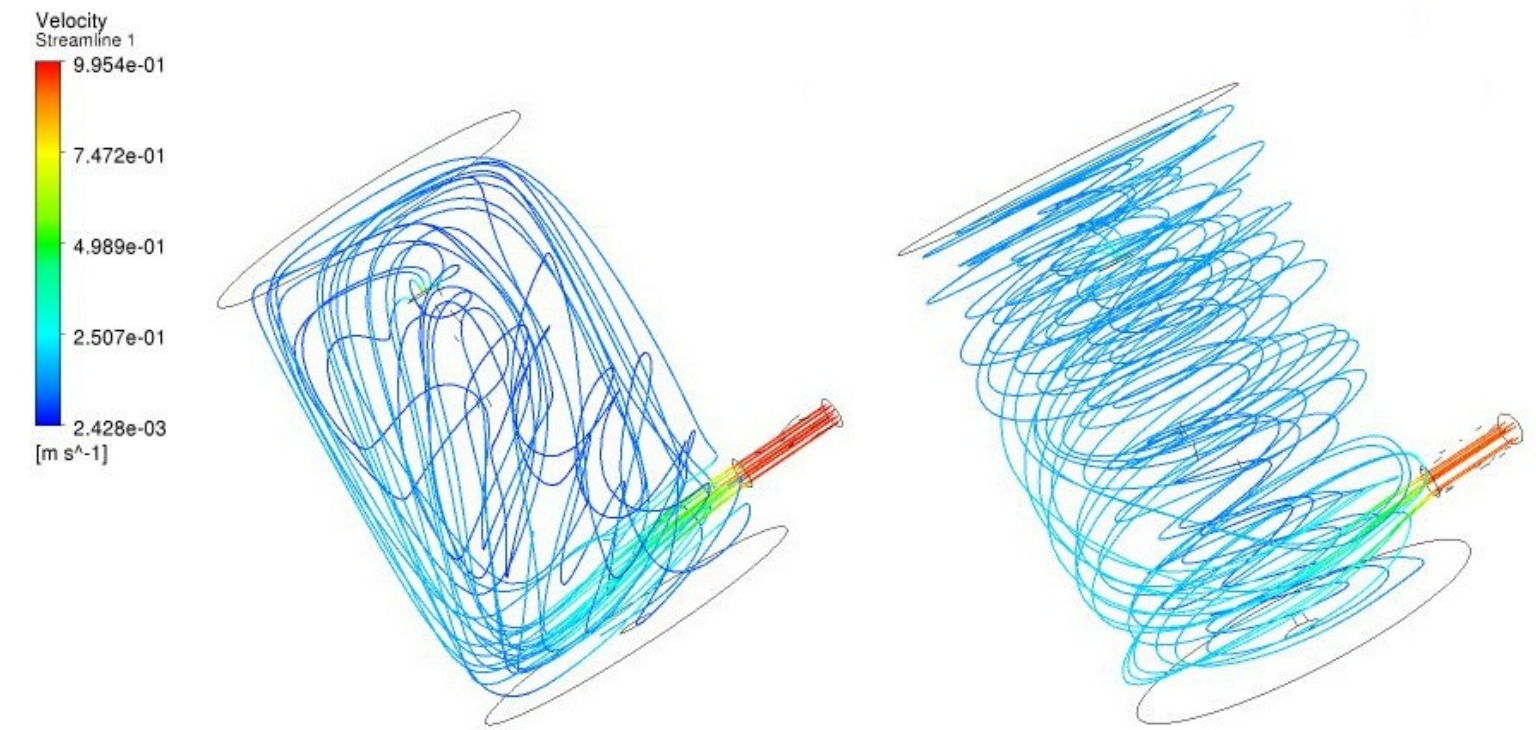

Figura 27 Comparação das linhas de corrente para as geometrias com h=120 cm e ângulo de entrada $90^{\circ}$ (esquerda) e ângulo de entrada $22,5^{\circ}$ (direita).

A geometria com ângulo de entrada igual a $22,5^{\circ}$ favorece o escoamento, com menor variância da DTR. O ângulo tangencial impulsiona o escoamento para a direção vertical, favorecendo também a saída do fluido, e garantindo maior uniformidade nos tempos em que cada poção de fluido permanece no interior do fermentador. Já a geometria com ângulo de entrada perpendicular tem linhas de corrente que não favorecem a saída do fluido do reservatório, o que resulta no alto valor da variância da DTR e, como pode ser observado no comportamento das linhas de corrente, aumenta a ocorrência de recirculação e zonas mortas. 
Com o objetivo de avaliar a tendência das curvas da variância da distribuição dos tempos de residência, em cada uma das 20 simulações, foi efetuada uma análise de sinal das curvas da variância em relação ao ângulo entre a tubulação de entrada e o tanque do fermentador. Para isso, foram propostas duas novas geometrias para cada uma das já testadas, totalizando 40 geometrias. Para cada ângulo já simulado, foi gerada uma nova geometria somando-se e subtraindo-se $\varepsilon=10^{-2}$ aos valores adotados para o ângulo $\alpha$ entre a tubulação de entrada e o tanque. $\mathrm{O}$ ângulo foi o parâmetro escolhido para análise por ter maior influência no escoamento, segundo o estudo qualitativo já efetuado A análise de sinais da derivada mostrou que, ao contrário do esperado, não há um único ponto de mínimo na curva da

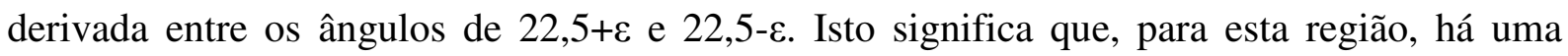
provável tendência patológica na superfície, ou seja, os pontos de mínimo local podem estar muito próximos do ponto de mínimo global. Sendo assim, conclui-se que a análise univariada limita a busca pela geometria ideal para o fermentador.

\subsubsection{Análise qualitativa das curvas de distribuição de tempos de residência.}

Através da análise qualitativa das curvas de distribuição de tempos de residência, é possível avaliar as frações do escoamento em regime morto e curtos circuitos. Esses fenômenos são definidos por SASSAKI, 2005 como desvios de idealidade, causados pelo escoamento. No estudo de SASSAKI, 2005, esses fenômenos são resumidos como:

- Curto circuito: os elementos do fluido escoam através do equipamento sem percorrer todo o seu interior. Indica deficiência no projeto e diminui a eficiência do dispositivo.

- Zonas mortas: são regiões do equipamento inacessíveis, onde o fluido nelas aprisionada não interage com regiões ativas. No caso do fermentador, essa região impede que as porções de fluido saiam do fermentador, causando a perda das propriedades dessas porções.

Curvas de concentração típicas de um reator com curto circuito geralmente apresentam oscilações bruscas nos primeiros intervalos de tempo, como pode ser observador na Figura 28. Estas oscilações foram observadas em todas as geometrias com ângulo de entrada igual a $90^{\circ}$ simuladas neste estudo. 

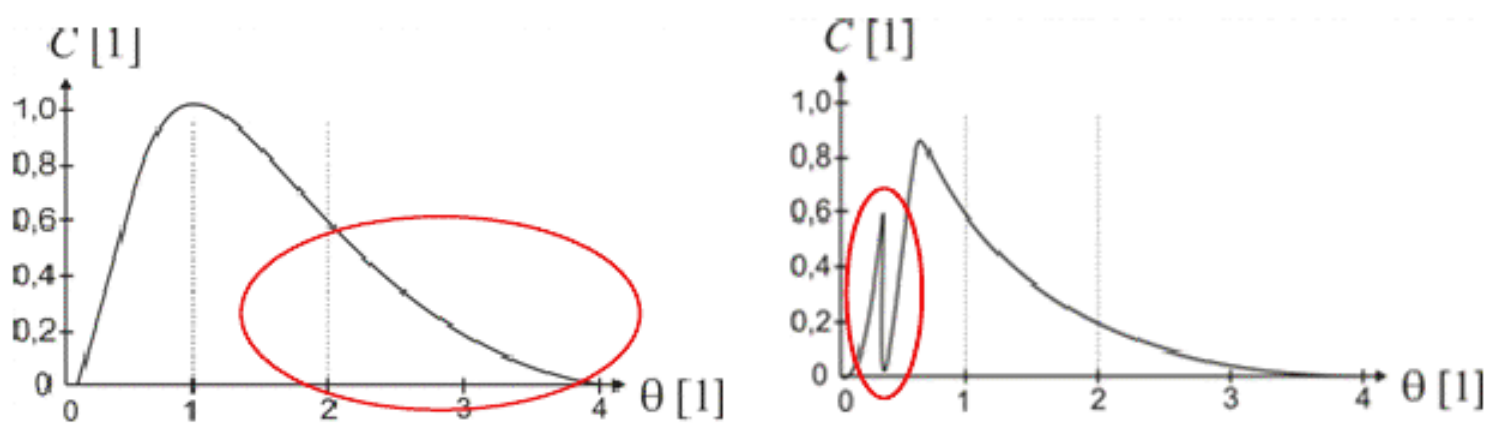

Figura 28 Curvas de concentração típicas de um reator com zonas mortas (Esquerda) e com curto circuito (Direita)

A Figura 29mostra as curvas de concentração em função do passo de tempo para valores de h igual a 57,5, 75, 97,5 e $120 \mathrm{~cm}$, respectivamente. As curvas correspondentes a $\mathrm{h}=30 \mathrm{~cm}$ e $\mathrm{h}=52,5 \mathrm{~cm}$ apresentam suaves oscilações nos primeiros passos de tempo, o que mostra o surgimento de curto circuito. Pode-se concluir que geometrias com valores mais baixos para $\mathrm{h}$ favorecem o aparecimento de curto circuito quando $\alpha=22,5^{\circ}$. Para os valores mais altos adotados para h, a curva não apresenta ruídos, caracterizando a ausência de curto circuitos.

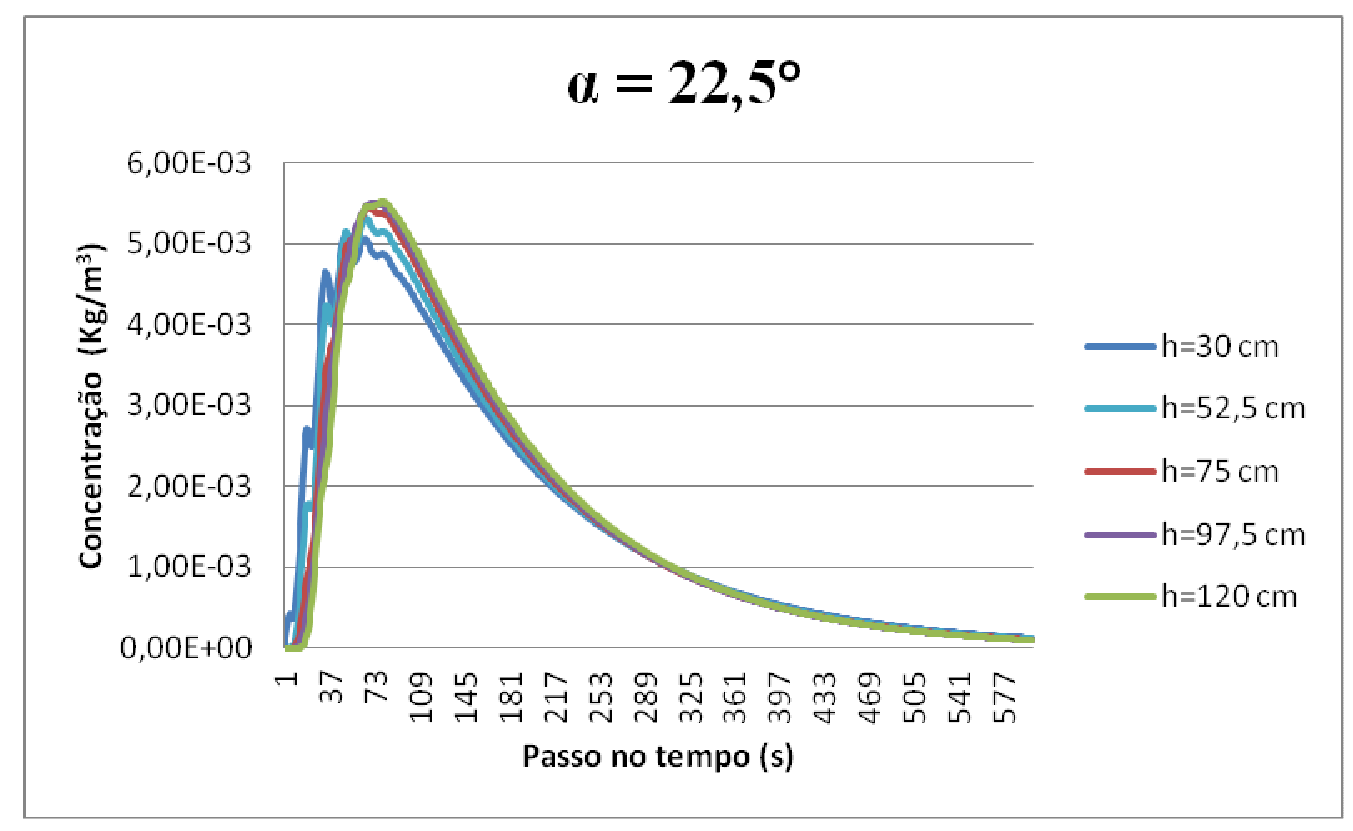

Figura 29 Curvas de concentração para ângulo de $22,5^{\circ}$ e respectivas alturas para a tubulação de saída.

As curvas de concentração para $\alpha=45^{\circ}$ para cada comprimento h testado podem ser observadas na Figura 30. Estas curvas apresentam tendência similar à encontrada para $\alpha=22,5^{\circ}$, e para $h=30 \mathrm{~cm}$, oscilações mais suaves podem ser identificadas, 90 
indicando que algumas porções do fluido sofrem curto circuito. No entanto, a diminuição das oscilações mostram que o aumento no valor de $\alpha$ desfavorece o aparecimento de curtos circuitos. $\mathrm{O}$ aumento no valor de $\alpha$ combinado ao aumento no valor de h colaboram para o desaparecimento das oscilações na curva.

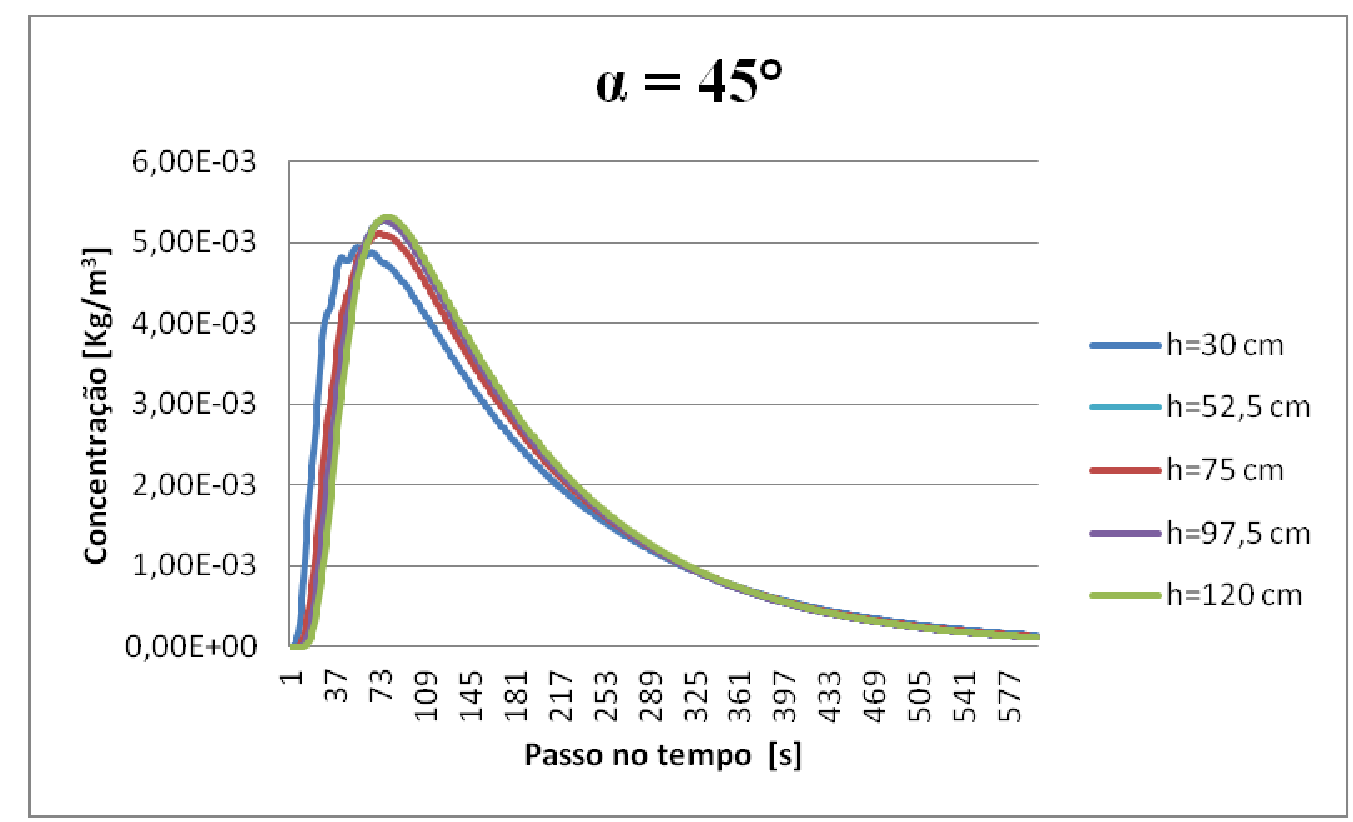

Figura 30 Curva de concentração para ângulo de $45^{\circ}$ em função das alturas simuladas para a tubulação de saída.

No entanto, esta melhora é observada somente até valores de $\alpha$ iguais a $67,5^{\circ}$. A Figura 31 mostra que o ângulo $\alpha=67,5^{\circ}$ proporciona escoamentos sem o surgimento de curto circuitos. Além disso, considerando a análise qualitativas das curvas para este caso, não há vantagens em relação a possíveis zonas mortas, ou seja, recirculação do fluido. As zonas mortas podem ser identificadas qualitativamente quando ainda existem altas concentrações de fluido no interior do fermentador já nos passos finais de tempo. Considerando a Figura 31, as curvas de concentração para cada h simulado apresentam tendências similares de concentração para cada valor de t, ou seja, o ângulo de $45^{\circ}$ não é um parâmetro que influencia o surgimento de zonas mortas. 


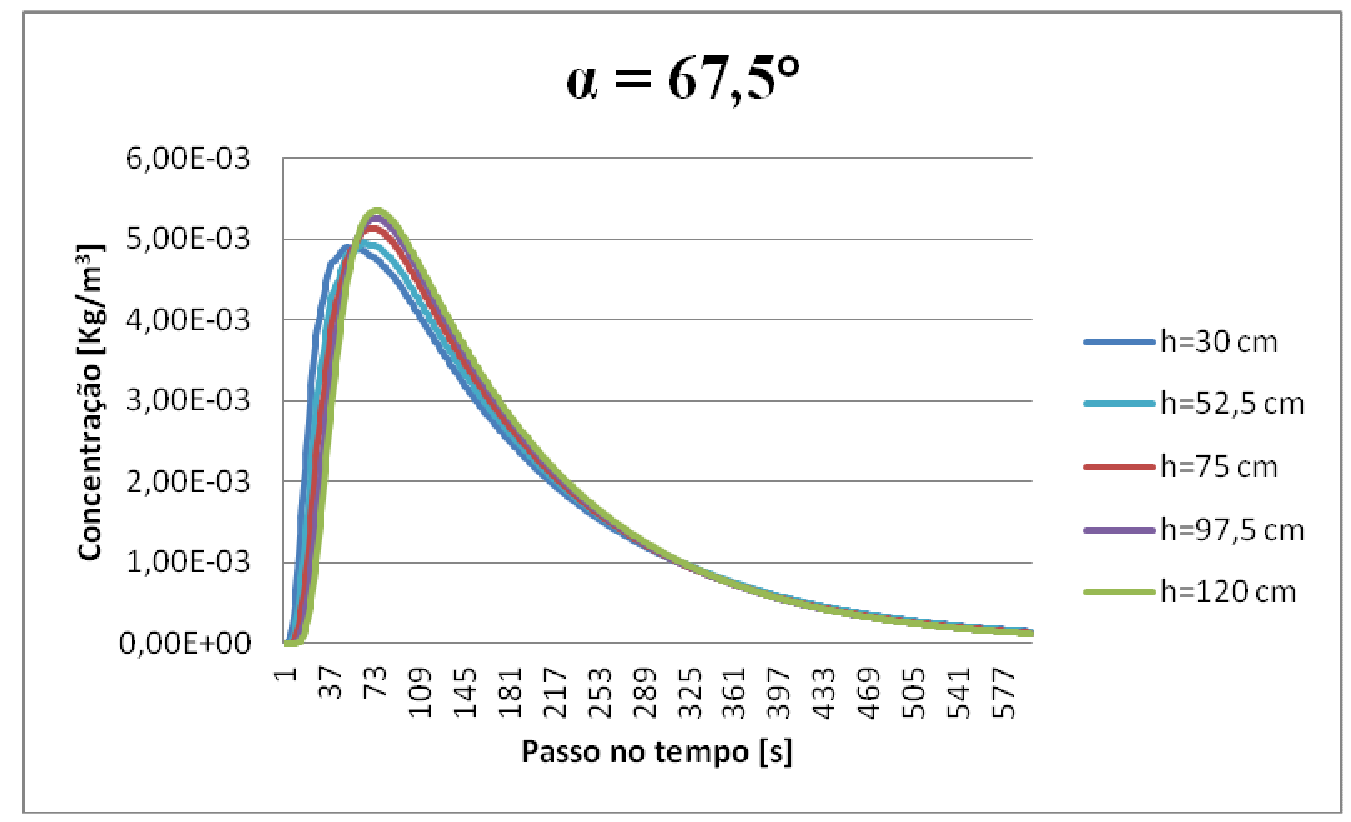

Figura 31 Curva de concentração para ângulo de 67,5 e respectivas alturas para tubulação de saída.

As geometrias com maior ocorrência de curto circuito foram as com ângulo perpendicular para entrada de fluido, como pode ser observado na Figura 32. Neste caso, analogamente ao que aconteceu para $\alpha=67,5^{\circ}$, a variação de $h$ não tem influência para o controle do surgimento de curtos circuitos. A maior influência no escoamento,

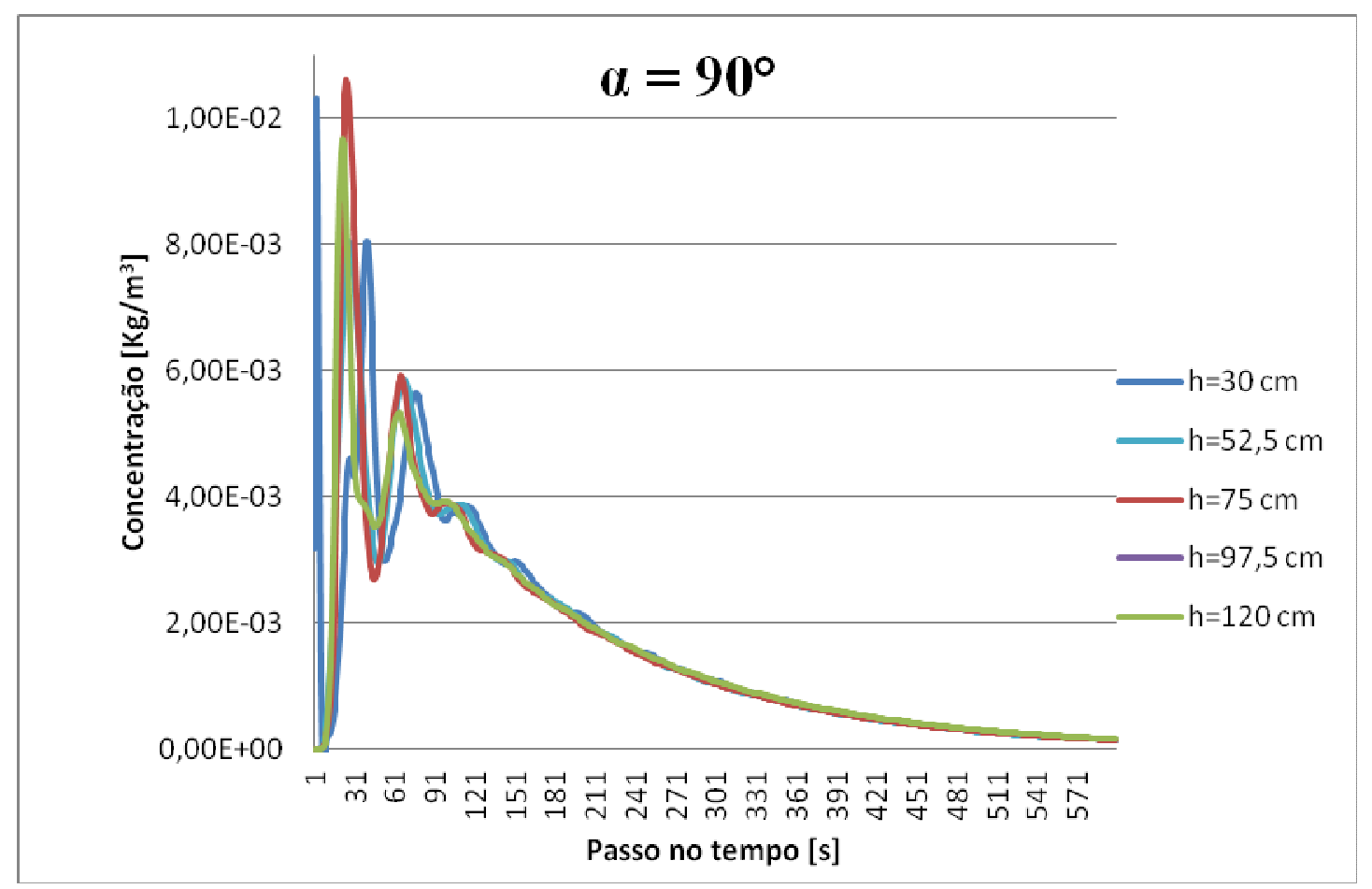

Figura 32 Curva de concentração para ângulo de $90^{\circ}$ e respectivas alturas para a tubulação de saída. 
neste caso, é do ângulo de $90^{\circ}$. Independentemente do valor adotado para h, a ocorrência de altas variações na concentração de fluido nos primeiros passos de tempo mostra que parte considerável das porções de fluido deixam o fermentador em um pequeno intervalo de tempo.

Após a análise das curvas de concentração em função do passo no tempo, o ângulo de entrada foi identificado como sendo o parâmetro da geometria com maior influência sobre o escoamento no fermentador. Mantendo-se o mesmo ângulo de entrada e variando-se o comprimento da tubulação de saída, as curvas mostraram comportamentos semelhantes, como pode ser observado nas Figuras 29, 30, 31 e 32.

A Figura 33 mostra as curvas de distribuição de tempo de residência para o caso em que $h=120 \mathrm{~cm}$, que permite avaliar com mais clareza a influência dos valores de $\alpha$ no escoamento, para um valor de $\mathrm{h}$ fixo. O pico no valor da concentração para $\alpha=90^{\circ}$ confirma que geometrias com entradas perpendicular têm o pior desempenho quando pretende-se evitar curtos circuitos. Considerando que o valor tomado para $h$ foi o mais alto dos simulados neste trabalho, ou seja, $h=120 \mathrm{~cm}$, conclui-se que valores mais elevados para h contribuem para a eliminação de zonas mortas.

No entanto, os valores mais altos de concentração ocorrentes no caso em que o ângulos utilizados foram $67,5^{\circ}$ e $22,5^{\circ}$ quando comparados ao valor da concentração neste mesmo ponto para o ângulo perpendicular, pode-se concluir que apesar de favorecer o curto circuito, a geometria com ângulo de entrada perpendicular não favorece a ocorrência de recirculação. A partir de t=289 s aproximadamente, os valores da concentração equilibram-se, e a variação da altura deixa de influenciar o surgimento das zonas mortas.

Vale salientar que a difusividade do fluido adotado neste trabalho foi tomada como nula. Assim, qualitativamente, a curva de distribuição de tempo de residência DTR apresenta o mesmo comportamento que a curva de concentração em função do tempo. Isso permite que a detecção de zonas mortas e curtos-circuitos através da análise das curvas de concentração. 


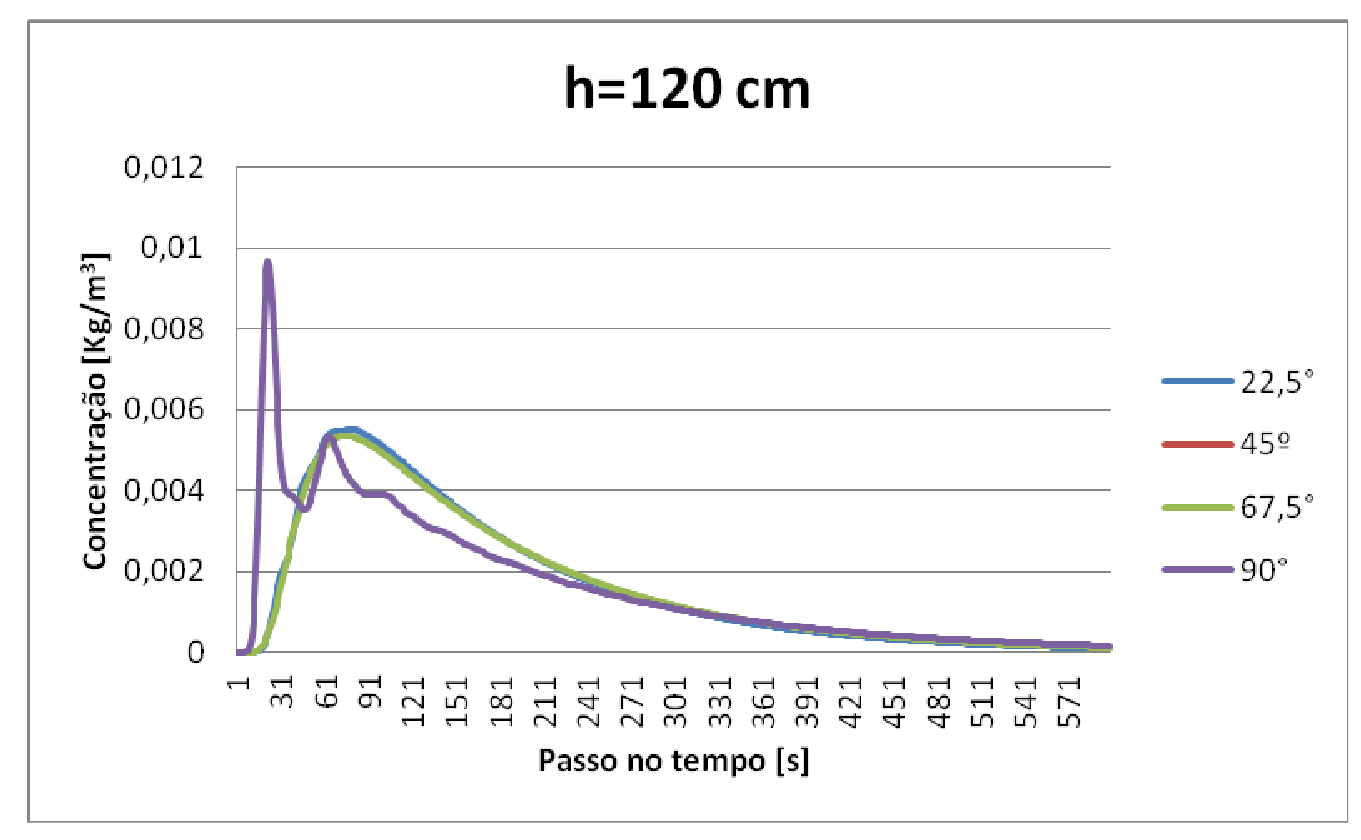

Figura 33 Curvas DTR para h=120 cm para cada um dos ângulos testados.

\section{Conclusões deste capítulo.}

Neste capítulo foram mostrados os resultados da otimização da tensão de cisalhamento e da distribuição de tempos de residência em um fermentador contínuo através da modificação de sua geometria. Estratégias de otimização diferentes foram aplicadas em cada uma das simulações. Para a análise da tensão de cisalhamento como função objetivo, o algoritmo de otimização escolhido foi o MOGA II. No caso do estudo da variância da distribuição dos tempos de residência, o algoritmo de otimização escolhido foi o método univariado. A distribuição de tempos de residência foi avaliada de forma quantitativa e também qualitativa, através da análise da curva de concentração, considerando o coeficiente de difusão como nulo.

A Tabela 9 mostra as geometrias ideais resultantes de cada uma das análises efetuadas, sintetizando a contribuição deste estudo. Conclui-se que a geometria que proporciona a menor tensão de cisalhamento para o fermentador não é concordante com a geometria que proporciona a menor variância na distribuição dos tempos de residência. Dessa forma, para propor uma geometria que contemple a otimização dos dois parâmetros simultaneamente, torna-se necessária uma análise com dois ou mais objetivos e um estudo da Fronteira de Pareto do problema.

Tabela 9 Geometria ideal para as duas funções objetivo analisadas neste trabalho. 


\begin{tabular}{|c|c|}
\hline Função Objetivo & Geometria ideal \\
\hline Tensão de cisalhamento & $\alpha=41^{\circ}$ e $\mathrm{h}=50 \mathrm{~cm}$ \\
\hline Distribuição de tempos de residência & $\alpha=22,5^{\circ} \mathrm{e} h=120 \mathrm{~cm}$ \\
\hline
\end{tabular}

Além da proposta de duas geometrias ideais para o fermentador, a análise dos sinais da curva da variância das distribuições de tempo de residência foi discrepante quando comparadas aos valores ótimos propostos para a geometria. Essa discordância leva à possibilidade de tratar-se de um problema patológico de otimização, ou seja, os mínimos e máximos locais provavelmente encontram-se muito próximo dos globais. Essa patologia ocasiona dificuldade de convergência para o método de otimização, cuja busca pode ficar aprisionada numa região de mínimo ou máximos locais. Esta convergência prematura foi encontrada também no trabalho de BRANDI, 2010, sendo identificada como um mau condicionamento na formulação do problema estudado.

Assim, pode-se concluir que os métodos de otimização determinísticos não são a melhor opção para análise de problemas como a otimização do escoamento do fermentador, pois a busca pelo valor ótimo acaba ficando limitada a algumas regiões da superfície de soluções, dificultando a identificação do ótimo global. Esta contribuição possibilita novos caminhos para análise do escoamento do fermentador, até então pouco discutidos na literatura. 



\section{CAPITULO 5 - CONCLUSÕES E PERSPECTIVAS}

Diante do panorama mundialmente favorável para a busca e melhoria de tecnologias para a obtenção de energia renovável, e considerando que fermentadores em operação contínua para produção de bioetanol estão presentes em $30 \%$ das usinas brasileiras, torna-se importante o estudo de melhorias na eficiência deste tipo de equipamento. Qualquer melhoria tem impactos ambientais e financeiros consideráveis, pois a produção de bioetanol ocorre em grandes escalas, ou seja, bilhões de litros produzidos por hora.

Este trabalho teve como objetivo melhorar a eficiência de um fermentador contínuo através da modificação da sua geometria, que possui influência direta no escoamento e, consequentemente, nas reações químicas envolvidas no processo de fermentação. Este tipo de estudo proporciona uma inovação no projeto deste tipo de equipamento. Dois parâmetros do escoamento foram considerados como função objetivo: a tensão de cisalhamento e a distribuição de tempos de residência. As geometrias que favorecem as melhores condições para o escoamento foram propostas através da aplicação de dois algoritmos de otimização diferentes.

Para a análise da tensão de cisalhamento foi aplicado o Algoritmo Genético Modificado II, com a variação de três parâmetros da geometria: o ângulo $\alpha$ entre a tubulação para entrada de fluido e o tanque do fermentador, a altura $\mathrm{H}$ do tanque, e o comprimento $\mathrm{h}$ da tubulação de saída do escoamento. A geometria ideal, ou seja, a que proporciona o menor valor na tensão de cisalhamento, possui ângulo de entrada de fluido igual a $41^{\circ} \mathrm{e}$ comprimento da tubulação de saída igual a $50 \mathrm{~cm}$. Através da limitação da literatura em resultados de simulações computacionais aplicadas na modelagem de fermentadores em escala industrial de produção de etanol, os resultados desenvolvidos neste trabalho foram comparados com alguns resultados para outros tipos de biorreatores, mas com análises de parâmetros semelhantes, e apresentaram um boa concordância.

Para o caso da análise da distribuição de tempos de residência foi aplicado o método de otimização univariada, com análise de $\alpha$ e h. O escoamento foi simulado em 20 geometrias diferentes, e a curva DTR foi obtida através do monitoramento da concentração de um traçador na saída do escoamento. Neste caso, a geometria ideal para o fermentador conta com 
ângulo de entrada igual a $22,5^{\circ}$ e $120 \mathrm{~cm}$ de comprimento da tubulação de saída. A análise dos pontos de máximo e mínimo na curva das variâncias mostrou que o problema de otimização apresenta uma tendência patológica, ou seja, pontos de mínimos locais estão localizados muito próximos de pontos de mínimos globais.

Considerando uma usina que processa 500 toneladas de cana de açúcar por hora (escala de processamento comum no cenário brasileiro), $1 \%$ de melhora na eficiência do equipamento será de grande impacto nos resultados da produção. Diante das grandes escalas de processamento desta aplicação, este trabalho traz contribuições significativas para melhora do equipamento para o processo de produção de bioetanol através de mudanças simples nas dimensões do fermentador.

Como trabalhos futuros, torna-se necessário um estudo mais aprofundado da tendência patológica do problema de otimização, e da aplicação de uma metodologia de otimização com múltiplos objetivos [EIRAS; ANDRADE, 1995]. Isso permitirá a proposta de uma geometria para o fermentador que contemple, ao mesmo tempo, as duas funções objetivos analisadas. Além disso, um estudo da otimização para scale-up da geometria do fermentador será efetuado. Estudos de scale-up foram efetuados através da análise de parâmetros das reações químicas envolvidas no processo de fermentação [NIENOW; NORDKVIST; BOULTON, 2011; GONZÁLEZ-SÁIZ; GARRIDO-VIDAL; PIZARRO, 2009]. Esta nova análise pode trazer importantes contribuições para melhoria nos fermentadores utilizados na indústria sucroalcooleira, pois os parâmetros ótimos para a geometria com volume de $1 \mathrm{~m}^{3}$ propostos neste estudo provavelmente não serão os mesmos para escalas maiores. Pretende-te efetuar a análise para escalas de $10 \mathrm{~m}^{3}$ e $100 \mathrm{~m}^{3}$.

Resultados iniciais do estudo de aumento de escala mostram a influencia no comportamento do escoamento, apesar do formato da geometria ter sido mantido. As linhas de corrente para fermentadores com escala de $10 \mathrm{~m}^{3}$ e $100 \mathrm{~m}^{3}$ podem ser observadas na Figura 34. O fermentador menor, de $10 \mathrm{~m}^{3}$ mostrado à esquerda apresenta linhas de corrente com escoamento regular, com menor taxa de recirculação próximo à tubulação de saída do fermentador. Com o aumento da escala para $100 \mathrm{~m}^{3}$, o comportamento das linhas de corrente se altera completamente. $\mathrm{O}$ fluido se choca com a parede do fermentador oposta à entrada do escoamento, resultando no aumento da recirculação, e consequentemente, no aumento da tensão de cisalhamento e no tempo de residência. Esta análise encoraja o estudo quantitativo desses parâmetros para o aumento na escala do fermentador. 

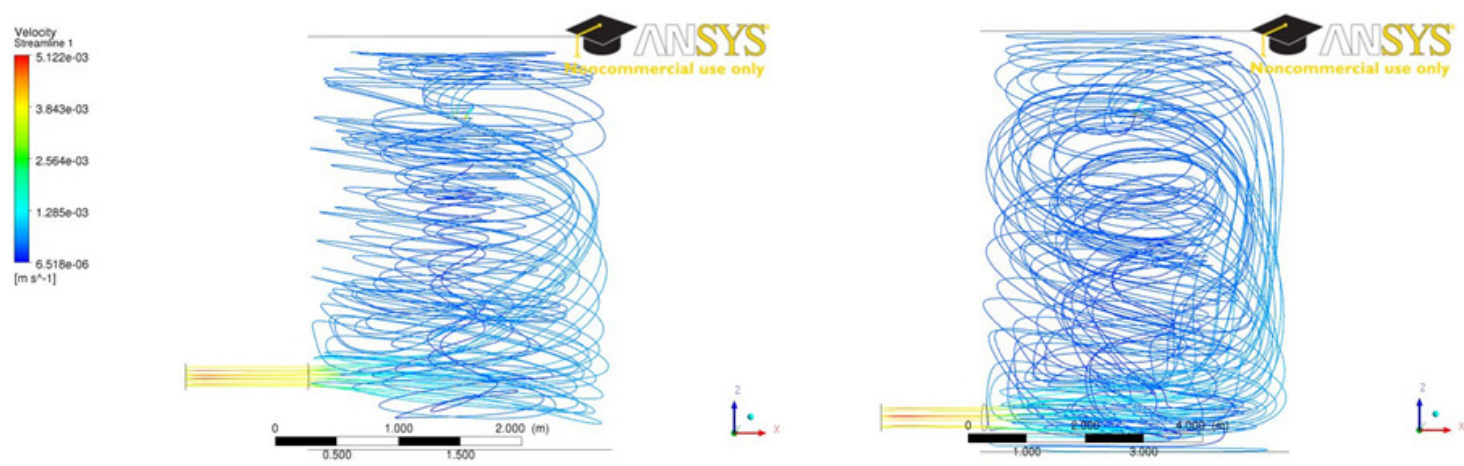

Figura 34 Comparação das linhas de corrente para o fermentador com $10 \mathrm{~m}^{3}$ (Esquerta) $100 \mathrm{~m}^{3}$ de volume (Direita)

Assim, este trabalho abre caminhos para novos estudos para melhorar equipamentos envolvidos na produção de bioetanol, neste caso, os fermentadores. Estes caminhos proporcionam a possibilidade de aplicação direta na indústria, a contribuição para a substituição de combustíveis fósseis por fontes de energia renováveis e, consequentemente, redução dos impactos ambientais. Melhorias neste campo são um desafio para pesquisadores, mas tornam o trabalho mais motivador. A multidisciplinaridade do tópico enriquece o trabalho acadêmico, e proporciona um maior entrosamento entre pesquisa científica e sociedade. 



\section{REREFERÊNCIAS BIBLIOGRÁFICAS}

ALIM, F. et al. (2008). New genetic algorithms (GA) to optimize PWR reactors: Part II: Simultaneous optimization of loading pattern and burnable poison placement for the TMI-1 reactor. Annals of Nuclear Energy, v.35, n.1, p.113-120.

ASTOLFI-FILHO, Z. et al. (2011). Rheology and fluid dynamics properties of sugarcane juice. Biochemical Engineering Journal, v.53, n.3, p.260-265.

BEIGHTLER, C.S.; PHILLIPS, D.T.; WILDE, D.J. (1979). Foundations of optimization. $2^{\mathrm{a}}$. Prentice-Hall.

BOSCO, F. (2006). Busca pela vanguarda. Disponível em: $<$ http://www.revistaalcoolbras.com.br/>. Acceso em: Julho

(2010). O fim dos consertos. Disponível em: $<$ http://www.revistaalcoolbras.com.br/>. Acceso em: julho 2012.

BRANDI, A.C. (2010). Desenvolvimento de uma Técnica Não Intrusivade Medição do Coeficiente de Convecção -Solução do Problema Térmico Inverso. 145 pp. (Doutorado) - Universidade de São Paulo, São Carlos, 2010.

CHOI, B.S. et al. (2004). Residence Time Distributions in a Stirred Tank: $\square$ Comparison of CFD Predictions with Experiment. Industrial \& Engineering Chemistry Research, v.43, n.20, p.6548-6556.

DAVIDSON, K.M. et al. (2003). Using Computational Fluid Dynamics Software to Estimate Circulation Time Distributions in Bioreactors. Biotechnology Prog., v.19, p.14801486.

DIAS, M. et al. (2011). Simulation of integrated first and second generation bioethanol production from sugarcane: comparison between different biomass pretreatment methods. Journal of Industrial Microbiology \&amp; Biotechnology, v.38, n.8, p.955-966.

DIAS, M.O.S. et al. (2009). Production of bioethanol and other bio-based materials from sugarcane bagasse: Integration to conventional bioethanol production process. Chemical Engineering Research and Design, v.87, n.9, p.1206-1216.

DING, J. et al. (2010). CFD optimization of continuous stirred-tank (CSTR) reactor for biohydrogen production. Bioresource Technology, v.101, n.18, p.7005-7013.

DONG, X.; WANG, K. (2008). Prediction and simulation on the shear stress and mass transfer in perfused bioreactors I: Circular bioreactors. 2008 Chinese Control Deciosion Conference, p.4237-4242.

EIRAS, S.P.; ANDRADE, J.C. (1995). O uso do simplex modificado como estratégia de otimização em química analítica. Química Nova, v.19, p.6.

FORTUNA, A.D.O. (2000). Técnicas Computacionais Para Dinâmica dos Fluidos: Conceitos Básicos e Aplicações. São Paulo. 
FREGONESI, A.D.A. (1998). Adesão de células de Sacharomices SP em materiais inorgânicos para a produção de etanol. 78 pp. (Mestrado) - Universidade Estadual de Campinas, Campinas, 1998.

GAVRILESCU, M.; TUDOSE, R.Z. (1999). Residence time distribution of the liquid phase in a concentric-tube airlift reactor. Chemical Engineering and Processing: Process Intensification, v.38, n.3, p.225-238.

GÓIS, E.R.C.; SELEGHIM, J.P. (2011). Design Optimization of a bioreactor for ethanol production using CFD simulations and genetic algortihms. Proceedings of XV Computational Methods and Experimental Measurements, v.51, p.67-75.

GOLDBERG, D.E. (1989). Genetic Algorithms in Search, Optimization, and Machine Learning. Addison -Wesley Publishing Company.

GONZÁlEZ-SÁIZ, J.-M.; GARRIDO-VIDAL, D.; PIZARRO, C. (2009). Scale up and design of processes in aerated-stirred fermenters for the industrial production of vinegar. Journal of Food Engineering, v.93, n.1, p.89-100.

HARRIS, C.K. et al. (1996). Computational fluid dynamics for chemical reactor engineering. Chemical Engineering Science, v.51, n.10, p.1569-1594.

HUTMACHER, D.W.; SINGH, H. (2008). Computational fluid dynamics for improved bioreactor design and 3D culture. Trends in Biotechnology, v.26, n.4, p.166-172.

KORDABADI, H.; JAHANMIRI, A. (2005). Optimization of methanol synthesis reactor using genetic algorithms. Chemical Engineering Journal, v.108, n.3, p.249-255.

LANGE, H.; TAILLANDIER, P.; RIBA, J.-P. (2001). Effect of high shear stress on microbial viability. Journal of Chemical Technology \& Biotechnology, v.76, n.5, p.501-505.

LE MOULLEC, Y. et al. (2008). Flow field and residence time distribution simulation of a cross-flow gas-liquid wastewater treatment reactor using CFD. Chemical Engineering Science, v.63, n.9, p.2436-2449.

LEITE, R.C.D.C.; LEAL, M.R.L.V. (2007). O biocombustível no Brasil. . Novos Estudos CEBRAP, v.78, p.15-21.

MARCOLIN, N. (2008). Era quase aguardente. Revista FAPESP, v.145.

MICALE, G. et al. (2004). CFD Simulation of Particle Suspension Height in Stirred Vessels. Chemical Engineering Research and Design, v.82, n.9, p.1204-1213.

MOUSAVI, S.M. et al. (2010). CFD simulation and optimization of effective parameters for biomass production in a horizontal tubular loop bioreactor. Chemical Engineering and Processing: Process Intensification, v.49, n.12, p.1249-1258.

NIENOW, A.W.; NORDKVIST, M.; BOULTON, C.A. (2011). Scale-down/scale-up studies leading to improved commercial beer fermentation. Biotechnology Journal, v.6, n.8, p.911-925.

NOGUEIRA, L.A.H. (2008). Bioetanol de Cana-de-açúcar. Energia para o desenvolvimento sustentável. Rio de Janeiro.

OGBONNA, J.C.; MASHIMA, H.; TANAKA, H. (2001). Scale up of fuel ethanol production from sugar beet juice using loofa sponge immobilized bioreactor. Bioresource Technology, v.76, n.1, p.1-8. 
PARK, K.; LEE, J. (2010). Optimal design of two-dimensional wings in ground effect using multi-objective genetic algorithm. Ocean Engineering, v.37, n.10, p.902-912.

PATWARDHAN, A.W. et al. (2005). Optimization of gas-liquid reactor using computational fluid dynamics. Chemical Engineering Science, v.60, n.11, p.3081-3089.

POLES, S. (2003). MOGA II: An Improved Multi Objective Genetic Algorithm.

PRIESKE, H.; DREWS, A.; KRAUME, M. (2008). Prediction of the circulation velocity in a membrane bioreactor. Desalination, v.231, n.1-3, p.219-226.

RAO, S.S. (2009). Engineering Optimization. $4^{\text {a }}$ Ed. John Wiley \& Sons.

RIVERA, E.C. et al. (2008). Kinetic Modeling and Parameter Estimation in a Tower Bioreactor for Bioethanol Production. Applied Biochemical Biotechnology, v.148, p.163-173.

ROLLI, C. (2011). Mesmo com aumento do álcool, crescem as vendas de carros flex. Disponível em: <http://www1.folha.uol.com.br/mercado/894199-mesmo-comaumento-do-alcool-crescem-as-vendas-de-carros-flex.shtml>. Acceso em: 26/07.

SARKAR, D.; MODAK, J.M. (2005). Pareto-optimal solutions for multi-objective optimization of fed-batch bioreactors using nondominated sorting genetic algorithm. Chemical Engineering Science, v.60, n.2, p.481-492.

SARRIS, I. et al. (2006). A three-dimensional CFD model of direct ethanol fuel cells: Anode flow bed analysis. Solid State Ionics, v.177, n.19-25, p.2133-2138.

SASSAKI, R.A. (2005). DISTRIBUIÇÃO DE TEMPOS DE RESIDÊNCIA EM SISTEMAS ALIMENTADOS COM VAZÃO VARIÁVEL. 100 pp. (Mestrado) Universidade Federal do Rio de Janeiro, Rio de Janeiro, 2005.

SCHMIDELL, W. et al. (2005). Biotecnologia Industrial.

SHAO, X. et al. (2010). Reactor scale up fo biological conversion of cellusosic biomass to ethanol. Bioprocess Biosystem Engineering, v.33, p.485-493.

SONGSTAD, D. et al. (2011). Historical Perspective of Biofuels: Learning from the Past to Rediscover the Future. Biofuels, p.1-7.

UM, B.-H.; HANLEY, T.R. (2008). A comparison of simple rheological parameters and simulation data for Zymomonas mobilis fermentation broths with high substrate loading in a 3-L bioreactor. Applied Biochemical Biotechnology, v.145, p.29-38.

WILLIAMS, K.A.; SAINI, S.; WICK, T.M. (2002). Computational Fluid Dynamics Modeling of Steady-State Momentum and Mass Transport in a Bioreactor for Cartilage Tissue Engineering. Biotechnology Progress, v.18, n.5, p.951-963.

XIA, J.-Y. et al. (2008). Computational investigation of fluid dynamics in a recently developed centrifugal impeller bioreactor. Biochemical Engineering Journal, v.38, n.3, p.406-413.

XIE, X.-M. et al. (2011). Dynamic changes of lignin contents of MT-1 elephant grass and its closely related cultivars. Biomass and Bioenergy, v.35, n.5, p.1732-1738.

ZHANG, L.; PAN, Q.; REMPEL, G.L. (2007). Residence Time Distribution in a Multistage Agitated Contactor with Newtonian Fluids: $\square$ CFD Prediction and Experimental Validation. Industrial \& Engineering Chemistry Research, v.46, n.11, p.35383546. 
